DOE-HDBK-1011/3-92

\title{
DOE FUNDAMENTALS HANDBOOK
}

\section{ELECTRICAL SCIENCE}

Volume 3 of 4

U.S. Department of Energy

Washington, D.C. 20585 
This document has been reproduced directly from the best available copy.

Available to DOE and DOE contractors from the Office of Scientific and Technical Information. P. O. Box 62, Oak Ridge, TN 37831; prices available from (615) 576-8401. FTS 626-8401.

Available to the public from the National Technical Information Service, U.S.

Department of Commerce, 5285 Port Royal Rd., Springfield, VA 22161. 


\section{DISCLAIMER}

This report was prepared as an account of work sponsored by an agency of the United States Government. Neither the United States Government nor any agency Thereof, nor any of their employees, makes any warranty, express or implied, or assumes any legal liability or responsibility for the accuracy, completeness, or usefulness of any information, apparatus, product, or process disclosed, or represents that its use would not infringe privately owned rights. Reference herein to any specific commercial product, process, or service by trade name, trademark, manufacturer, or otherwise does not necessarily constitute or imply its endorsement, recommendation, or favoring by the United States Government or any agency thereof. The views and opinions of authors expressed herein do not necessarily state or reflect those of the United States Government or any agency thereof. 


\section{DISCLAIMER}

Portions of this document may be illegible in electronic image products. Images are produced from the best available original document. 


\section{DOE FUNDAMENTALS HANDBOOK ELECTRICAL SCIENCE Volume 3 of 4}

\section{Washington, D.C. 20585}

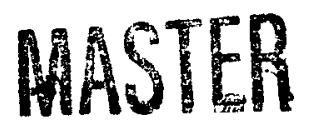




\section{ABSTRACT}

The Electrical Science Fundamentals Handbook was developed to assist nuclear facility operating contractors provide operators, maintenance personnel, and the technical staff with the necessary fundamentals training to ensure a basic understanding of electrical theory, terminology, and application. The handbook includes information on alternating current (AC) and direct current (DC) theory, circuits, motors, and generators; $A C$ power and reactive components; batteries; $\mathrm{AC}$ and $\mathrm{DC}$ voltage regulators; transformers; and electrical test instruments and measuring devices. This information will provide personnel with a foundation for understanding the basic operation of various types of DOE nuclear facility electrical equipment.

Key Words: Training Material, Magnetism, DC Theory, DC Circuits, Batteries, DC Generators, DC Motors, AC Theory, AC Power, AC Generators, Voltage Regulators, AC Motors, Transformers, Test Instruments, Electrical Distribution 


\section{FOREWORD}

The Department of Energy (DOE) Fundamentals Handbooks consist of ten academic subjects, which include Mathematics; Classical Physics; Thermodynamics, Heat Transfer, and Fluid Flow; Instrumentation and Control; Electrical Science; Material Science; Mechanical Science; Chemistry; Engineering Symbology, Prints, and Drawings; and Nuclear Physics and Reactor Theory. The handbooks are provided as an aid to DOE nuclear facility contractors.

These handbooks were first published as Reactor Operator Fundamentals Manuals in 1985 for use by DOE category A reactors. The subject areas, subject matter content, and level of detail of the Reactor Operator Fundamentals Manuals were determined from several sources. DOE Category A reactor training managers determined which materials should be included, and served as a primary reference in the initial development phase. Training guidelines from the commercial nuclear power industry, results of job and task analyses, and independent input from contractors and operations-oriented personnel were all considered and included to some degree in developing the text material and learning objectives.

The DOE Fundamentals Handbooks represent the needs of various DOE nuclear facilities' fundamental training requirements. To increase their applicability to nonreactor nuclear facilities, the Reactor Operator Fundamentals Manual learning objectives were distributed to the Nuclear Facility Training Coordination Program Steering Committee for review and comment. To update their reactor-specific content, DOE Category $A$ reactor training managers also reviewed and commented on the content. On the basis of feedback from these sources, information that applied to two or more DOE nuclear facilities was considered generic and was included. The final draft of each of the handbooks was then reviewed by these two groups. This approach has resulted in revised modular handbooks that contain sufficient detail such that each facility may adjust the content to fit their specific needs.

Each handbook contains an abstract, a foreword, an overview, learning objectives, and text material, and is divided into modules so that content and order may be modified by individual DOE contractors to suit their specific training needs. Each subject area is supported by a separate examination bank with an answer key.

The DOE Fundamentals Handbooks have been prepared for the Assistant Secretary for Nuclear Energy, Office of Nuclear Safety Policy and Standards, by the DOE Training Coordination Program. This program is managed by EG\&G Idaho, Inc. 


\section{OVERVIEW}

The Department of Energy Fundamentals Handbook entitled Electrical Science was prepared as an information resource for personnel who are responsible for the operation of the Department's nuclear facilities. A basic understanding of electricity and electrical systems is necessary for DOE nuclear facility operators, maintenance personnel, and the technical staff to safely operate and maintain the facility and facility support systems. The information in the handbook is presented to provide a foundation for applying engineering concepts to the job. This knowledge will help personnel more fully understand the impact that their actions may have on the safe and reliable operation of facility components and systems.

The Electrical Science handbook consists of fifteen modules that are contained in four volumes. The following is a brief description of the information presented in each module of the handbook.

Volume 1 of 4

Module 1 - Basic Electrical Theory

This module describes basic electrical concepts and introduces electrical terminology.

Module 2 - Basic DC Theory

This module describes the basic concepts of direct current (DC) electrical circuits and discusses the associated terminology.

Volume 2 of 4

Module 3 - DC Circuits

This module introduces the rules associated with the reactive components of inductance and capacitance and how they affect DC circuits.

Module 4 - Batteries

This module introduces batteries and describes the types of cells used, circuit arrangements, and associated hazards. 
Module 5 - DC Generators

This module describes the types of DC generators and their application in terms of voltage production and load characteristics.

Module 6 - DC Motors

This module describes the types of DC motors and includes discussions of speed control, applications, and load characteristics.

Volume 3 of 4

Module 7 - Basic AC Theory

This module describes the basic concepts of alternating current (AC) electrical circuits and discusses the associated terminology.

Module 8 - AC Reactive Components

This module describes inductance and capacitance and their effects on $\mathrm{AC}$ circuits.

Module 9 - AC Power

This module presents power calculations for single-phase and three-phase AC circuits and includes the power triangle concept.

Module 10 - AC Generators

This module describes the operating characteristics of AC generators and includes terminology, methods of voltage production, and methods of paralleling $\mathrm{AC}$ generation sources.

Module 11 - Voltage Regulators

This module describes the basic operation and application of voltage regulators.

Volume 4 of 4

Module 12 - AC Motors

This module explains the theory of operation of AC motors and discusses the various types of $\mathrm{AC}$ motors and their application. 


\section{Module 13 - Transformers}

This module introduces transformer theory and includes the types of transformers, voltage/current relationships, and application.

Module 14 - Test Instruments and Measuring Devices

This module describes electrical measuring and test equipment and includes the parameters measured and the principles of operation of common instruments.

Module 15 - Electrical Distribution Systems

This module describes basic electrical distribution systems and includes characteristics of system design to ensure personnel and equipment safety.

The information contained in this handbook is by no means all encompassing. An attempt to present the entire subject of electrical science would be impractical. However, the Electrical Science handbook does present enough information to provide the reader with a fundamental knowledge level sufficient to understand the advanced theoretical concepts presented in other subject areas, and to better understand basic system and equipment operations. 


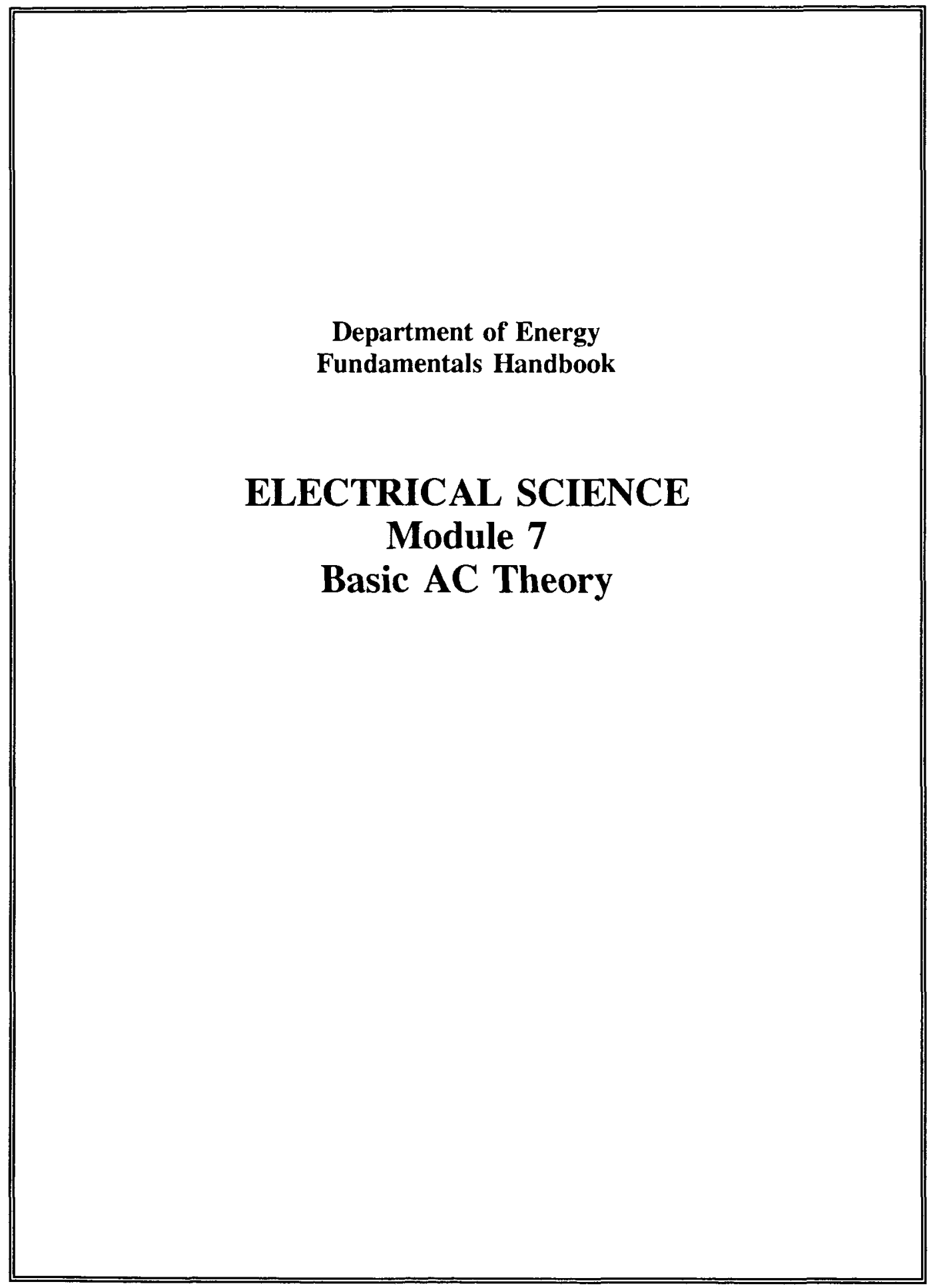




\section{TABLE OF CONTENTS}

LIST OF FIGURES $\ldots \ldots \ldots \ldots \ldots \ldots \ldots \ldots \ldots \ldots \ldots \ldots$

LIST OF TABLES $\ldots \ldots \ldots \ldots \ldots \ldots \ldots \ldots \ldots \ldots$ iii

REFERENCES $\ldots \ldots \ldots \ldots \ldots \ldots \ldots \ldots \ldots \ldots \ldots \ldots \ldots \ldots$

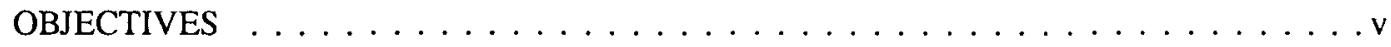

AC GENERATION $\ldots \ldots \ldots \ldots \ldots \ldots \ldots \ldots \ldots \ldots \ldots \ldots \ldots \ldots \ldots \ldots \ldots$

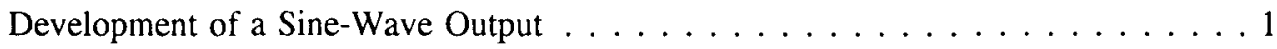

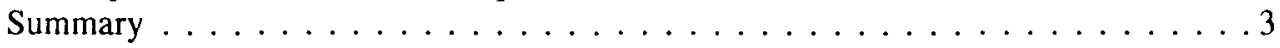

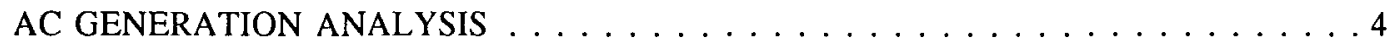

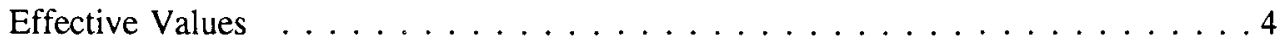

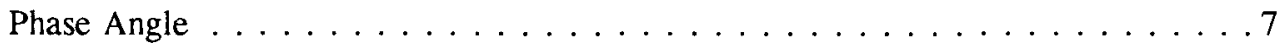

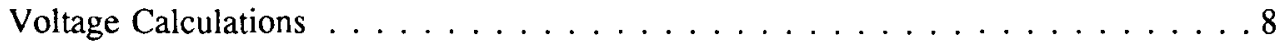

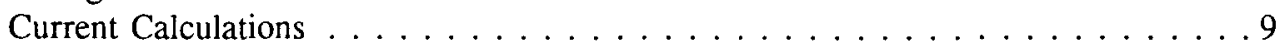

Frequency Calculations $\ldots \ldots \ldots \ldots \ldots \ldots$

Summary . . . . . . . . . . . . . . . . . . . . . 10 


\section{LIST OF FIGURES}

Figure 1 Simple AC Generator $\ldots \ldots \ldots \ldots \ldots \ldots \ldots \ldots \ldots \ldots \ldots \ldots \ldots \ldots \ldots \ldots \ldots$

Figure 2 Developing a Sine-Wave Voltage $\ldots \ldots \ldots \ldots \ldots \ldots \ldots \ldots \ldots \ldots \ldots \ldots$

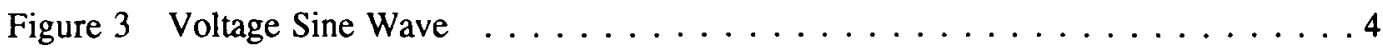

Figure 4 Effective Value of Current $\ldots \ldots \ldots \ldots \ldots \ldots \ldots \ldots \ldots \ldots \ldots \ldots \ldots \ldots \ldots$

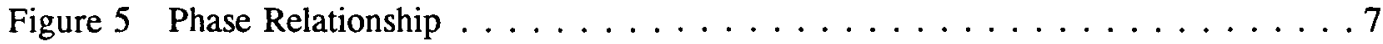




\section{LIST OF TABLES}

NONE 


\section{REFERENCES}

- Gussow, Milton, Schaum's Outline Series, Basic Electricity, McGraw-Hill.

- Academic Program for Nuclear Power Plant Personnel, Volume IV, Columbia, MD:

General Physics Corporation, Library of Congress Card \#A 326517, 1982.

- Sienko and Plane, Chemical Principles and Properties, $2^{\text {nd }}$ Edition, McGraw-Hill.

- $\quad$ Academic Program for Nuclear Power Plant Personnel, Volume II, Columbia, MD:

General Physics Corporation, Library of Congress Card \#A 326517, 1981.

- Nasar and Unnewehr, Electromechanics and Electric Machines, John Wiley and Sons.

- Van Valkenburgh, Nooger, and Neville, Basic Electricity, Vol. 5, Hayden Book Company.

- Exide Industrial Marketing Division, The Storage Battery, Lead-Acid Type, The Electric Storage Battery Company.

- Lister, Eugene C., Electric Circuits and Machines, $5^{\text {th }}$ Edition, McGraw-Hill.

- Croft, Carr, Watt, and Summers, American Electricians Handbook, $10^{\text {th }}$ Edition, McGraw-Hill.

- Mason, C. Russel, The Art and Science of Protective Relaying, John Wiley and Sons.

- Mileaf, Harry, Electricity One - Seven, Revised $2^{\text {nd }}$ Edition, Hayden Book Company.

- Buban and Schmitt, Understanding Electricity and Electronics, $3^{\text {rd }}$ Edition, McGrawHill.

- Kidwell, Walter, Electrical Instruments and Measurements, McGraw-Hill. 


\section{TERMINAL OBJECTIVE}

1.0 Given an alternating current (AC) waveform, DESCRIBE the relationship between average and RMS values of voltage and current, and the angular velocity within that waveform.

\section{ENABLING OBJECTIVES}

1.1 DESCRIBE the construction and operation of a simple AC generator.

1.2 EXPLAIN the development of a sine-wave output in an AC generator.

1.3 DEFINE the following terms in relation to $\mathrm{AC}$ generation:
a. Radians/second
b. Hertz
c. Period

1.4 DEFINE effective value of an AC current relative to DC current.

1.5 Given a maximum value, CALCULATE the effective (RMS) and average values of $\mathrm{AC}$ voltage.

1.6 Given a diagram of two sine waves, DESCRIBE the phase relationship between the two waves. 
Intentionally Left Blank 


\section{AC GENERATION}

An understanding of how an $A C$ generator develops an $A C$ output will help the student analyze the $A C$ power generation process.

EO 1.1 DESCRIBE the construction and operation of a simple AC generator.

EO 1.2 EXPLAIN the development of a sine-wave output in an AC generator.

The elementary AC generator (Figure 1) consists of a conductor, or loop of wire in a magnetic field that is produced by an electromagnet. The two ends of the loop are connected to slip rings, and they are in contact with two brushes. When the loop rotates it cuts magnetic lines of force, first in one direction and then the other.

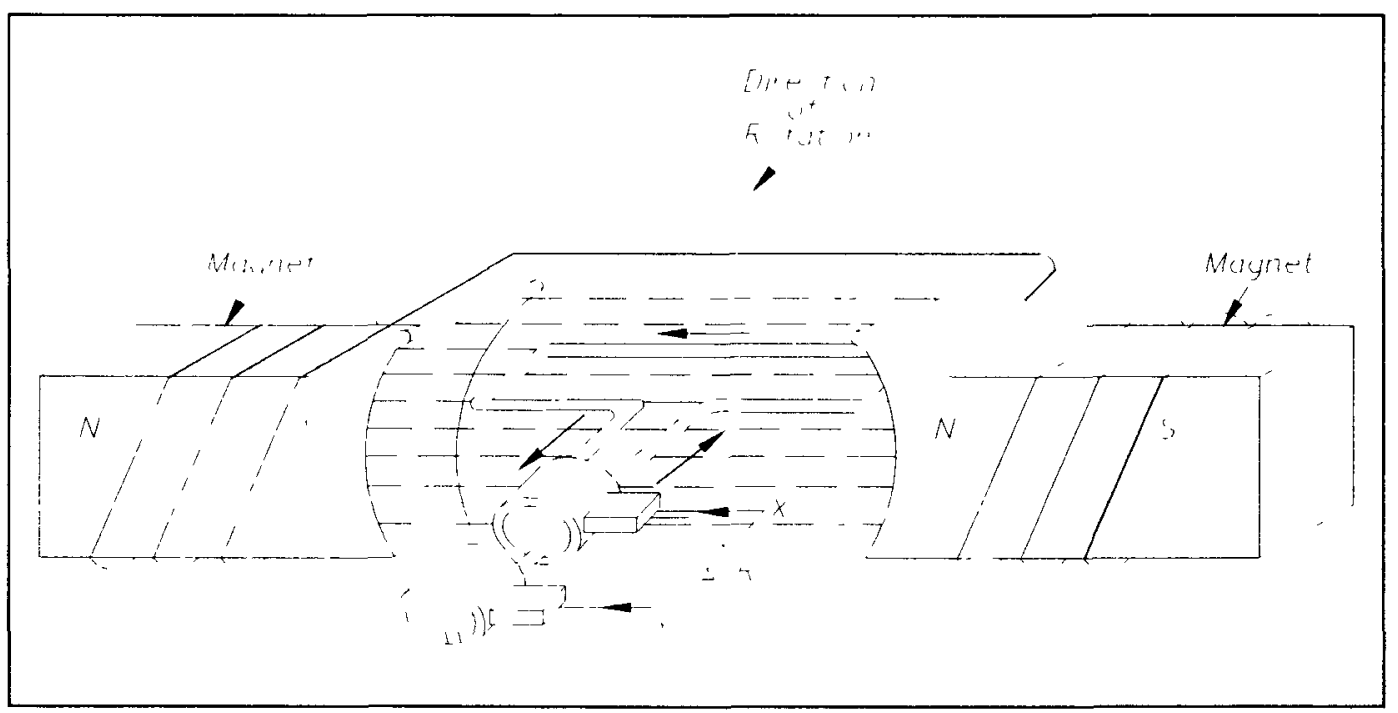

Figure 1 Simple AC Generator

\section{Development of a Sine-Wave Output}

At the instant the loop is in the vertical position (Figure $2,0^{\circ}$ ), the coil sides are moving parallel to the field and do not cut magnetic lines of force. In this instant, there is no voltage induced in the loop. As the coil rotates in a counter-clockwise direction, the coil sides will cut the magnetic lines of force in opposite directions. The direction of the induced voltages depends on the direction of movement of the coil. 
The induced voltages add in series, making slip ring $X$ (Figure 1) positive $(+)$ and slip ring $Y$ (Figure 1) negative (-). The potential across resistor $R$ will cause a current to flow from $Y$ to $\mathrm{X}$ through the resistor. This current will increase until it reaches a maximum value when the coil is horizontal to the magnetic lines of force (Figure 2, $90^{\circ}$ ). The horizontal coil is moving perpendicular to the field and is cutting the greatest number of magnetic lines of force. As the coil continues to turn, the voltage and current induced decrease until they reach zero, where the coil is again in the vertical position (Figure $2,180^{\circ}$ ). In the other half revolution, an equal voltage is produced except that the polarity is reversed (Figure 2, 270, $360^{\circ}$ ). The current flow through $\mathrm{R}$ is now from $\mathrm{X}$ to $\mathrm{Y}$ (Figure 1 ).

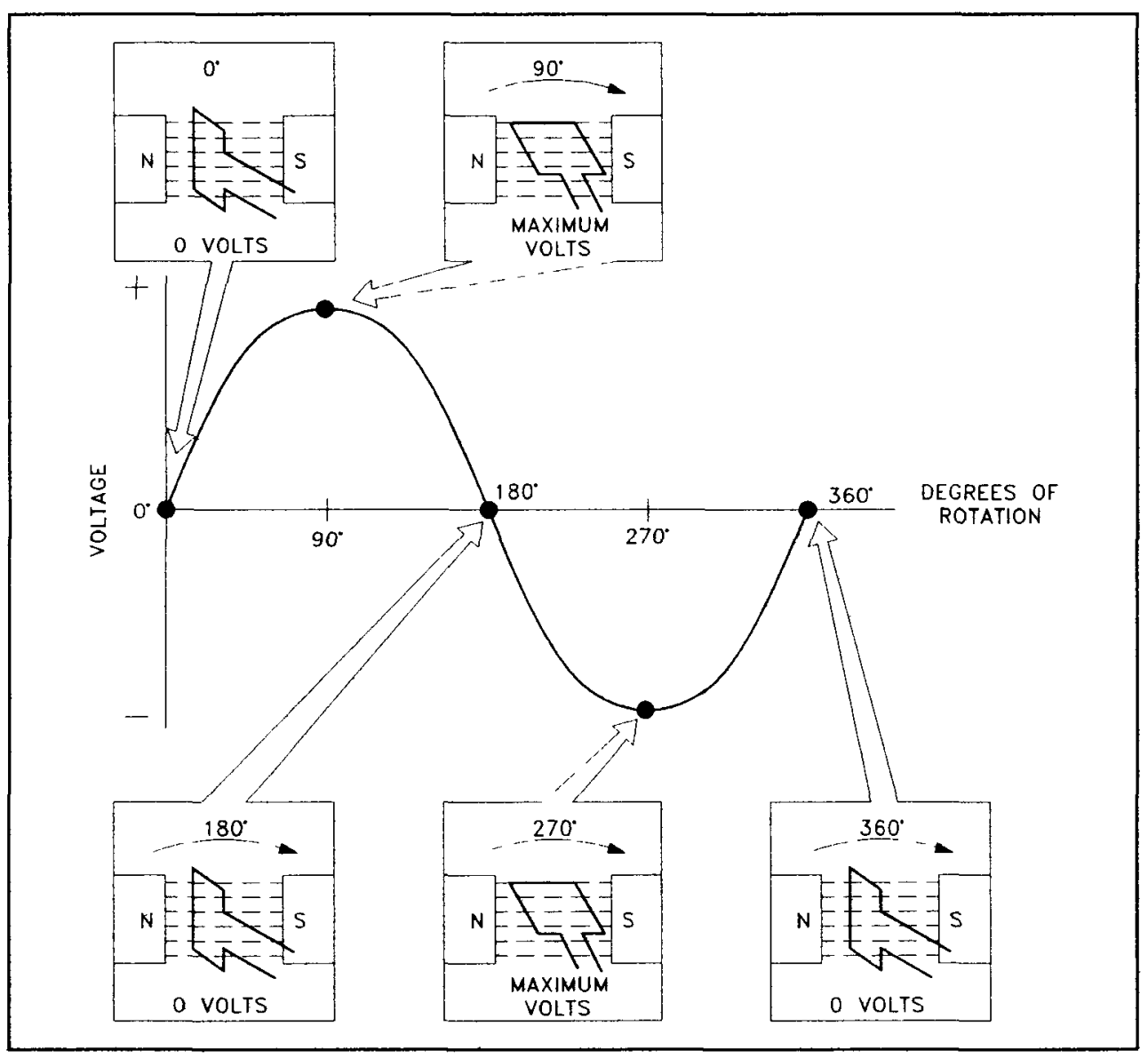

Figure 2 Developing a Sine-Wave Voltage 
The periodic reversal of polarity results in the generation of a voltage, as shown in Figure 2. The rotation of the coil through $360^{\circ}$ results in an $\mathrm{AC}$ sine wave output.

\section{Summary}

AC generation is summarized below.

\section{AC Generation Summary}

- A simple generator consists of a conductor loop turning in a magnetic field, cutting across the magnetic lines of force.

- The sine wave output is the result of one side of the generator loop cutting lines of force. In the first half turn of rotation this produces a positive current and in the second half of rotation produces a negative current. This completes one cycle of $\mathrm{AC}$ generation. 


\section{AC GENERATION ANALYSIS}

Analysis of the AC power generation process and of the alternating current we use in almost every aspect of our lives is necessary to better understand how $A C$ power is used in today's technology.

EO 1.3 DEFINE the following terms in relation to $\mathrm{AC}$ generation:

a. Radians/second

b. Hertz

c. Period

EO 1.4 DEFINE effective value of an $\mathrm{AC}$ current relative to $\mathrm{DC}$ current.

EO 1.5 Given a maximum value, CALCULATE the effective (RMS) and average values of $A C$ voltage.

EO 1.6 Given a diagram of two sine waves, DESCRIBE the phase relationship between the two waves.

\section{Effective Values}

The output voltage of an AC generator can be expressed in two ways. One is graphically by use of a sine wave (Figure 3 ). The second way is algebraically by the equation $\mathrm{e}=\mathrm{E}_{\mathrm{max}} \sin \omega \mathrm{t}$, which will be covered later in the text.

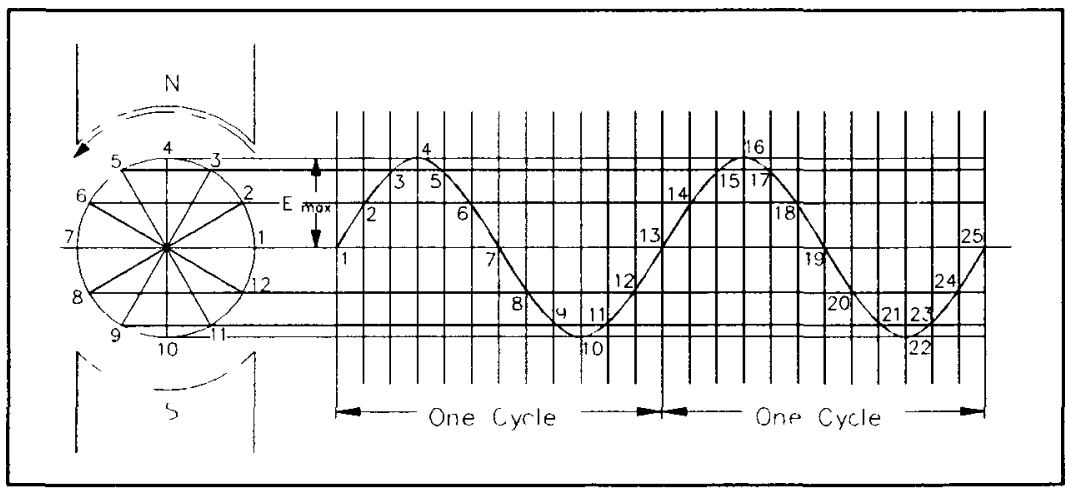

Figure 3 Voltage Sine Wave 
When a voltage is produced by an AC generator, the resulting current varies in step with the voltage. As the generator coil rotates $360^{\circ}$, the output voltage goes through one complete cycle. In one cycle, the voltage increases from zero to $E_{\max }$ in one direction, decreases to zero, increases to $\mathrm{E}_{\mathrm{max}}$ in the opposite direction (negative $\mathrm{E}_{\mathrm{max}}$ ), and then decreases to zero again. The value of $E_{\max }$ occurs at $90^{\circ}$ and is referred to as peak voltage. The time it takes for the generator to complete one cycle is called the period, and the number of cycles per second is called the frequency (measured in hertz).

One way to refer to $A C$ voltage or current is by peak voltage $\left(E_{p}\right)$ or peak current $\left(I_{p}\right)$. This is the maximum voltage or current for an $\mathrm{AC}$ sine wave.

Another value, the peak-to-peak value $\left(E_{p-p}\right.$ or $\left.I_{p-p}\right)$, is the magnitude of voltage, or current range, spanned by the sine wave. However, the value most commonly used for $\mathrm{AC}$ is effective value. Effective value of $\mathrm{AC}$ is the amount of $\mathrm{AC}$ that produces the same heating effect as an equal amount of DC. In simpler terms, one ampere effective value of $\mathrm{AC}$ will produce the same amount of heat in a conductor, in a given time, as one ampere of DC. The heating effect of a given $\mathrm{AC}$ current is proportional to the square of the current. Effective value of $\mathrm{AC}$ can be calculated by squaring all the amplitudes of the sine wave over one period, taking the average of these values, and then taking the square root. The effective value, being the root of the mean (average) square of the currents, is known as the root-mean-square, or RMS value. In order to understand the meaning of effective current applied to a sine wave, refer to Figure 4.

The values of I are plotted on the upper curve, and the corresponding values of $\mathrm{I}^{2}$ are plotted on the lower curve. The $I^{2}$ curve has twice the frequency of $I$ and varies above and below a new axis. The new axis is the average of the $\mathrm{I}^{2}$ values, and the square root of that value is the RMS, or effective value, of current. The average value is $1 / 2 I_{\max }^{2}$. The RMS value is then $\frac{\sqrt{2 I_{\max }^{2}}}{2}$ OR $\frac{\sqrt{2}}{2} \mathrm{I}_{\max }$, which is equal to $0.707 \mathrm{I}_{\max }$.

There are six basic equations that are used to convert a value of $\mathrm{AC}$ voltage or current to another value, as listed below.

Average value $=$ peak value $\times 0.637$

Effective value (RMS) $=$ peak value $\times 0.707$

Peak value $=$ average value $\times 1.57$

Effective value (RMS) $=$ average value $\times 1.11$

Peak value $=$ effective value $(\mathrm{RMS}) \times 1.414$

Average value $=$ effective $(\mathrm{RMS}) \times 0.9$

The values of current (I) and voltage (E) that are normally encountered are assumed to be RMS values; therefore, no subscript is used. 


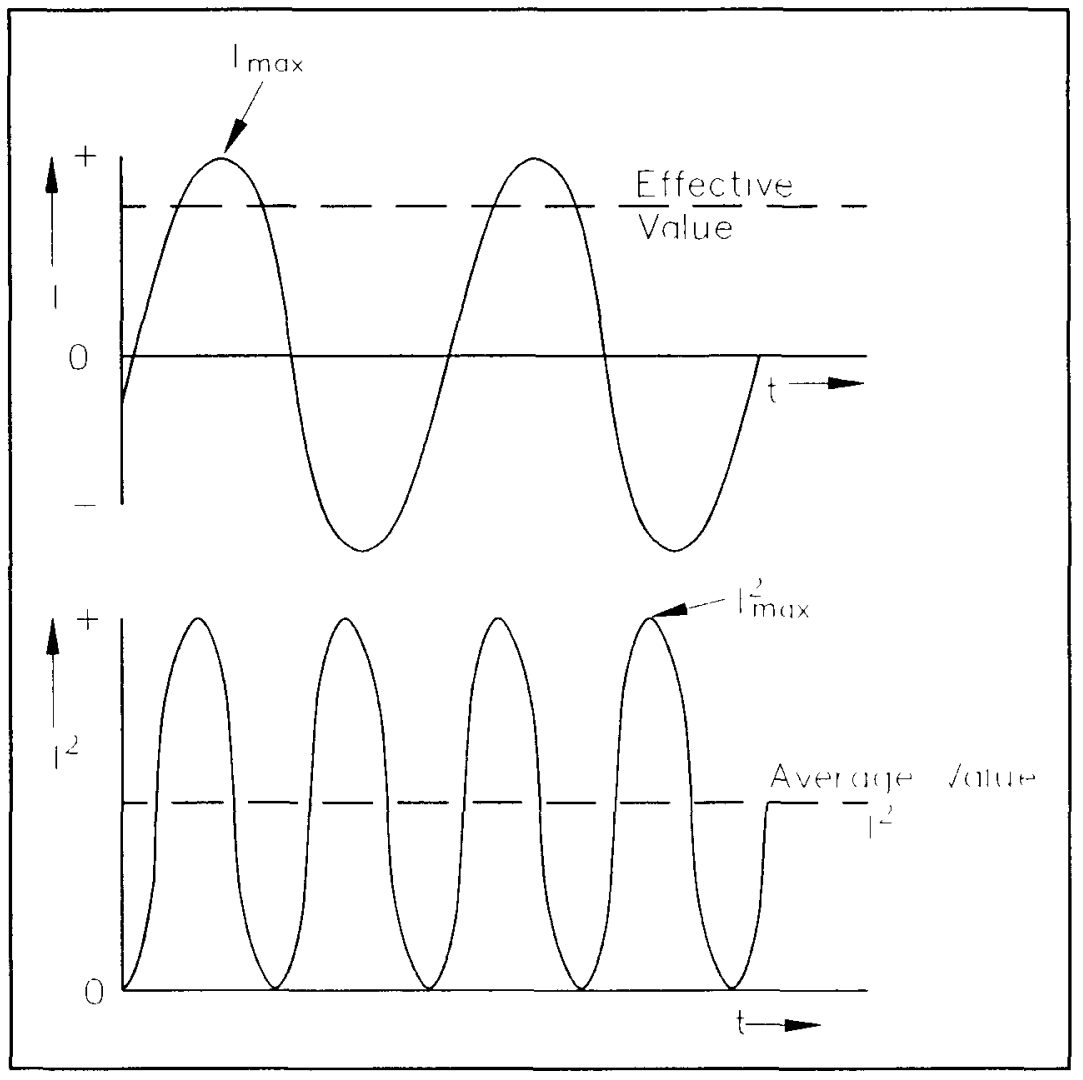

Figure 4 Effective Value of Current

Another useful value is the average value of the amplitude during the positive half of the cycle. Equation (7-7) is the mathematical relationship between $I_{a v}, I_{\max }$, and $I$.

$$
\mathrm{I}_{\mathrm{av}}=0.637 \mathrm{I}_{\max }=0.90 \mathrm{I}
$$

Equation (7-8) is the mathematical relationship between $E_{a v}, E_{m a x}$, and $E$.

$$
\mathrm{E}_{\mathrm{av}}=0.637 \mathrm{E}_{\max }=0.90 \mathrm{E}
$$

Example 1: The peak value of voltage in an AC circuit is $200 \mathrm{~V}$. What is the RMS value of the voltage?

$$
\begin{aligned}
& E=0.707 E_{\max } \\
& E=0.707(200 \mathrm{~V}) \\
& E=141.4 V
\end{aligned}
$$


Example 2: The peak current in an AC circuit is 10 amps. What is the average value of current in the circuit?

$$
\begin{aligned}
& I_{a v}=0.637 I_{\max } \\
& I_{a v}=0.637(10 \mathrm{amps}) \\
& I_{a v}=6.37 \mathrm{amps}
\end{aligned}
$$

\section{Phase Angle}

Phase angle is the fraction of a cycle, in degrees, that has gone by since a voltage or current has passed through a given value. The given value is normally zero. Referring back to Figure 3, take point 1 as the starting point or zero phase. The phase at Point 2 is $30^{\circ}$, Point 3 is $60^{\circ}$, Point 4 is $90^{\circ}$, and so on, until Point 13 where the phase is $360^{\circ}$, or zero. A term more commonly used is phase difference. The phase difference can be used to describe two different voltages that have the same frequency, which pass through zero values in the same direction at different times. In Figure 5, the angles along the axis indicate the phases of voltages $e_{1}$ and $e_{2}$ at any point in time. At $120^{\circ}, e_{1}$ passes through the zero value, which is $60^{\circ}$ ahead of $e_{2}\left(e_{2}\right.$ equals zero at $180^{\circ}$ ). The voltage $e_{1}$ is said to lead $e_{2}$ by 60 electrical degrees, or it can be said that $e_{2}$ lags $e_{1}$ by 60 electrical degrees.

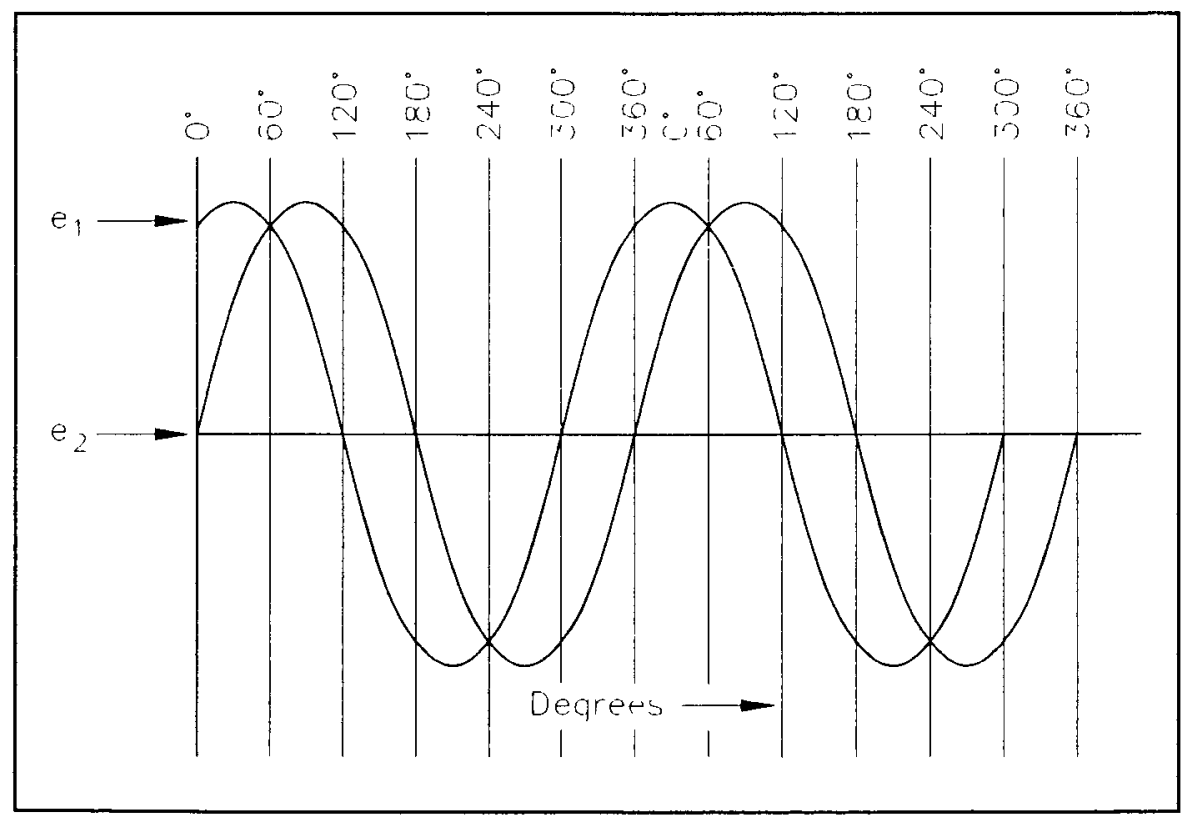

Figure 5 Phase Relatıonship 
Phase difference is also used to compare two different currents or a current and a voltage. If the phase difference between two currents, two voltages, or a voltage and a current is zero degrees, they are said to be "in-phase." If the phase difference is an amount other than zero, they are said to be "out-of-phase."

\section{Voltage Calculations}

Equation (7-9) is a mathematical representation of the voltage associated with any particular orientation of a coil (inductor).

$$
\mathrm{e}=\mathrm{E}_{\max } \sin \theta
$$

where

$$
\begin{array}{ll}
\mathbf{e} & =\text { induced EMF } \\
\mathrm{E}_{\max } & =\text { maximum induced EMF } \\
\theta & =\text { angle from reference (degrees or radians) }
\end{array}
$$

Example 1: What is the induced EMF in a coil producing a maximum EMF of $120 \mathrm{~V}$ when the angle from reference is $45^{\circ}$ ?

$$
\begin{aligned}
& \mathrm{e}=\mathrm{E}_{\max } \sin \theta \\
& \mathrm{e}=120 \mathrm{~V}\left(\sin 45^{\circ}\right) \\
& \mathrm{e}=84.84 \mathrm{~V}
\end{aligned}
$$

The maximum induced voltage can also be called peak voltage $E_{p}$. If $(t)$ is the time in which the coil turns through the angle $(\theta)$, then the angular velocity $(\omega)$ of the coil is equal to $\theta / t$ and is expressed in units of radians/sec. Equation (7-10) is the mathematical representation of the angular velocity.

$$
\theta=\omega t
$$

where

$$
\begin{aligned}
& \omega=\text { angular velocity (radians/sec) } \\
& \mathrm{t}=\text { time to turn through the angle from reference }(\mathrm{sec}) \\
& \theta=\text { angle from reference (radians) }
\end{aligned}
$$

Using substitution laws, a relationship between the voltage induced, the maximum induced voltage, and the angular velocity can be expressed. Equation (7-11) is the mathematical representation of the relationship between the voltage induced, the maximum voltage, and the angular velocity, and is equal to the output of an AC Generator.

$$
\mathrm{e}=\mathrm{E}_{\max } \sin (\omega \mathrm{t})
$$


where

$$
\begin{array}{lll}
\mathrm{e} & = & \text { induced EMF (volts) } \\
\mathrm{E}_{\max } & =\text { maximum induced EMF (volts) } \\
\omega & = & \text { angular velocity (radians/sec) } \\
\mathrm{t} & = & \text { time to turn through the angle from reference (sec) }
\end{array}
$$

\section{Current Calculations}

Maximum induced current is calculated in a similar fashion. Equation (7-12) is a mathematical representation of the relationship between the maximum induced current and the angular velocity.

$$
\mathrm{i}=\mathrm{I}_{\max } \sin (\omega \mathrm{t})
$$

where

$$
\begin{array}{ll}
\mathrm{i} & =\text { induced current (amps) } \\
\mathrm{I}_{\max } & =\text { maximum induced current (amps) } \\
\omega & =\text { angular velocity (radians/sec) } \\
\mathrm{t} & =\text { time to turn through the angle from reference (sec) }
\end{array}
$$

\section{Frequency Calculations}

The frequency of an alternating voltage or current can be related directly to the angular velocity of a rotating coil. The units of angular velocity are radians per second, and $2 \pi$ radians is a full revolution. A radian is an angle that subtends an arc equal to the radius of a circle. One radian equals 57.3 degrees. One cycle of the sine wave is generated when the coil rotates $2 \pi$ radians. Equation (7-13) is the mathematical relationship between frequency ( $f$ ) and the angular velocity $(\omega)$ in an $\mathrm{AC}$ circuit.

$$
\omega=2 \pi f
$$

where

$$
\begin{aligned}
& \omega=\text { angular velocity (radians } / \mathrm{sec} \text { ) } \\
& \mathrm{f}=\text { frequency }(\mathrm{HZ})
\end{aligned}
$$


Example 1: The frequency of a $120 \mathrm{~V} \mathrm{AC}$ circuit is $60 \mathrm{~Hz}$. Find the following:

1. Angular velocity

2. Angle from reference at $1 \mathrm{msec}$

3. Induced EMF at that point

Solution:

$$
\begin{aligned}
\text { 1. } \quad \omega & =2 \pi \mathrm{f} \\
& =2(3.14)(60 \mathrm{~Hz}) \\
& =376.8 \text { radians } / \mathrm{sec} \\
\text { 2. } \quad \theta & =\omega \mathrm{t} \\
& =(376.8 \text { radian } / \mathrm{sec})(.001 \mathrm{sec}) \\
& =0.3768 \text { radians } \\
3 . \quad \mathrm{e} & =\mathrm{E}_{\max } \sin \theta \\
& =(120 \mathrm{~V})(\sin 0.3768 \text { radians }) \\
& =(120 \mathrm{~V})(0.3679) \\
& =44.15 \mathrm{~V}
\end{aligned}
$$

\section{Summary}

AC generation analysis is summarized below.

\section{Voltage, Current, and Frequency Summary}

- The following terms relate to the AC cycle: radians/second, the velocity the loop turns; hertz, the number of cycles in one second; period, the time to complete one cycle.

- Effective value of $\mathrm{AC}$ equals effective value of DC.

- Root mean square (RMS) values equate $\mathrm{AC}$ to $\mathrm{DC}$ equivalents:

$-\mathrm{I}=0.707 \mathrm{I}_{\max }=$ Effective Current

- $\mathrm{E}=0.707 \mathrm{E}_{\max }=$ Effective Voltage

- $\mathrm{I}_{\mathrm{av}}=0.636 \mathrm{I}_{\max }=0.9 \mathrm{I}=$ Average Current

- $\mathrm{E}_{\mathrm{av}}=0.636 \mathrm{E}_{\max }=0.9 \mathrm{E}=$ Average Voltage

- Phase angle is used to compare two wave forms. It references the start, or zero point, of each wave. It compares differences by degrees of rotation. Wave forms with the same start point are "in-phase" while wave forms "out-of-phase" either lead or lag. 
Department of Energy

Fundamentals Handbook

\section{ELECTRICAL SCIENCE}

Module 8

Basic AC Reactive Components 


\section{TABLE OF CONTENTS}

LIST OF FIGURES $\ldots \ldots \ldots \ldots \ldots \ldots \ldots \ldots \ldots \ldots \ldots \ldots \ldots$

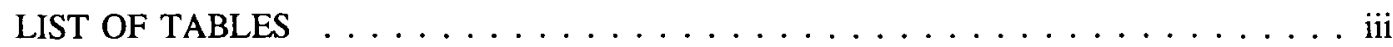

REFERENCES $\ldots \ldots \ldots \ldots \ldots \ldots \ldots \ldots \ldots \ldots \ldots \ldots \ldots$

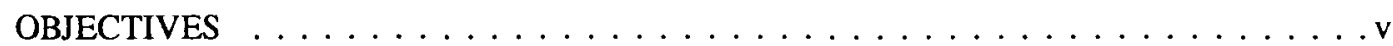

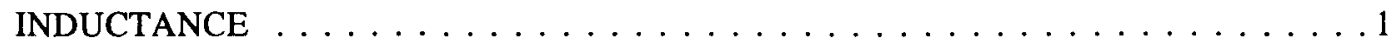

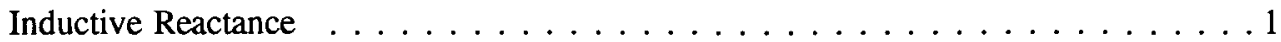

Voltage and Current Phase Relationships in an Inductive Circuit . . . . . . . . 2

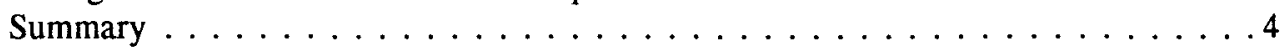

CAPACITANCE $\ldots \ldots \ldots \ldots \ldots \ldots \ldots \ldots \ldots \ldots \ldots \ldots \ldots \ldots \ldots \ldots \ldots \ldots \ldots \ldots$

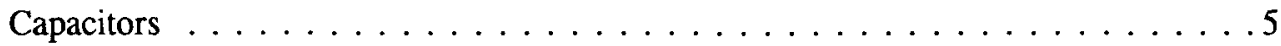

Capacitive Reactance . . . . . . . . . . . . . . . . . . 6

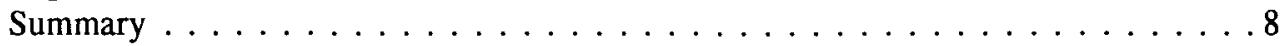

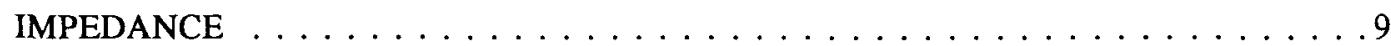

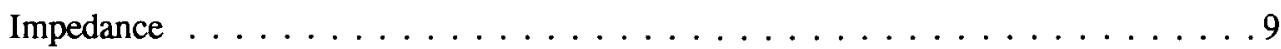

Impedance in R-L Circuits $\ldots \ldots \ldots \ldots \ldots \ldots \ldots \ldots$

Impedance in R-C Circuits . . . . . . . . . . . . . . . . . . 12

Impedance in R-C-L Circuits . . . . . . . . . . . . . . . . 13

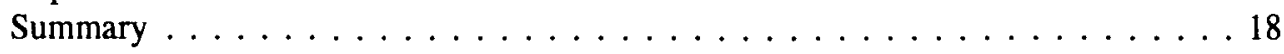

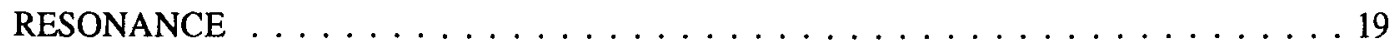

Resonant Frequency ... . . . . . . . . . . . . . . . . . 19

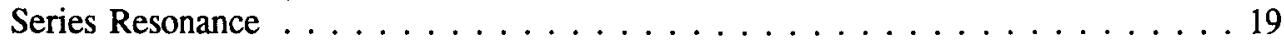

Parallel Resonance . . . . . . . . . . . . . . . . . . 20

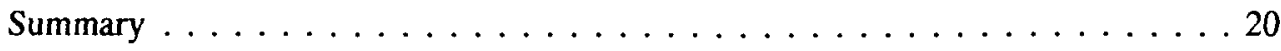




\section{LIST OF FIGURES}

Figure 1 Current, Self-Induced EMF, and Applied Voltage in Inductive Circuit . . . . . . . . . . . . . . . . . 2

Figure $2 \quad$ Coil Circuit and Phasor Diagram $\ldots \ldots \ldots \ldots \ldots \ldots$

Figure $3 \quad$ Voltage, Charge, and Current in a Capacitor $\ldots \ldots \ldots \ldots$

Figure $4 \quad$ Circuit and Phasor Diagram $\ldots \ldots \ldots \ldots \ldots \ldots \ldots$

Figure $5 \quad$ Relationship Between Resistance, Reactance, and Impedance . . . . . . 10

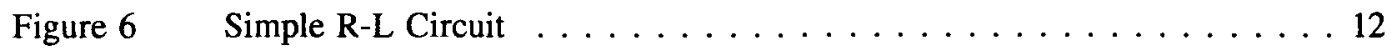

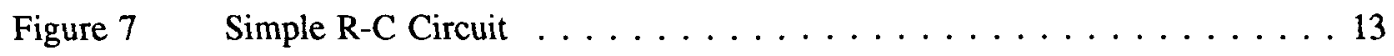

Figure $8 \quad$ Series R-C-L Impedance-Phasor $\ldots \ldots \ldots \ldots \ldots \ldots$

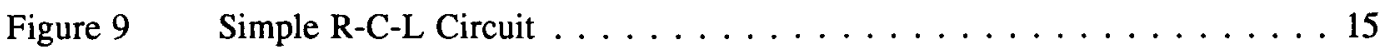

Figure $10 \quad$ Simple Parallel R-C-L Circuit $\ldots \ldots \ldots \ldots \ldots$ 


\section{LIST OF TABLES}

NONE 


\section{REFERENCES}

- Gussow, Milton, Schaum's Outline Series, Basic Electricity, McGraw-Hill.

- $\quad$ Academic Program for Nuclear Power Plant Personnel, Volume IV, Columbia, MD:

General Physics Corporation, Library of Congress Card \#A 326517, 1982.

- Sienko and Plane, Chemical Principles and Properties, $2^{\text {nd }}$ Edition, McGraw-Hill.

- Academic Program for Nuclear Power Plant Personnel, Volume II, Columbia, MD:

General Physics Corporation, Library of Congress Card \#A 326517, 1982.

- Nasar and Unnewehr, Electromechanics and Electric Machines, John Wiley and Sons.

- Van Valkenburgh, Nooger, and Neville, Basic Electricity, Vol. 5, Hayden Book Company.

- $\quad$ Exide Industrial Marketing Division, The Storage Battery, Lead-Acid Type, The Electric Storage Battery Company.

- $\quad$ Lister, Eugene C., Electric Circuits and Machines, $5^{\text {th }}$ Edition, McGraw-Hill.

- Croft, Carr, Watt, and Summers, American Electricians Handbook, $10^{\text {th }}$ Edition, McGraw-Hill.

- Mason, C. Russel, The Art and Science of Protective Relaying, John Wiley and Sons.

- Mileaf, Harry, Electricity One - Seven, Revised $2^{\text {nd }}$ Edition, Hayden Book Company.

- Buban and Schmitt, Understanding Electricity and Electronics, $3^{\text {rd }}$ Edition, McGrawHill.

- Kidwell, Walter, Electrical Instruments and Measurements, McGraw-Hill. 


\section{TERMINAL OBJECTIVE}

1.0 Using the rules associated with inductors and capacitors, DESCRIBE the characteristics of these elements when they are placed in an $\mathrm{AC}$ circuit.

\section{ENABLING OBJECTIVES}

1.1 DESCRIBE inductive reactance $\left(\mathrm{X}_{\mathrm{L}}\right)$.

1.2 Given the operation frequency (f) and the value of inductance (L), CALCULATE the inductive reactance $\left(X_{L}\right)$ of a simple circuit.

1.3 DESCRIBE the effect of the phase relationship between current and voltage in an inductive circuit.

1.4 DRAW a simple phasor diagram representing $\mathrm{AC}$ current (I) and voltage (E) in an inductive circuit.

1.5 DEFINE capacitive reactance $\left(\mathrm{X}_{\mathrm{C}}\right)$.

1.6 Given the operating frequency ( $f$ ) and the value of capacitance (C), CALCULATE the capacitive reactance $\left(\mathrm{X}_{\mathrm{C}}\right)$ of a simple $\mathrm{AC}$ circuit.

1.7 DESCRIBE the effect on phase relationship between current (I) and voltage (E) in a capacitive circuit.

1.8 DRAW a simple phasor diagram representing AC current (I) and voltage (E) in a capacitive circuit.

1.9 DEFINE impedance (Z).

1.10 Given the values for resistance (R) and inductance ( $L$ ) and a simple R-L series AC circuit, CALCULATE the impedance $(Z)$ for that circuit.

1.11 Given the values for resistance (R) and capacitance (C) and a simple R-C series AC circuit, CALCULATE the impedance $(Z)$ for that circuit.

1.12 Given a simple R-C-L series AC circuit and the values for resistance (R), inductive reactance $\left(X_{L}\right)$, and capacitive reactance $\left(X_{C}\right)$, CALCULATE the impedance $(Z)$ for that circuit. 


\section{ENABLING OBJECTIVES (Cont.)}

1.13 STATE the formula for calculating total current $\left(\mathrm{I}_{\mathrm{T}}\right)$ in a simple parallel $\mathrm{R}-\mathrm{C}-\mathrm{L}$ AC circuit.

1.14 Given a simple R-C-L parallel $A C$ circuit and the values for voltage $\left(V_{T}\right)$, resistance $(R)$, inductive reactance $\left(X_{L}\right)$, and capacitive reactance $\left(X_{C}\right)$, CALCULATE the impedance $(Z)$ for that circuit.

1.15 DEFINE resonance.

1.16 Given the values of capacitance (C) and inductance (L), CALCULATE the resonant frequency.

1.17 Given a series R-C-L circuit at resonance, DESCRIBE the net reactance of the circuit.

1.18 Given a parallel R-C-L circuit at resonance, DESCRIBE the circuit output relative to current (I). 


\section{INDUCTANCE}

Any device relying on magnetism or magnetic fields to operate is a form of inductor. Motors, generators, transformers, and coils are inductors. The use of an inductor in a circuit can cause current and voltage to become out-of-phase and inefficient unless corrected.

EO 1.1 DESCRIBE inductive reactance $\left(X_{L}\right)$.

EO 1.2 Given the operation frequency (f) and the value of inductance $(\mathrm{L})$, CALCULATE the inductive reactance $\left(X_{L}\right)$ of a simple circuit.

EO 1.3 DESCRIBE the effect of the phase relationship between current and voltage in an inductive circuit.

EO 1.4 DRAW a simple phasor diagram representing AC current (I) and voltage (E) in an inductive circuit.

\section{Inductive Reactance}

In an inductive $\mathrm{AC}$ circuit, the current is continually changing and is continuously inducing an EMF. Because this EMF opposes the continuous change in the flowing current, its effect is measured in ohms. This opposition of the inductance to the flow of an alternating current is called inductive reactance $\left(\mathrm{X}_{\mathrm{L}}\right)$. Equation $(8-1)$ is the mathematical representation of the current flowing in a circuit that contains only inductive reactance.

$$
I=\frac{E}{X_{L}}
$$

where

$$
\begin{aligned}
& \mathrm{I}=\text { effective current }(\mathrm{A}) \\
& \mathrm{X}_{\mathrm{L}}=\text { inductive reactance }(\Omega) \\
& \mathrm{E}=\text { effective voltage across the reactance }(\mathrm{V})
\end{aligned}
$$

The value of $X_{L}$ in any circuit is dependent on the inductance of the circuit and on the rate at which the current is changing through the circuit. This rate of change depends on the frequency of the applied voltage. Equation (8-2) is the mathematical representation for $\mathrm{X}_{\mathrm{L}}$.

$$
X_{L}=2 \pi f L
$$


where

$$
\begin{aligned}
& \pi=\sim 3.14 \\
& \mathrm{f}=\text { frequency (Hertz) } \\
& \mathrm{L}=\text { inductance (Henries) }
\end{aligned}
$$

The magnitude of an induced EMF in a circuit depends on how fast the flux that links the circuit is changing. In the case of self-induced EMF (such as in a coil), a counter EMF is induced in the coil due to a change in current and flux in the coil. This CEMF opposes any change in current, and its value at any time will depend on the rate at which the current and flux are changing at that time. In a purely inductive circuit, the resistance is negligible in comparison to the inductive reactance. The voltage applied to the circuit must always be equal and opposite to the EMF of self-induction.

\section{Voltage and Current Phase Relationships in an Inductive Circuit}

As previously stated, any change in current in a coil (either a rise or a fall) causes a corresponding change of the magnetic flux around the coil. Because the current changes at its maximum rate when it is going through its zero value at $90^{\circ}$ (point $b$ on Figure 1) and $270^{\circ}$ (point d), the flux change is also the greatest at those times. Consequently, the self-induced EMF in the coil is at its maximum (or minimum) value at these points, as shown in Figure 1. Because the current is not changing at the point when it is going through its peak value at $0^{\circ}$ (point a), $180^{\circ}$ (point c), and $360^{\circ}$ (point e), the flux change is zero at those times. Therefore, the self-induced EMF in the coil is at its zero value at these points.

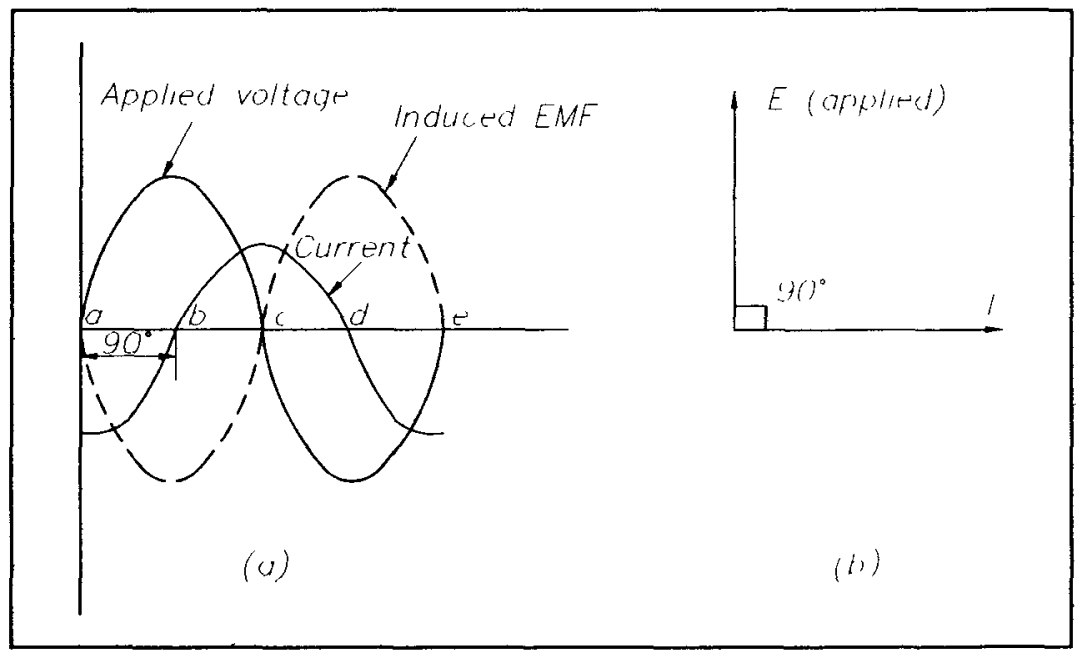

Figure 1 Current, Self-Induced EMF, and Applied Voltage in an Inductive Circuit 
According to Lenz's Law (refer to Module 1, Basic Electrical Theory), the induced voltage always opposes the change in current. Referring to Figure 1, with the current at its maximum negative value (point a), the induced EMF is at a zero value and falling. Thus, when the current rises in a positive direction (point a to point c), the induced EMF is of opposite polarity to the applied voltage and opposes the rise in current. Notice that as the current passes through its zero value (point $b$ ) the induced voltage reaches its maximum negative value. With the current now at its maximum positive value (point $\mathrm{c}$ ), the induced EMF is at a zero value and rising. As the current is falling toward its zero value at $180^{\circ}$ (point $c$ to point $d$ ), the induced EMF is of the same polarity as the current and tends to keep the current from falling. When the current reaches a zero value, the induced EMF is at its maximum positive value. Later, when the current is increasing from zero to its maximum negative value at $360^{\circ}$ (point $d$ to point $e$ ), the induced voltage is of the opposite polarity as the current and tends to keep the current from increasing in the negative direction. Thus, the induced EMF can be seen to lag the current by $90^{\circ}$.

The value of the self-induced EMF varies as a sine wave and lags the current by $90^{\circ}$, as shown in Figure 1. The applied voltage must be equal and opposite to the self-induced EMF at all times; therefore, the current lags the applied voltage by $90^{\circ}$ in a purely inductive circuit.

If the applied voltage $(E)$ is represented by a vector rotating in a counterclockwise direction (Figure lb), then the current can be expressed as a vector that is lagging the applied voltage by $90^{\circ}$. Diagrams of this type are referred to as phasor diagrams.

Example: A $0.4 \mathrm{H}$ coil with negligible resistance is connected to a $115 \mathrm{~V}, 60 \mathrm{~Hz}$ power source (see Figure 2). Find the inductive reactance of the coil and the current through the circuit. Draw a phasor diagram showing the phase relationship between current and applied voltage.
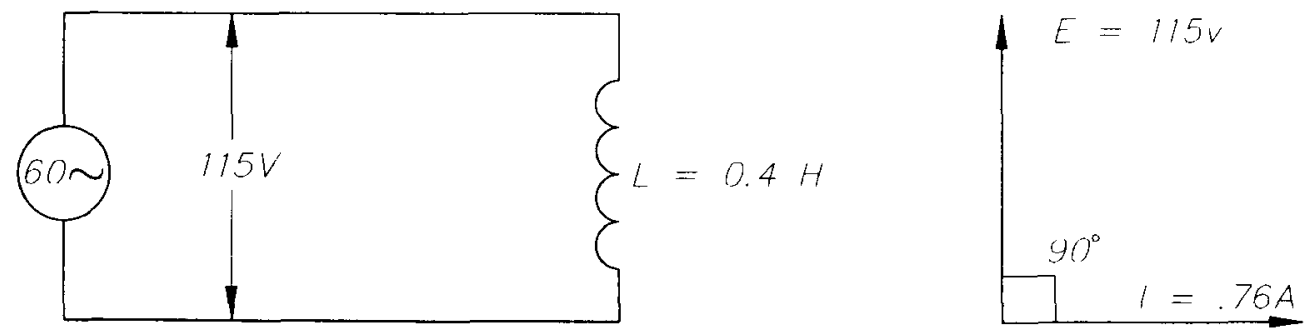

(a)

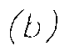

Figure 2 Coil Circuit and Phasor Diagram 
Solution:

1. Inductive reactance of the coil

$$
\begin{aligned}
X_{L} & =2 \pi f L \\
& =(2)(3.14)(60)(0.4) \\
X_{L} & =150.7 \Omega
\end{aligned}
$$

2. Current through the circuit

$$
\begin{aligned}
I & =\frac{E}{X_{L}} \\
& =\frac{115}{150.7} \\
I & =0.76 \text { amps }
\end{aligned}
$$

3. Draw a phasor diagram showing the phase relationship between current and applied voltage.

Phasor diagram showing the current lagging voltage by $90^{\circ}$ is drawn in Figure $2 \mathrm{~b}$.

\section{Summary}

Inductive reactance is summarized below.

\section{Inductive Reactance Summary}

- Opposition to the flow of alternating current caused by inductance is called Inductive Reactance $\left(\mathrm{X}_{\mathrm{L}}\right)$.

- The formula for calculating $\mathrm{X}_{\mathrm{L}}$ is:

$$
\mathrm{X}_{\mathrm{L}}=2 \pi \mathrm{fL}
$$

- $\quad$ Current (I) lags applied voltage (E) in a purely inductive circuit by $90^{\circ}$ phase angle.

- The phasor diagram shows the applied voltage (E) vector leading (above) the current (I) vector by the amount of the phase angle differential due to the relationship between voltage and current in an inductive circuit. 


\section{CAPACITANCE}

There are many natural causes of capacitance in $A C$ power circuits, such as transmission lines, fluorescent lighting, and computer monitors. Normally, these are counteracted by the inductors previously discussed. However, where capacitors greatly outnumber inductive devices, we must calculate the amount of capacitance to add or subtract from an AC circuit by artificial means.

EO 1.5 DEFINE capacitive reactance $\left(\mathbf{X}_{\mathrm{C}}\right)$.

EO 1.6 Given the operating frequency (f) and the value of capacitance $(C)$, CALCULATE the capacitive reactance $\left(X_{C}\right)$ of a simple $A C$ circuit.

EO 1.7 DESCRIBE the effect on phase relationship between current (I) and voltage (E) in a capacitive circuit.

EO 1.8 DRAW a simple phasor diagram representing AC current ( $I$ ) and voltage (E) in a capacitive circuit.

\section{Capacitors}

The variation of an alternating voltage applied to a capacitor, the charge on the capacitor, and the current flowing through the capacitor are represented by Figure 3 .

The current flow in a circuit containing capacitance depends on the rate at which the voltage changes. The current flow in Figure 3 is greatest at points a, c, and e. At these points, the voltage is changing at its maximum rate (i.e., passing through zero). Between points $a$ and $b$, the voltage and charge are increasing, and the current flow is into the capacitor, but decreasing in value. At point $b$, the capacitor is fully charged, and the current is zero. From points b to $c$, the voltage and charge are decreasing as the capacitor discharges, and its current flows in a direction opposite to the voltage. From points $c$ to $\mathrm{d}$, the capacitor begins to charge in the opposite direction, and the voltage and current are again in the same direction.

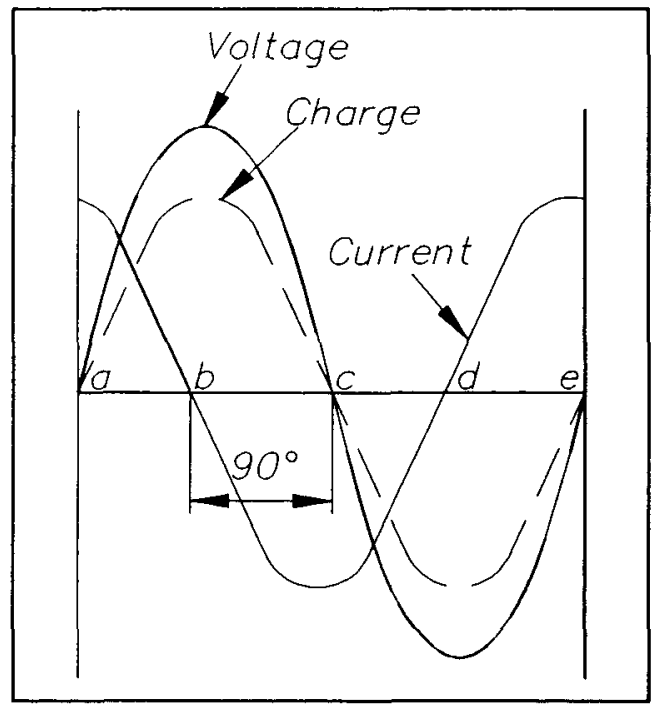

Figure 3 Voltage, Charge, and Current in a Capacitor 
At point $d$, the capacitor is fully charged, and the current flow is again zero. From points $d$ to $\mathrm{e}$, the capacitor discharges, and the flow of current is opposite to the voltage. Figure 3 shows the current leading the applied voltage by $90^{\circ}$. In any purely capacitive circuit, current leads applied voltage by $90^{\circ}$.

\section{Capacitive Reactance}

Capacitive reactance is the opposition by a capacitor or a capacitive circuit to the flow of current. The current flowing in a capacitive circuit is directly proportional to the capacitance and to the rate at which the applied voltage is changing. The rate at which the applied voltage is changing is determined by the frequency of the supply; therefore, if the frequency of the capacitance of a given circuit is increased, the current flow will increase. It can also be said that if the frequency or capacitance is increased, the opposition to current flow decreases; therefore, capacitive reactance, which is the opposition to current flow, is inversely proportional to frequency and capacitance. Capacitive reactance $X_{C}$, is measured in ohms, as is inductive reactance. Equation (8-3) is a mathematical representation for capacitive reactance.

$$
\mathrm{X}_{\mathrm{C}}=\frac{1}{2 \pi \mathrm{fC}}
$$

where

$$
\begin{aligned}
& \mathrm{f}=\text { frequency }(\mathrm{Hz}) \\
& \pi=-3.14 \\
& \mathrm{C}=\text { capacitance (farads) }
\end{aligned}
$$

Equation (8-4) is the mathematical representation of capacitive reactance when capacitance is expressed in microfarads $(\mu \mathrm{F})$.

$$
\mathrm{X}_{\mathrm{C}}=\frac{1,000,000}{2 \pi \mathrm{fC}}
$$

Equation (8-5) is the mathematical representation for the current that flows in a circuit with only capacitive reactance.

$$
I=\frac{E}{X_{C}}
$$


where

$$
\begin{aligned}
& \mathrm{I}=\text { effective current }(\mathrm{A}) \\
& \mathrm{E}=\text { effective voltage across the capacitive reactance }(\mathrm{V}) \\
& \mathrm{X}_{\mathrm{C}}=\text { capacitive reactance }(\Omega)
\end{aligned}
$$

Example: A $10 \mu \mathrm{F}$ capacitor is connected to a $120 \mathrm{~V}, 60 \mathrm{~Hz}$ power source (see Figure 4). Find the capacitive reactance and the current flowing in the circuit. Draw the phasor diagram.

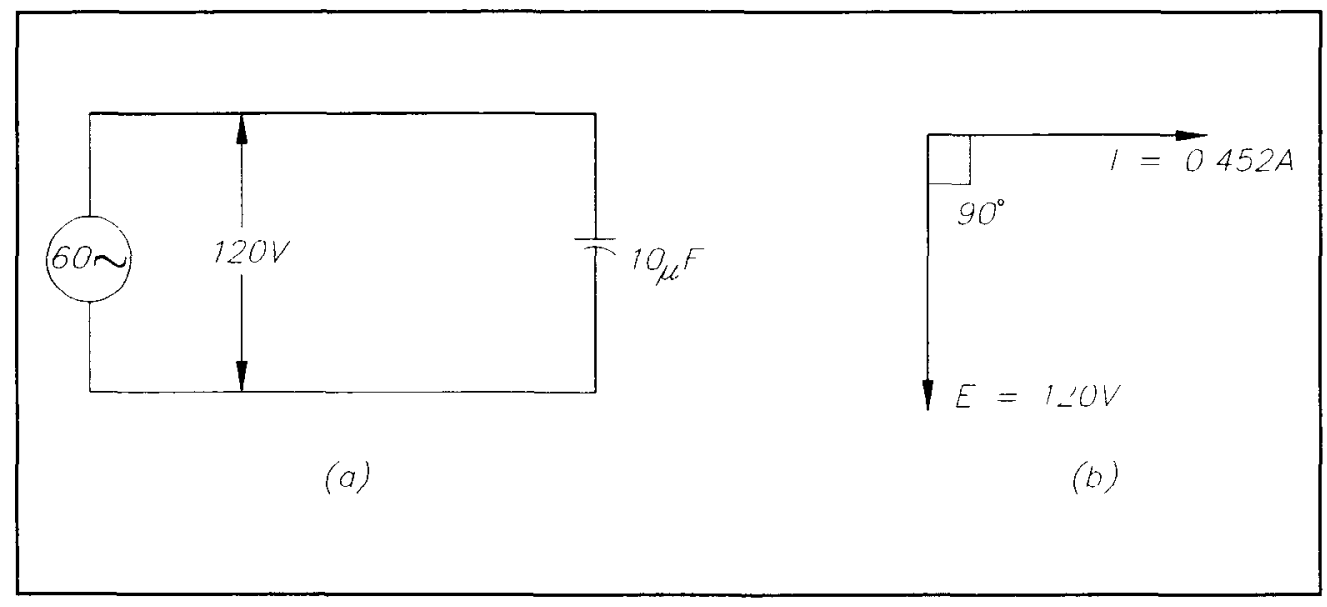

Figure 4 Circuit and Phasor Diagram

Solution:

1. Capacitive reactance

$$
\begin{aligned}
X_{C} & =\frac{1,000,000}{2 \pi f C} \\
& =\frac{1,000,000}{(2)(3.14)(60)(10)} \\
& =\frac{1,000,000}{3768} \\
X_{C} & =265.4 \Omega
\end{aligned}
$$


2. Current flowing in the circuit

$$
\begin{aligned}
I & =\frac{E}{X_{C}} \\
& =\frac{120}{265.4} \\
I & =0.452 \mathrm{amps}
\end{aligned}
$$

3. Phasor diagram showing current leading voltage by $90^{\circ}$ is drawn in Figure $4 \mathrm{~b}$.

\section{Summary}

Capacitive reactance is summarized below.

\section{Capacitive Reactance Summary}

- Opposition to the flow of alternating current caused by capacitance is called capacitive reactance $\left(\mathrm{X}_{\mathrm{C}}\right)$.

- The formula for calculating $\mathrm{X}_{\mathrm{C}}$ is:

$$
X_{\mathrm{c}}=\frac{1}{2 \pi \mathrm{fC}}
$$

- $\quad$ Current (I) leads applied voltage by $90^{\circ}$ in a purely capacitive circuit.

- The phasor diagram shows the applied voltage (E) vector leading (below) the current (I) vector by the amount of the phase angle differential due to the relationship between voltage and current in a capacitive circuit. 


\section{IMPEDANCE}

Whenever inductive and capacitive components are used in an AC circuit, the calculation of their effects on the flow of current is important.

EO 1.9 DEFINE impedance (Z).

EO 1.10 Given the values for resistance $(R)$ and inductance (L) and a simple R-L series AC circuit, CALCULATE the impedance $(Z)$ for that circuit.

EO 1.11 Given the values for resistance $(R)$ and capacitance (C) and a simple $R-C$ series $A C$ circuit, CALCULATE the impedance $(Z)$ for that circuit.

EO 1.12 Given a simple R-C-L series AC circuit and the values for resistance $(R)$, inductive reactance $\left(X_{L}\right)$, and capacitive reactance $\left(X_{C}\right)$, CALCULATE the impedance (Z) for that circuit.

EO 1.13 STATE the formula for calculating total current $\left(\mathrm{I}_{\mathrm{T}}\right)$ in a simple parallel R-C-L AC circuit.

EO 1.14 Given a simple R-C-L parallel AC circuit and the values for voltage $\left(V_{T}\right)$, resistance $(R)$, inductive reactance $\left(X_{L}\right)$, and capacitive reactance $\left(X_{C}\right)$, CALCULATE the impedance $(Z)$ for that circuit.

\section{Impedance}

No circuit is without some resistance, whether desired or not. Resistive and reactive components in an AC circuit oppose current flow. The total opposition to current flow in a circuit depends on its resistance, its reactance, and the phase relationships between them. Impedance is defined as the total opposition to current flow in a circuit. Equation (8-6) is the mathematical representation for the magnitude of impedance in an AC circuit.

$$
Z=\sqrt{R^{2}+X^{2}}
$$


where

$$
\begin{aligned}
& \mathrm{Z}=\text { impedance }(\boldsymbol{\Omega}) \\
& \mathrm{R}=\text { resistance }(\boldsymbol{\Omega}) \\
& \mathrm{X}=\text { net reactance }(\boldsymbol{\Omega})
\end{aligned}
$$

The relationship between resistance, reactance, and impedance is shown in Figure 5.

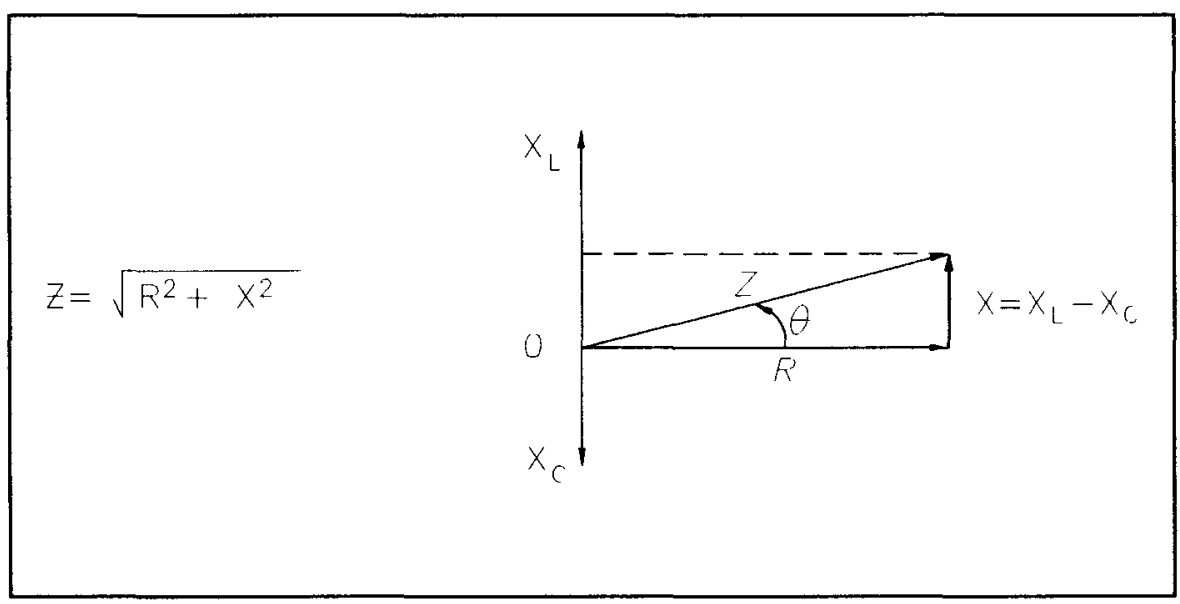

Figure 5 Relationship Between Resistance, Reactance, and Impedance

The current through a certain resistance is always in phase with the applied voltage. Resistance is shown on the zero axis. The current through an inductor lags applied voltage by $90^{\circ}$; inductive reactance is shown along the $90^{\circ}$ axis. Current through a capacitor leads applied voltage by $90^{\circ}$; capacitive reactance is shown along the $-90^{\circ}$ axis. Net reactance in an AC circuit is the difference between inductive and capacitive reactance. Equation (8-7) is the mathematical representation for the calculation of net reactance when $X_{L}$ is greater than $X_{C}$.

$$
\mathrm{X}=\mathrm{X}_{\mathrm{L}}-\mathrm{X}_{\mathrm{C}}
$$

where

$$
\begin{aligned}
& X=\text { net reactance }(\Omega) \\
& X_{L}=\text { inductive reactance }(\Omega) \\
& X_{C}=\text { capacitive reactance }(\Omega)
\end{aligned}
$$


Equation (8-8) is the mathematical representation for the calculation of net reactance when $\mathrm{X}_{C}$ is greater than $X_{L}$.

$$
\mathrm{X}=\mathrm{X}_{\mathrm{C}}-\mathrm{X}_{\mathrm{L}}
$$

Impedance is the vector sum of the resistance and net reactance (X) in a circuit, as shown in Figure 5. The angle $\theta$ is the phase angle and gives the phase relationship between the applied voltage and the current. Impedance in an $\mathrm{AC}$ circuit corresponds to the resistance of a DC circuit. The voltage drop across an AC circuit element equals the current times the impedance. Equation (8-9) is the mathematical representation of the voltage drop across an AC circuit.

$$
\mathrm{V}=\mathrm{IZ}
$$

where

$$
\begin{aligned}
& \mathrm{V}=\text { voltage drop }(\mathrm{V}) \\
& \mathrm{I}=\text { current }(\mathrm{A}) \\
& \mathrm{Z}=\text { impedance }(\Omega)
\end{aligned}
$$

The phase angle $\theta$ gives the phase relationship between current and the voltage.

\section{Impedance in R-L Circuits}

Impedance is the resultant of phasor addition of $R$ and $X_{L}$. The symbol for impedance is $Z$. Impedance is the total opposition to the flow of current and is expressed in ohms. Equation (8-10) is the mathematical representation of the impedance in an RL circuit.

$$
Z=\sqrt{R^{2}+X_{L}^{2}}
$$

Example: $\quad$ If a $100 \Omega$ resistor and a $60 \Omega \mathrm{X}_{\mathrm{L}}$ are in series with a $115 \mathrm{~V}$ applied voltage (Figure 6), what is the circuit impedance? 


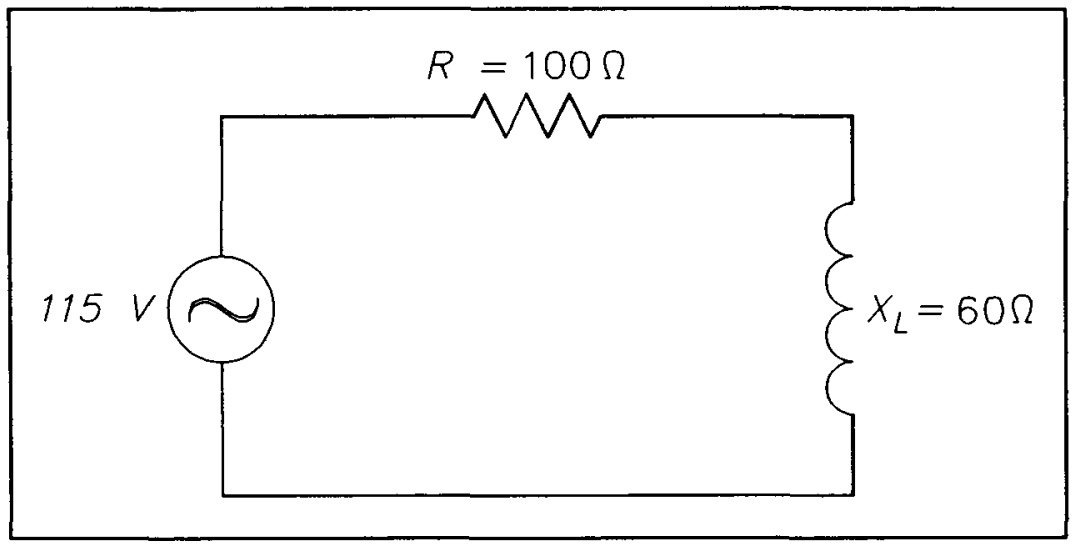

Figure 6 Simple R-L Circuit

Solution:

$$
\begin{aligned}
Z & =\sqrt{R^{2}+X_{L}^{2}} \\
& =\sqrt{100^{2}+60^{2}} \\
& =\sqrt{10,000+3600} \\
& =\sqrt{13,600} \\
Z & =116.6 \Omega
\end{aligned}
$$

\section{Impedance in R-C Circuits}

In a capacitive circuit, as in an inductive circuit, impedance is the resultant of phasor addition of $R$ and $X_{C}$. Equation (8-11) is the mathematical representation for impedance in an $R-C$ circuit.

$$
Z=\sqrt{R^{2}+X_{C}^{2}}
$$

Example: $\quad$ A $50 \Omega \mathrm{X}_{\mathrm{C}}$ and a $60 \Omega$ resistance are in series across a $110 \mathrm{~V}$ source (Figure 7). Calculate the impedance. 


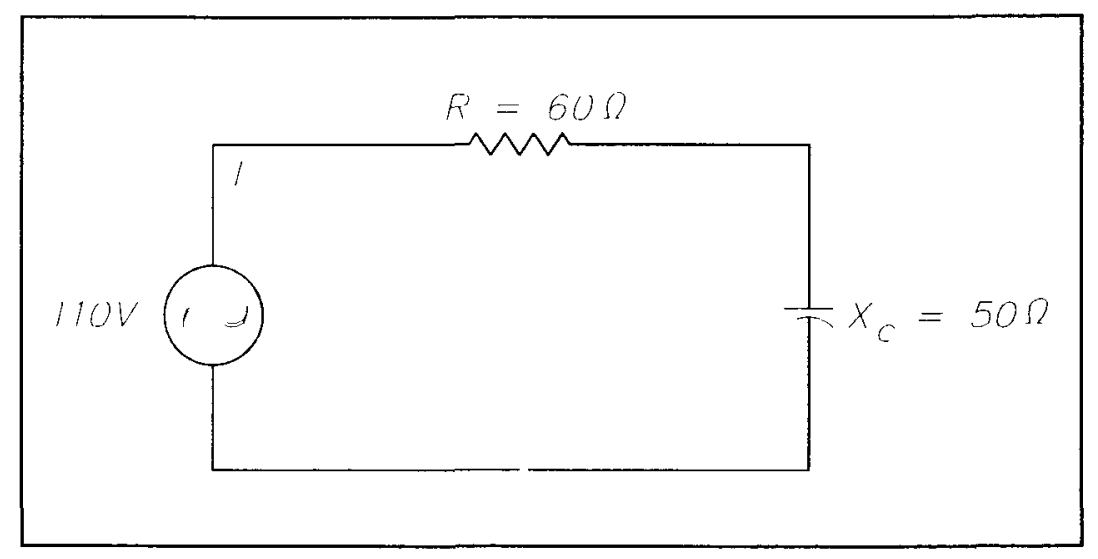

Figure 7 Simple R-C Circuit

Solution:

$$
\begin{aligned}
Z & =\sqrt{R^{2}+X_{C}^{2}} \\
& =\sqrt{60^{2}+50^{2}} \\
& =\sqrt{3600+2500} \\
& =\sqrt{6100} \\
Z & =78.1 \Omega
\end{aligned}
$$

\section{Impedance in R-C-L Circuits}

Impedance in an R-C-L series circuit is equal to the phasor sum of resistance, inductive reactance, and capacitive reactance (Figure 8). 


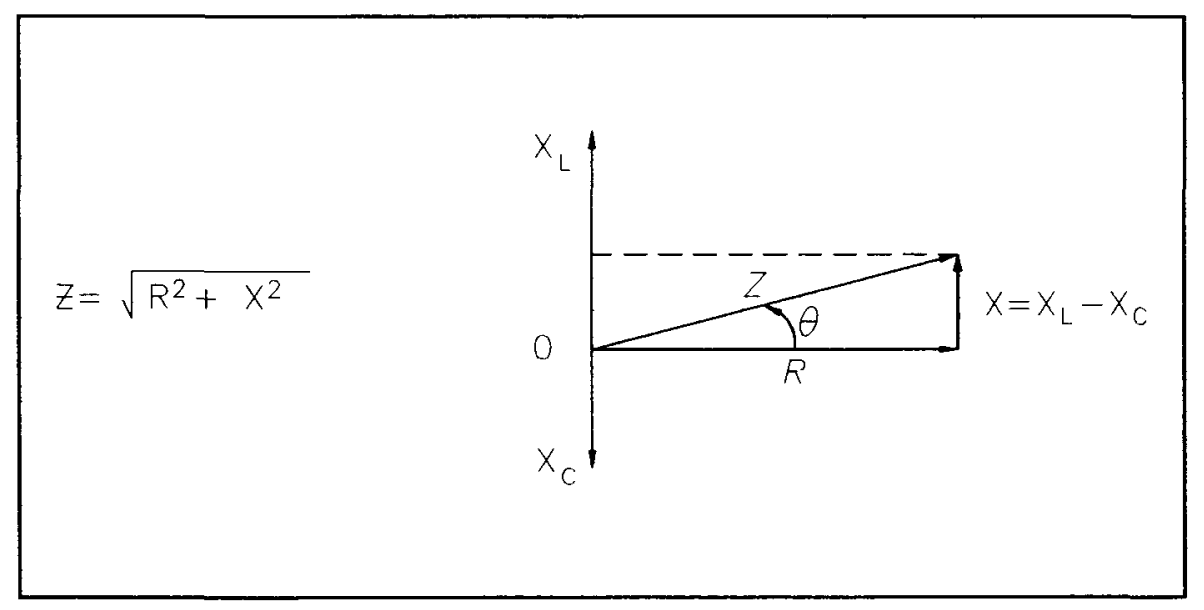

Figure 8 Series R-C-L Impedance-Phasor

Equations (8-12) and (8-13) are the mathematical representations of impedance in an R-C-L circuit. Because the difference between $X_{L}$ and $X_{C}$ is squared, the order in which the quantities are subtracted does not affect the answer.

$$
\begin{aligned}
& Z=\sqrt{R^{2}+\left(X_{L}-X_{C}\right)^{2}} \\
& Z=\sqrt{R^{2}+\left(X_{C}-X_{L}\right)^{2}}
\end{aligned}
$$

Example: Find the impedance of a series R-C-L circuit, when $R=6 \Omega, X_{L}=20 \Omega$, and $\mathrm{X}_{\mathrm{C}}=10 \Omega$ (Figure 9). 


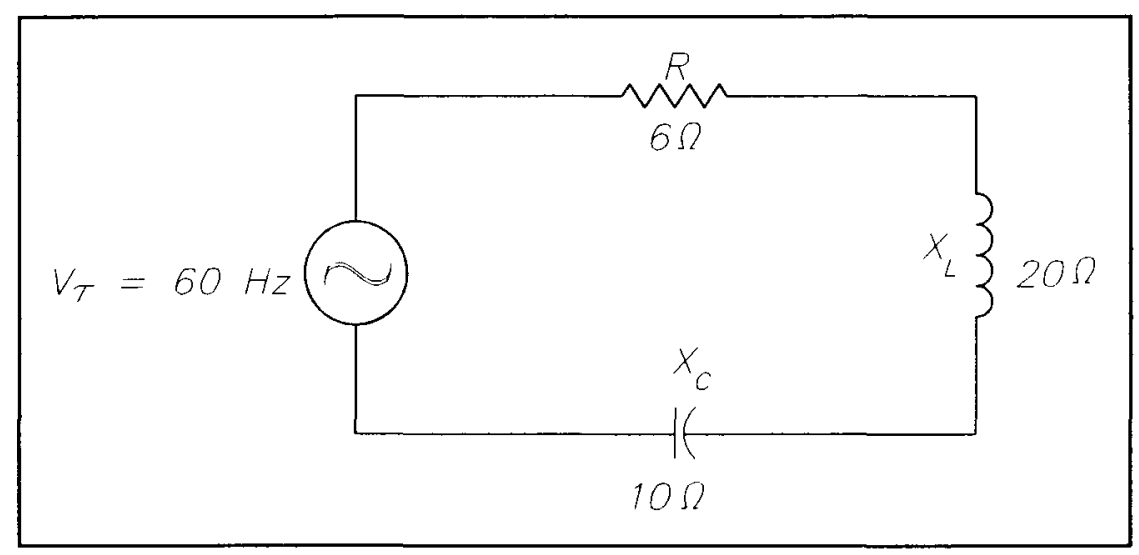

Figure 9 Simple R-C-L Circuit

Solution:

$$
\begin{aligned}
Z & =\sqrt{R^{2}+\left(X_{L}-X_{C}\right)^{2}} \\
& =\sqrt{6^{2}+(20-10)^{2}} \\
& =\sqrt{6^{2}+10^{2}} \\
& =\sqrt{36+100} \\
& =\sqrt{136} \\
Z & =11.66 \Omega
\end{aligned}
$$

Impedance in a parallel R-C-L circuit equals the voltage divided by the total current. Equation (8-14) is the mathematical representation of the impedance in a parallel $\mathrm{R}-\mathrm{C}-\mathrm{L}$ circuit.

$$
\mathrm{Z}_{\mathrm{T}}=\frac{\mathrm{V}_{\mathrm{T}}}{\mathrm{I}_{\mathrm{T}}}
$$


where

$$
\begin{aligned}
& \mathrm{Z}_{\mathrm{T}}=\text { total impedance }(\Omega) \\
& \mathrm{V}_{\mathrm{T}}=\text { total voltage }(\mathrm{V}) \\
& \mathrm{I}_{\mathrm{T}}=\text { total current }(\mathrm{A})
\end{aligned}
$$

Total current in a parallel R-C-L circuit is equal to the square root of the sum of the squares of the current flows through the resistance, inductive reactance, and capacitive reactance branches of the circuit. Equations (8-15) and (8-16) are the mathematical representations of total current in a parallel R-C-L circuit. Because the difference between $I_{L}$ and $I_{C}$ is squared, the order in which the quantities are subtracted does not affect the answer.

$$
\begin{aligned}
& I_{T}=\sqrt{I_{R}^{2}+\left(I_{C}-I_{L}\right)^{2}} \\
& I_{T}=\sqrt{I_{R}^{2}+\left(I_{L}-I_{C}\right)^{2}}
\end{aligned}
$$

where

$$
\begin{array}{ll}
I_{\mathrm{T}}= & \text { total current }(\mathrm{A}) \\
\mathrm{I}_{\mathrm{R}}= & \text { current through resistance leg of circuit (A) } \\
\mathrm{I}_{\mathrm{C}}= & \text { current through capacitive reactance leg of circuit (A) } \\
\mathrm{I}_{\mathrm{L}}= & \text { current through inductive reactance leg of circuit (A) }
\end{array}
$$

Example: $\quad$ A $200 \Omega$ resistor, a $100 \Omega \mathrm{X}_{\mathrm{L}}$, and an $80 \Omega \mathrm{X}_{\mathrm{C}}$ are placed in parallel across a $120 \mathrm{~V}$ AC source (Figure 10). Find: (1) the branch currents, (2) the total current, and (3) the impedance.

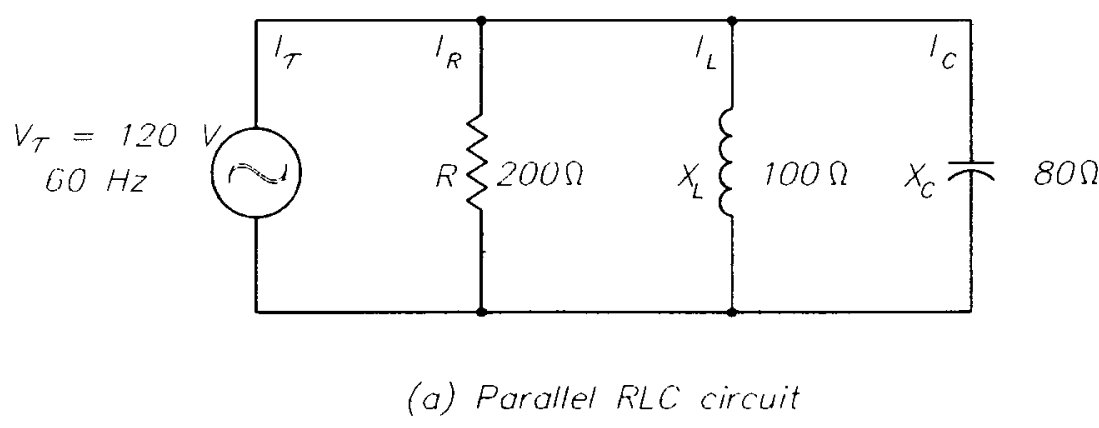

Figure 10 Simple Parallel R-C-L Circuit 
Solution:

1. Branch currents

$$
\begin{aligned}
& I_{R}=\frac{V_{T}}{R} \quad I_{L}=\frac{V_{T}}{X_{L}} \quad I_{C}=\frac{V_{T}}{X_{C}} \\
& =\frac{120}{200}=\frac{120}{100}=\frac{120}{80} \\
& I_{R}=0.6 \mathrm{~A} \quad I_{L}=1.2 \mathrm{~A} \quad I_{C}=1.5 \mathrm{~A}
\end{aligned}
$$

2. Total current

$$
\begin{aligned}
I_{T} & =\sqrt{I_{R}^{2}+\left(I_{C}-I_{L}\right)^{2}} \\
& =\sqrt{(0.6)^{2}+(1.5-1.2)^{2}} \\
& =\sqrt{(0.6)^{2}+(0.3)^{2}} \\
& =\sqrt{0.36+0.09} \\
& =\sqrt{0.45} \\
I_{T} & =0.671 \mathrm{~A}
\end{aligned}
$$

3. Impedance

$$
\begin{aligned}
Z & =\frac{V_{T}}{I_{T}} \\
& =\frac{120}{0.671} \\
Z & =178.8 \Omega
\end{aligned}
$$




\section{Summary}

Impedance is summarized below.

\section{Impedance Summary}

- Impedance (Z) is the total opposition to current flow in an $\mathrm{AC}$ circuit.

- The formula for impedance in a series AC circuit is:

$$
Z=\sqrt{R^{2}+X^{2}}
$$

- The formula for impedance in a parallel R-C-L circuit is:

$$
Z=\sqrt{R^{2}+\left(X_{C}-X_{L}\right)^{2}}
$$

- The formulas for finding total current $\left(\mathrm{I}_{\mathrm{T}}\right)$ in a parallel R-C-L circuit are:

$$
\begin{aligned}
& \text { where } I_{C}>I_{L}, I_{T}=\sqrt{I_{R}^{2}+\left(I_{C}-I_{L}\right)^{2}} \\
& \text { where } I_{L}>I_{C}, I_{T}=\sqrt{I_{R}^{2}+\left(I_{L}-I_{C}\right)^{2}}
\end{aligned}
$$




\section{RESONANCE}

In the chapters on inductance and capacitance we have learned that both conditions are reactive and can provide opposition to current flow, but for opposite reasons. Therefore, it is important to find the point where inductance and capacitance cancel one another to achieve efficient operation of AC circuits.

EO 1.15 DEFINE resonance.

EO 1.16 Given the values of capacitance (C) and inductance (L), CALCULATE the resonant frequency.

EO 1.17 Given a series $R-C-L$ circuit at resonance, DESCRIBE the net reactance of the circuit.

EO 1.18 Given a parallel R-C-L circuit at resonance, DESCRIBE the circuit output relative to current (I).

\section{Resonant Frequency}

Resonance occurs in an AC circuit when inductive reactance and capacitive reactance are equal to one another: $X_{L}=X_{C}$ When this occurs, the total reactance, $X=X_{L}-X_{C}$ becomes zero and the impendence is totally resistive. Because inductive reactance and capacitive reactance are both dependent on frequency, it is possible to bring a circuit to resonance by adjusting the frequency of the applied voltage. Resonant frequency $\left(f_{\text {Res }}\right)$ is the frequency at which resonance occurs, or where $X_{L}=X_{C}$. Equation (8-14) is the mathematical representation for resonant frequency.

$$
f_{\text {Res }}=\frac{1}{2 \pi \sqrt{L C}}
$$

where

$$
\begin{array}{ll}
\mathbf{f}_{\mathrm{Res}} & =\text { resonant frequency }(\mathrm{Hz}) \\
\mathrm{L} & =\text { inductance }(\mathrm{H}) \\
\mathrm{C} & =\text { capacitance }(\mathrm{f})
\end{array}
$$

\section{Series Resonance}

In a series R-C-L circuit, as in Figure 9, at resonance the net reactance of the circuit is zero, and the impedance is equal to the circuit resistance; therefore, the current output of a series resonant circuit is at a maximum value for that circuit and is determined by the value of the resistance. $(Z=R)$

$$
I=\frac{V_{T}}{Z_{T}}=\frac{V_{T}}{R}
$$




\section{Parallel Resonance}

Resonance in a parallel $\mathrm{R}-\mathrm{C}$ - $\mathrm{L}$ circuit will occur when the reactive current in the inductive branches is equal to the reactive current in the capacitive branches (or when $X_{L}=X_{C}$ ). Because inductive and capacitive reactance currents are equal and opposite in phase, they cancel one another at parallel resonance.

If a capacitor and an inductor, each with negligible resistance, are connected in parallel and the frequency is adjusted such that reactances are exactly equal, current will flow in the inductor and the capacitor, but the total current will be negligible. The parallel $\mathrm{C}$-L circuit will present an almost infinite impedance. The capacitor will alternately charge and discharge through the inductor. Thus, in a parallel R-C-L, as in Figure 10, the net current flow through the circuit is at minimum because of the high impendence presented by $\mathrm{X}_{\mathrm{L}}$ and $\mathrm{X}_{\mathrm{C}}$ in parallel.

\section{Summary}

Resonance is summarized below.

\section{Resonance Summary}

- $\quad$ Resonance is a state in which the inductive reactance equals the capacitive reactance $\left(X_{L}=X_{C}\right)$ at a specified frequency $\left(f_{R e s}\right)$.

- $\quad$ Resonant frequency is:

$$
\mathrm{f}_{\text {Res }}=\frac{1}{2 \pi \sqrt{\mathrm{LC}}}
$$

- $\quad$ R-C-L series circuit at resonance is when net reactance is zero and circuit current output is determined by the series resistance of the circuit.

- $\quad$ R-C-L parallel circuit at resonance is when net reactance is maximum and circuit current output is at minimum. 


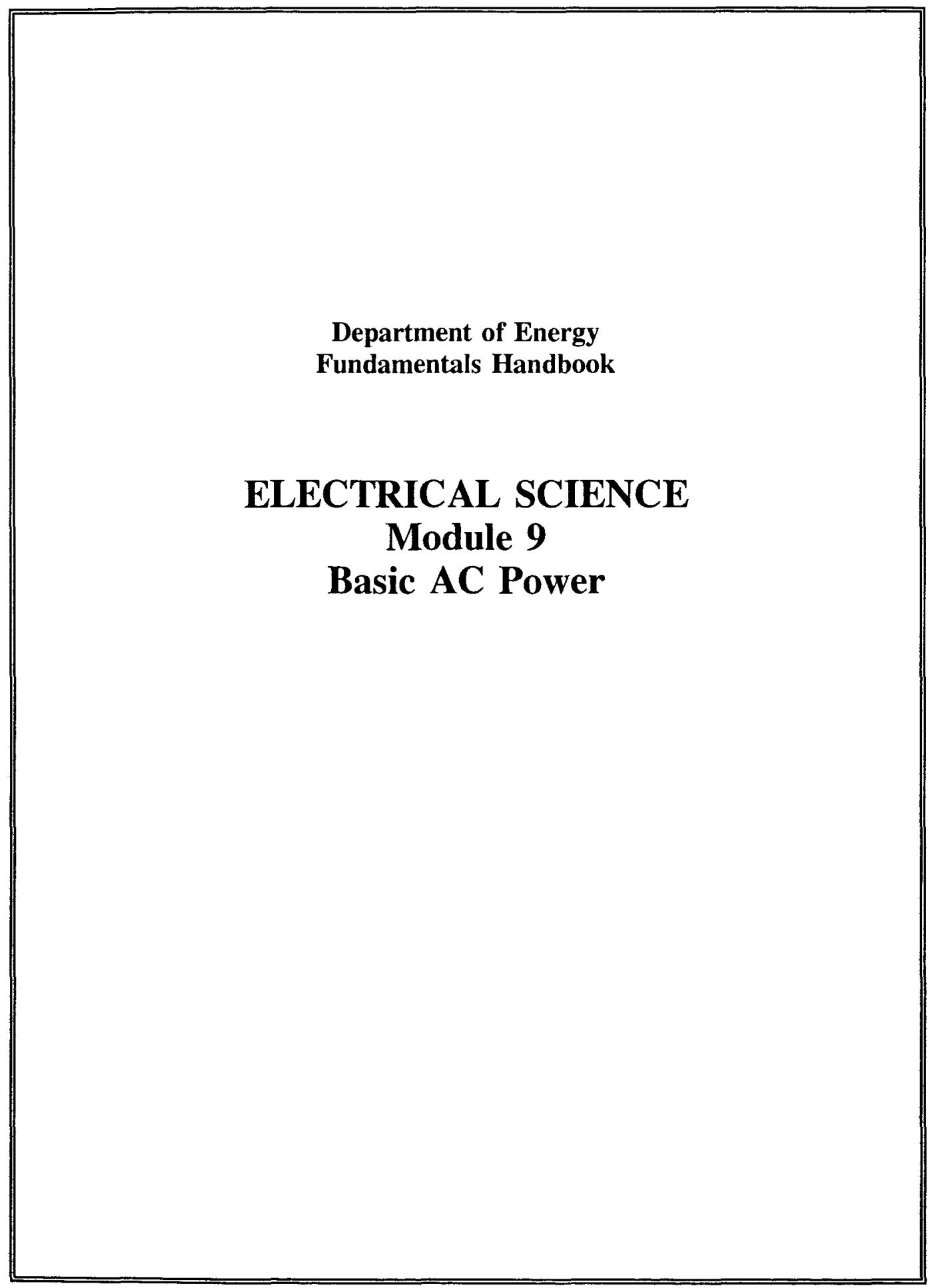




\section{TABLE OF CONTENTS}

LIST OF FIGURES $\ldots \ldots \ldots \ldots \ldots \ldots \ldots \ldots \ldots \ldots \ldots \ldots$

LIST OF TABLES $\ldots \ldots \ldots \ldots \ldots \ldots \ldots \ldots \ldots \ldots \ldots \ldots$

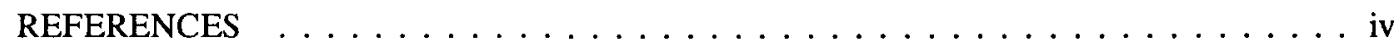

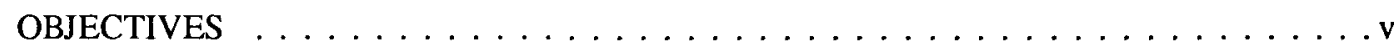

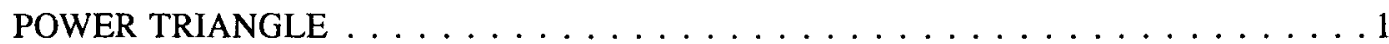

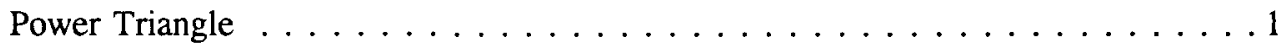

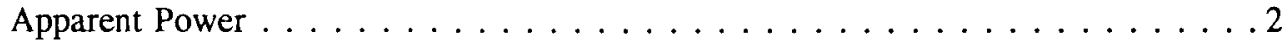

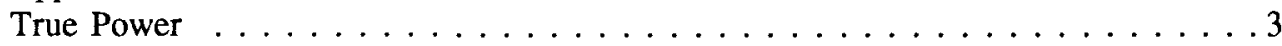

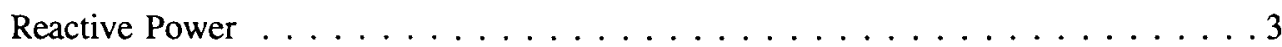

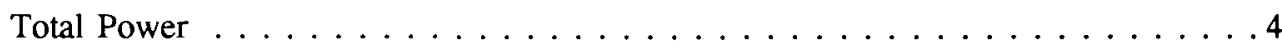

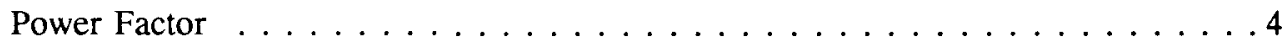

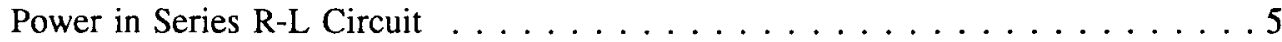

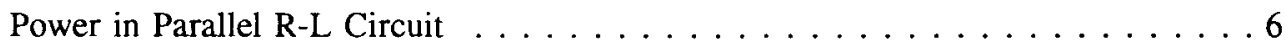

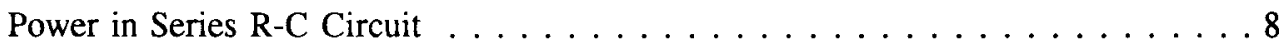

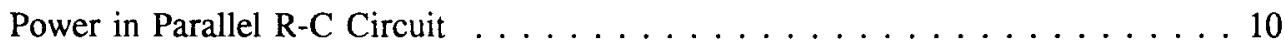

Power in Series R-C-L Circuit . . . . . . . . . . . . . . . . . . . 12

Power in Parallel R-C-L Circuit . . . . . . . . . . . . . . . . . 14

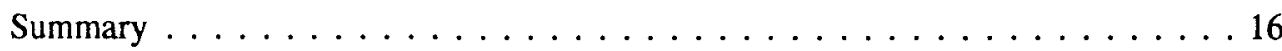

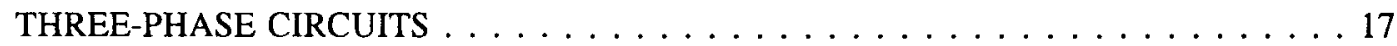

Three-Phase Systems . . . . . . . . . . . . . . . . . . . 17

Power in Balanced $3 \phi$ Loads . . . . . . . . . . . . . . . . . . . 19

Unbalanced $3 \phi$ Loads . . . . . . . . . . . . . . . . . 23

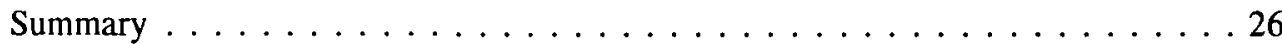




\section{LIST OF FIGURES}

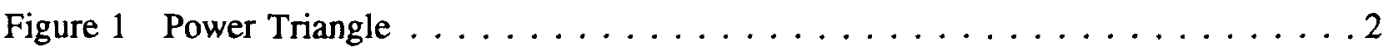

Figure 2 Lagging Power Factor $\ldots \ldots \ldots \ldots \ldots \ldots \ldots \ldots \ldots \ldots \ldots \ldots \ldots \ldots \ldots \ldots \ldots$

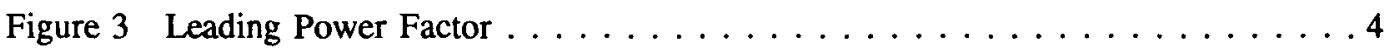

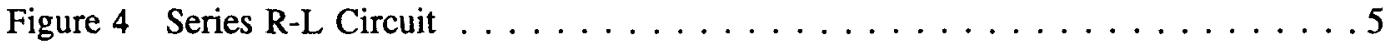

Figure 5 Parallel R-L Circuit $\ldots \ldots \ldots \ldots \ldots \ldots \ldots \ldots \ldots \ldots \ldots \ldots \ldots \ldots \ldots$

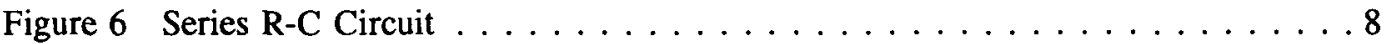

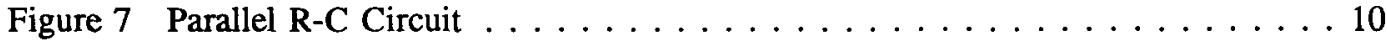

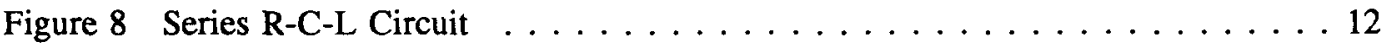

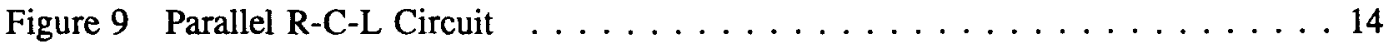

Figure 10 Three-Phase $\mathrm{AC} \ldots \ldots \ldots \ldots \ldots \ldots$

Figure $113 \phi$ AC Power Connections $\ldots \ldots \ldots \ldots$

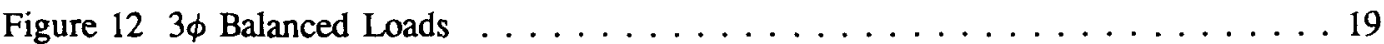

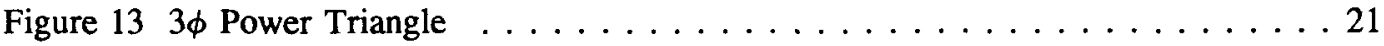

Figure 14 Three-Phase Delta Generator $\ldots \ldots \ldots \ldots \ldots \ldots \ldots \ldots$

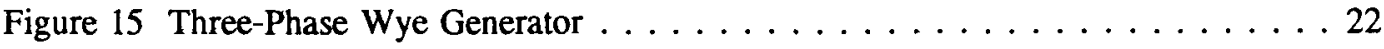

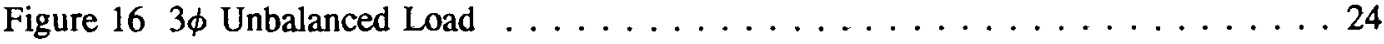




\section{LIST OF TABLES}

NONE 


\section{REFERENCES}

- Gussow, Milton, Schaum's Outline Series, Basic Electricity, McGraw-Hill.

- $\quad$ Academic Program for Nuclear Power Plant Personnel, Volume IV, Columbia, MD: General Physics Corporation, Library of Congress Card \#A 326517, 1982.

- $\quad$ Academic Program for Nuclear Power Plant Personnel, Volume II, Columbia, MD: General Physics Corporation, Library of Congress Card \#A 326517, 1982.

- Nasar and Unnewehr, Electromechanics and Electric Machines, John Wiley and Sons.

- Van Valkenburgh, Nooger, and Neville, Basic Electricity, Vol. 5, Hayden Book Company.

- Lister, Eugene C., Electric Circuits and Machines, $5^{\text {th }}$ Edition, McGraw-Hill.

- Croft, Carr, Watt, and Summers, American Electricians Handbook, $10^{\text {th }}$ Edition, McGraw-Hill.

- Mason, C. Russel, The Art and Science of Protective Relaying, John Wiley and Sons.

- Mileaf, Harry, Electricity One - Seven, Revised $2^{\text {nd }}$ Edition, Hayden Book Company.

- Buban and Schmitt, Understanding Electricity and Electronics, $3^{\text {rd }}$ Edition, McGrawHill.

- Kidwell, Walter, Electrical Instruments and Measurements, McGraw-Hill. 


\section{TERMINAL OBJECTIVE}

1.0 Given an AC single-phase or three-phase circuit, DESCRIBE the power characteristics in the circuit.

\section{ENABLING OBJECTIVES}

1.1 DESCRIBE the relationship between apparent, true, and reactive power by definition or by using a power triangle.

1.2 DEFINE power factor as it relates to true power and apparent power.

1.3 Given the necessary values for voltage $(E)$, resistance $(R)$, reactance $(X)$, impedance (Z), and/or current (I), CALCULATE the following power components for an AC circuit:
a. True power (P)
b. Apparent power (S)
c. Reactive power (Q)
d. Power factor (pf)

1.4 DEFINE the following terms:
a. Leading power factor
b. Lagging power factor

1.5 STATE the reasons that three-phase power systems are used in the industry.

1.6 Given values for current, voltage, and power factor in a three-phase system, CALCULATE the following:
a. Real power
b. Reactive power
c. Apparent power

1.7 Given a diagram of a wye- or delta-connected three-phase system, DESCRIBE the voltage/current relationships of the circuit.

1.8 STATE the indications of an unbalanced load in a three-phase power system. 
Intentionally Left Blank 
While direct current has one form of power, alternating current has three different forms of power that are related in a unique relationship. In this chapter, you will learn that power in AC circuits cannot be calculated in the same manner as in DC circuits.

EO 1.1 DESCRIBE the relationship between apparent, true, and reactive power by definition or by using a power triangle.

EO 1.2 DEFINE power factor as it relates to true power and apparent power.

EO 1.3 Given the necessary values for voltage (E), resistance $(R)$, reactance $(X)$, impedance $(Z)$, and/or current (I), CALCULATE the following power components for an AC circuit:
a. True power $(\mathrm{P})$
b. Apparent power (S)
c. Reactive power $(Q)$
d. Power factor (pf)

EO 1.4 DEFINE the following terms:

a. Leading power factor

b. Lagging power factor

\section{Power Triangle}

In AC circuits, current and voltage are normally out of phase and, as a result, not all the power produced by the generator can be used to accomplish work. By the same token, power cannot be calculated in $\mathrm{AC}$ circuits in the same manner as in DC circuits. The power triangle, shown in Figure 1, equates $A C$ power to $D C$ power by showing the relationship between generator output (apparent power - S) in volt-amperes (VA), usable power (true power - P) in watts, and wasted or stored power (reactive power - Q) in volt-amperes-reactive (VAR). The phase angle $(\theta)$ represents the inefficiency of the $\mathrm{AC}$ circuit and corresponds to the total reactive impedance (Z) to the current flow in the circuit. 


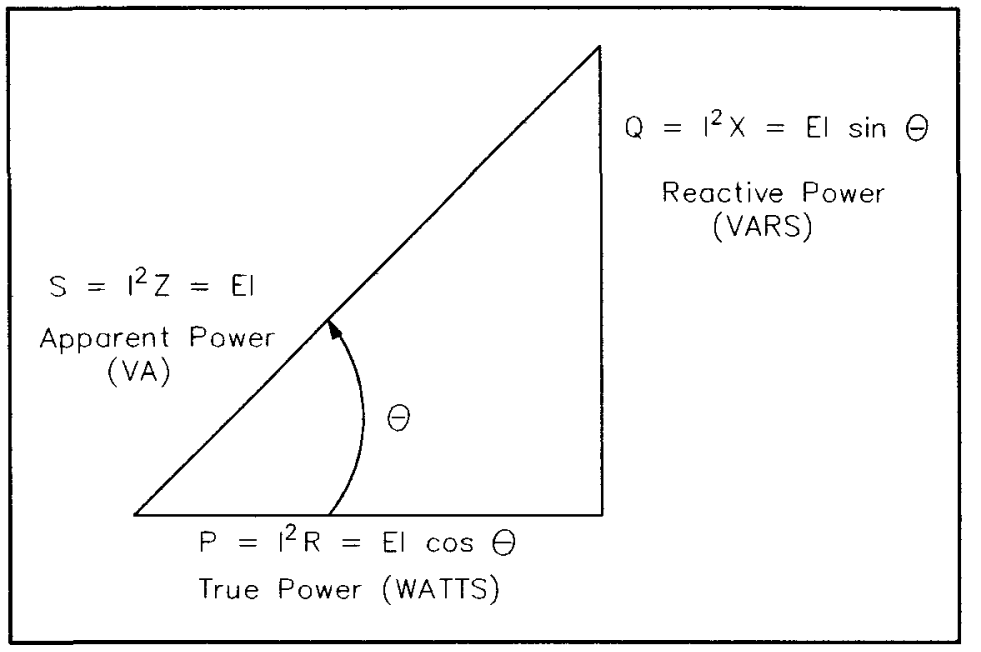

Figure 1 Power Triangle

The power triangle represents comparable values that can be used directly to find the efficiency level of generated power to usable power, which is expressed as the power factor (discussed later). Apparent power, reactive power, and true power can be calculated by using the DC equivalent (RMS value) of the $\mathrm{AC}$ voltage and current components along with the power factor.

\section{Apparent Power}

Apparent power (S) is the power delivered to an electrical circuit. Equation (9-1) is a mathematical representation of apparent power. The measurement of apparent power is in voltamperes (VA).

$$
S=I^{2} Z=I_{T} E
$$

where

$$
\begin{aligned}
& \mathbf{S}=\text { apparent power (VA) } \\
& \mathbf{I}=\text { RMS current }(\mathrm{A}) \\
& \mathbf{E}=\text { RMS voltage }(\mathrm{V}) \\
& \mathrm{Z}=\text { impedance }(\boldsymbol{\Omega})
\end{aligned}
$$




\section{True Power}

True power $(\mathrm{P})$ is the power consumed by the resistive loads in an electrical circuit. Equation (9-2) is a mathematical representation of true power. The measurement of true power is in watts.

$$
P=I^{2} R=E I \cos \theta
$$

where

$$
\begin{aligned}
& \mathrm{P}=\text { true power (watts) } \\
& \mathrm{I}=\text { RMS current }(\mathrm{A}) \\
& \mathrm{E}=\text { RMS voltage }(\mathrm{V}) \\
& \mathrm{R}=\text { resistance }(\Omega) \\
& \theta=\text { angle between } \mathrm{E} \text { and } \mathrm{I} \text { sine waves }
\end{aligned}
$$

\section{Reactive Power}

Reactive power $(\mathrm{Q})$ is the power consumed in an $\mathrm{AC}$ circuit because of the expansion and collapse of magnetic (inductive) and electrostatic (capacitive) fields. Reactive power is expressed in volt-amperes-reactive (VAR). Equation (9-3) is a mathematical representation for reactive power.

$$
\mathrm{Q}=\mathrm{I}^{2} \mathrm{X}=\mathrm{EI} \sin \theta
$$

where

$$
\begin{aligned}
& \mathrm{Q}=\text { reactive power (VAR) } \\
& \mathrm{I}=\mathrm{RMS} \text { current }(\mathrm{A}) \\
& \mathrm{X}=\text { net reactance }(\Omega) \\
& \mathrm{E}=\mathrm{RMS} \text { voltage }(\mathrm{V}) \\
& \theta=\text { angle between the } \mathrm{E} \text { and } \mathrm{I} \text { sine waves }
\end{aligned}
$$

Unlike true power, reactive power is not useful power because it is stored in the circuit itself. This power is stored by inductors, because they expand and collapse their magnetic fields in an attempt to keep current constant, and by capacitors, because they charge and discharge in an attempt to keep voltage constant. Circuit inductance and capacitance consume and give back reactive power. Reactive power is a function of a system's amperage. The power delivered to the inductance is stored in the magnetic field when the field is expanding and returned to the source when the field collapses. The power delivered to the capacitance is stored in the electrostatic field when the capacitor is charging and returned to the source when the capacitor discharges. None of the power delivered to the circuit by the source is consumed. It is all returned to the source. The true power, which is the power consumed, is thus zero. We know that alternating current constantly changes; thus, the cycle of expansion and collapse of the magnetic and electrostatic fields constantly occurs. 


\section{Total Power}

The total power delivered by the source is the apparent power. Part of this apparent power, called true power, is dissipated by the circuit resistance in the form of heat. The rest of the apparent power is returned to the source by the circuit inductance and capacitance.

\section{Power Factor}

Power factor (pf) is the ratio between true power and apparent power. True power is the power consumed by an $\mathrm{AC}$ circuit, and reactive power is the power that is stored in an $\mathrm{AC}$ circuit. $\cos \theta$ is called the power factor (pf) of an AC circuit. It is the ratio of true power to apparent power, where $\theta$ is the phase angle between the applied voltage and current sine waves and also between $\mathrm{P}$ and $\mathrm{S}$ on a power triangle (Figure1). Equation (9-4) is a mathematical representation of power factor.

$$
\cos \theta=\frac{\mathrm{P}}{\mathrm{S}}
$$

where

$$
\begin{array}{lll}
\cos \theta & = & \text { power factor }(\mathrm{pf}) \\
\mathrm{P} & = & \text { true power (watts) } \\
\mathrm{S} & = & \text { apparent power (VA) }
\end{array}
$$

Power factor also determines what part of the apparent power is real power. It can vary from 1 , when the phase angle is $0^{\circ}$, to 0 , when the phase angle is $90^{\circ}$. In an inductive circuit, the current lags the voltage and is said to have a lagging power factor, as shown in Figure 2.

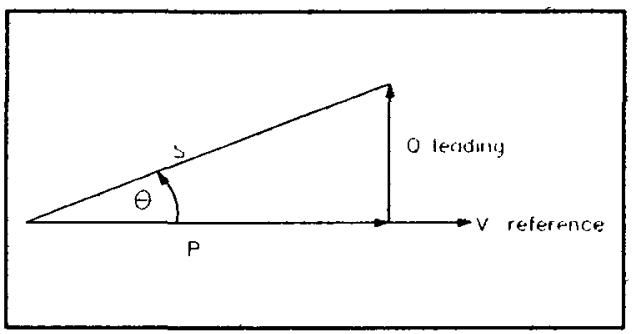

Figure 3 Leading Power Factor

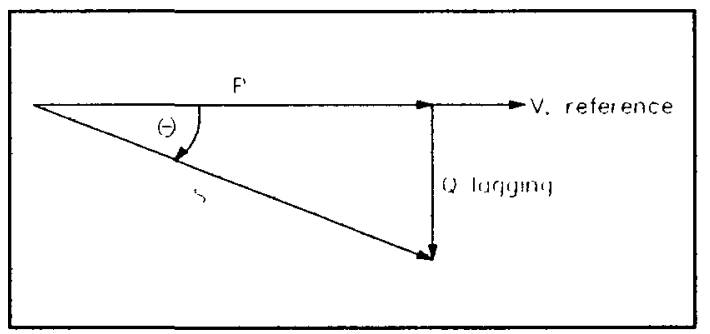

Figure 2 Lagging Power Factor

In a capacitive circuit, the current leads the voltage and is said to have a leading power factor, as shown in Figure 3.

A mnemonic memory device, "ELI the ICE man," can be used to remember the voltage/current relationship in AC circuits. ELI refers to an inductive circuit (L) where current (l) lags voltage (E). ICE refers to a capacitive circuit (C) where current (I) leads voltage (E). 


\section{Power in Series R-L Circuit}

Example: A $200 \Omega$ resistor and a $50 \Omega \mathrm{X}_{\mathrm{L}}$ are placed in series with a voltage source, and the total current flow is 2 amps, as shown in Figure 4.

Find: 1. pf

2. applied voltage, $\mathrm{V}$

3. $\mathrm{P}$

4. Q

5. S

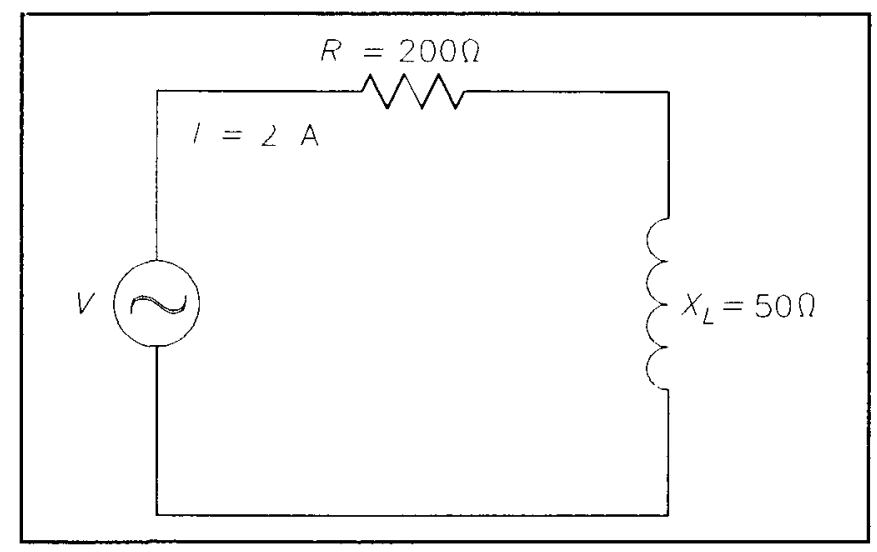

Solution:

$$
\begin{aligned}
& \text { 1. } \mathrm{pf}=\cos \theta \quad \theta=\arctan \left(\frac{\mathrm{X}_{\mathrm{L}}}{\mathrm{R}}\right) \\
& =\cos \left(\arctan \left(\frac{X_{L}}{R}\right)\right) \\
& =\cos \left(\arctan \left(\frac{50}{200}\right)\right] \\
& =\cos \left(14^{\circ}\right) \\
& \mathrm{pf}=0.097 \\
& \text { 2. } \mathrm{V}=\mathrm{IZ} \quad \mathrm{Z}=\sqrt{\mathrm{R}^{2}+\mathrm{X}_{\mathrm{L}}^{2}} \\
& =I \sqrt{R^{2}+X_{L}^{2}} \\
& =2 \sqrt{200^{2}+50^{2}} \\
& =2 \sqrt{42,500} \\
& =(2)(206.16) \\
& \mathrm{V}=412.3 \text { volts }
\end{aligned}
$$

Figure 4 Series R-L Circuit 
3. $\mathrm{P}=\mathrm{EI} \cos \theta$

$$
=(412.3)(2)(0.97)
$$

$P=799.86$ watts

4. $\mathrm{Q}=\mathrm{EI} \sin \theta$

$$
=(412.3)(2)(0.242)
$$

$\mathrm{Q}=199.6 \mathrm{VAR}$

5. $\mathrm{S}=\mathrm{EI}$

$$
\begin{aligned}
& =(412.3)(2) \\
S & =824.6 \mathrm{VA}
\end{aligned}
$$

\section{Power in Parallel R-L Circuit}

Example: A $600 \Omega$ resistor and $200 \Omega \mathrm{X}_{\mathrm{L}}$ are in parallel with a $440 \mathrm{~V}$ source, as shown in Figure 5.

Find: $1 . I_{T}$

2. $\mathrm{pf}$

3. $\mathrm{P}$

4. $\mathrm{Q}$

5. S

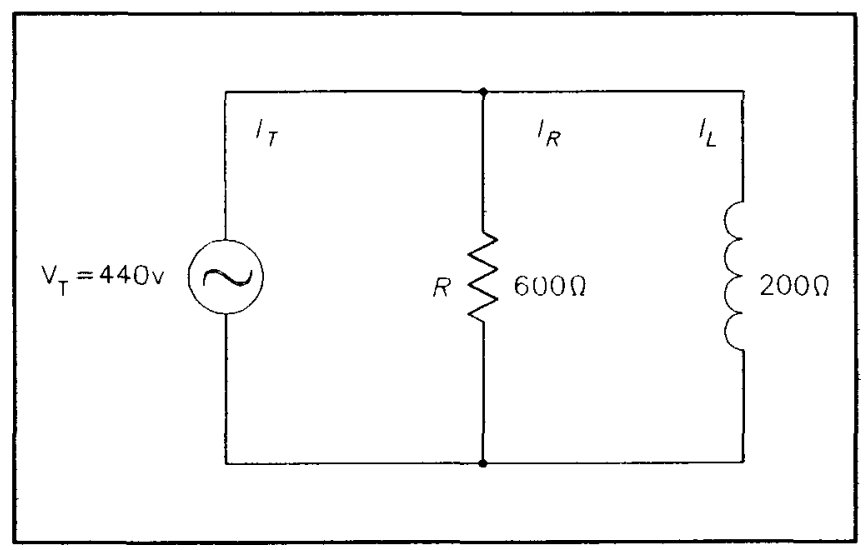

Figure 5 Parallel R-L Circuit 
Solution:

1. $\mathrm{I}_{\mathrm{T}}=\sqrt{\mathrm{I}_{\mathrm{R}}^{2}+\mathrm{I}_{\mathrm{L}}^{2}} \quad \mathrm{I}_{\mathrm{R}}=\frac{\mathrm{V}_{\mathrm{T}}}{\mathrm{R}} \quad \mathrm{I}_{\mathrm{L}}=\frac{\mathrm{V}_{\mathrm{T}}}{\mathrm{X}_{\mathrm{L}}}$

$$
\begin{aligned}
& =\sqrt{\left(\frac{V_{T}}{R}\right)^{2}+\left(\frac{V_{T}}{X_{L}}\right)^{2}} \\
& =\sqrt{\left(\frac{440}{600}\right)^{2}+\left(\frac{440}{200}\right)^{2}} \\
& =\sqrt{(0.73)^{2}+(2.2)^{2}} \\
& I_{T}=2.3 \mathrm{amps}
\end{aligned}
$$

2. $\mathrm{pf}=\cos \theta \quad \theta=\arctan \left(-\frac{\mathrm{I}_{\mathrm{L}}}{\mathrm{I}_{\mathrm{R}}}\right)$

$$
\begin{aligned}
& =\cos \left(\arctan \left(-\frac{I_{L}}{I_{R}}\right)\right) \\
& =\cos \left(\arctan \left(-\frac{2.2}{0.73}\right)\right) \\
& =\cos (\arctan (-3)) \\
& =\cos \left(-71.5^{\circ}\right)
\end{aligned}
$$$$
\text { pf }=0.32
$$

3. $\mathrm{P}=\mathrm{EI} \cos \theta$

$=(440)(2.3)(0.32)$

$P=323.84$ watts

4. $\mathrm{Q}=\mathrm{EI} \sin \theta$

$$
=(440)(2.3)(0.948)
$$

$\mathrm{Q}=959.4 \mathrm{VAR}$ 
5. $S=E I$

$$
\begin{aligned}
& =(440)(2.3) \\
S & =1012 \mathrm{VA}
\end{aligned}
$$

\section{Power in Series R-C Circuit}

Example: An $80 \Omega \mathrm{X}_{\mathrm{c}}$ and a $60 \Omega$ resistance are in series with a $120 \mathrm{~V}$ source, as shown in Figure 6.

Find: $1 . \mathrm{Z}$

2. $\mathrm{I}_{\mathrm{T}}$

3. $\mathrm{pf}$

4. $P$

5. Q

6. $S$

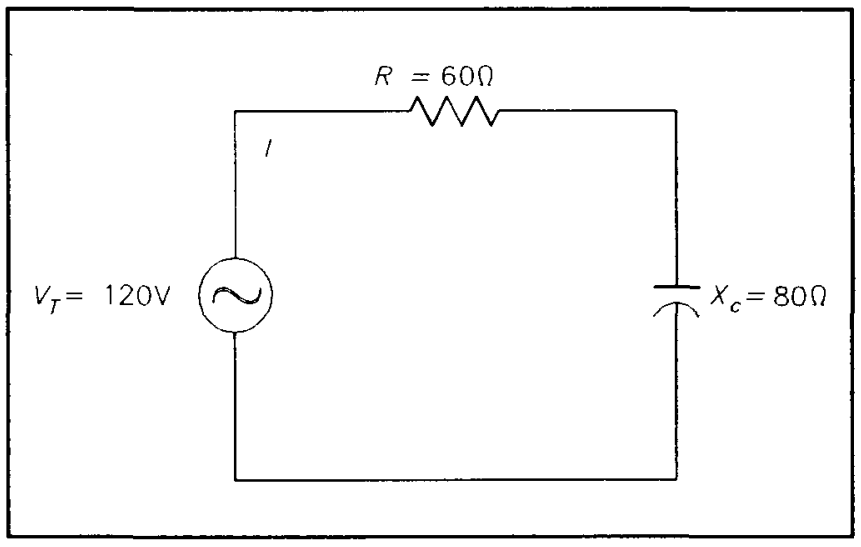

Solution:

Figure 6 Series R-C Circuit

1. $\mathrm{Z}=\sqrt{\mathrm{R}^{2}+\mathrm{X}_{\mathrm{C}}^{2}}$

$$
\begin{aligned}
& =\sqrt{60^{2}+80^{2}} \\
& =\sqrt{3600+6400} \\
Z & =100 \Omega
\end{aligned}
$$

2. $\mathrm{I}_{\mathrm{T}}=\frac{\mathrm{V}_{\mathrm{T}}}{\mathrm{Z}}$

$$
\begin{aligned}
& =\frac{120}{100} \\
I_{T} & =1.2 \mathrm{amps}
\end{aligned}
$$


3. $\mathrm{pf}=\cos \theta \quad \theta=\arctan \left(-\frac{\mathrm{X}_{\mathrm{C}}}{\mathrm{R}}\right)$

$$
\begin{aligned}
& =\cos \left(\arctan \left(-\frac{\mathrm{X}_{C}}{\mathrm{R}}\right)\right] \\
& =\cos \left(\arctan \left(-\frac{80}{60}\right)\right) \\
& =\cos (\arctan (-1.33)) \\
& =\cos \left(-53^{\circ}\right) \\
\text { pf } & =0.60
\end{aligned}
$$

4. $\mathrm{P}=\mathrm{EI} \cos \theta$

$$
=(120)(1.2)(0.60)
$$

$P=86.4$ watts

5. $\mathrm{Q}=\mathrm{EI} \sin \theta$

$$
=(120)(1.2)(0.798)
$$

$$
\mathrm{Q}=114.9 \mathrm{VAR}
$$

6. $S=E I$

$$
=(120)(1.2)
$$

$\mathrm{S}=144 \mathrm{VA}$ 


\section{Power in Parallel R-C Circuit}

Example: A $30 \Omega$ resistance and a $40 \Omega X_{C}$ are in parallel with a $120 \mathrm{~V}$ power source, as shown in Figure 7.

Find: 1 . $\mathrm{I}_{\mathrm{T}}$

2. $\mathrm{Z}$

3. $\mathrm{pf}$

4. $\mathrm{P}$

5. Q

6. $S$

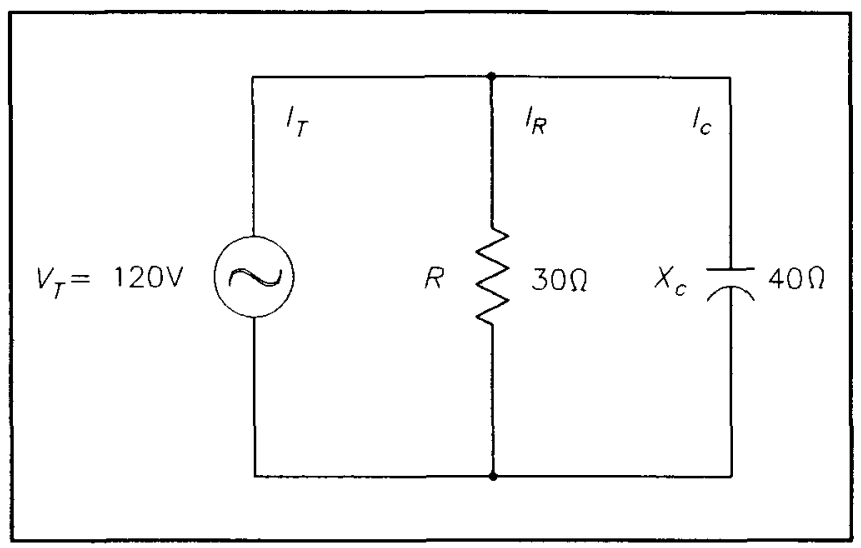

Solution:

Figure 7 Parallel R-C Circuit

1. $\mathrm{I}_{\mathrm{T}}=\sqrt{\mathrm{I}_{\mathrm{R}}^{2}+\mathrm{I}_{\mathrm{C}}^{2}} \quad \mathrm{I}_{\mathrm{R}}=\frac{\mathrm{V}_{\mathrm{T}}}{\mathrm{R}} \quad \mathrm{I}_{\mathrm{C}}=\frac{\mathrm{V}_{\mathrm{T}}}{\mathrm{X}_{\mathrm{C}}}$

$$
\begin{aligned}
& =\sqrt{\left(\frac{V_{T}}{R}\right)^{2}+\left(\frac{V_{T}}{X_{C}}\right)^{2}} \\
& =\sqrt{\left(\frac{120}{30}\right)^{2}+\left(\frac{120}{40}\right)^{2}} \\
& =\sqrt{4^{2}+3^{2}}
\end{aligned}
$$

$I_{T}=5$ amps

2. $\mathrm{Z}=\frac{\mathrm{V}_{\mathrm{T}}}{\mathrm{I}_{\mathrm{T}}}$

$$
=\frac{120}{5}
$$

$$
\mathrm{Z}=24 \Omega
$$


3. $\mathrm{pf}=\cos \theta \quad \theta=\arctan \left(\frac{\mathrm{I}_{\mathrm{C}}}{\mathrm{I}_{\mathrm{R}}}\right)$

$$
\begin{aligned}
& =\cos \left(\arctan \left(\frac{I_{C}}{I_{R}}\right)\right) \\
& =\cos \left(\arctan \left(\frac{3}{4}\right)\right) \\
& =\cos \left(\arctan \left(36.9^{\circ}\right)\right) \\
\text { pf } & =0.80
\end{aligned}
$$

4. $\mathrm{P}=\mathrm{EI} \cos \theta$

$$
=(120)(5)(0.80)
$$

$P=480$ watts

5. $\mathrm{Q}=\mathrm{EI} \sin \theta$

$$
=(120)(5)(0.6)
$$

$$
Q=360 \text { VAR }
$$

6. $S=E I$

$$
\begin{aligned}
& =(120)(5) \\
S & =600 \mathrm{VA}
\end{aligned}
$$




\section{Power in Series R-C-L Circuit}

Example: An $8 \Omega$ resistance, a $40 \Omega X_{L}$, and a $24 \Omega X_{C}$ are in series with a $60 \mathrm{~Hz}$ source with a current flow of 4 amps, as shown in Figure 8.

Find: $1 . \mathrm{Z}$

2. $\mathrm{V}_{\mathrm{T}}$

3. $\mathrm{pf}$

4. $P$

5. Q

6. $S$

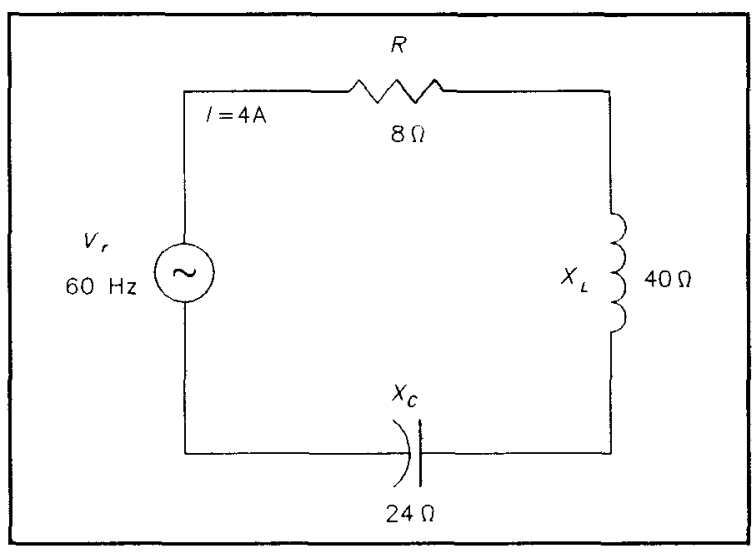

Figure 8 Series R-C-L Circuit

1. $\mathrm{Z}=\sqrt{\mathrm{R}^{2}+\left(\mathrm{X}_{\mathrm{L}}-\mathrm{X}_{\mathrm{C}}\right)^{2}}$

$=\sqrt{8^{2}+(40-24)^{2}}$

$=\sqrt{8^{2}+16^{2}}$

$Z=17.9 \Omega$

2. $\mathrm{V}_{\mathrm{T}}=\mathrm{IZ}$

$=(4)(17.9)$

$V_{T}=71.6$ volts 
3. $\mathrm{pf}=\cos \theta \quad \theta=\arctan \left(\frac{\mathrm{X}}{\mathrm{R}}\right)$

$$
\begin{aligned}
& =\cos \left(\arctan \left(\frac{\mathrm{X}}{\mathrm{R}}\right)\right) \\
& =\cos \left(\arctan \left(\frac{16}{8}\right)\right) \\
& =\cos (\arctan (2)) \\
& =\cos \left(63.4^{\circ}\right) \\
\text { pf } & =0.45
\end{aligned}
$$

4. $\mathrm{P}=\mathrm{EI} \cos \theta$

$=(71.6)(4)(0.45)$

$P=128.9$ watts

5. $\mathrm{Q}=\mathrm{EI} \sin \theta$

$$
=(71.6)(4)(0.89)
$$

$$
\mathrm{Q}=254.9 \mathrm{VAR}
$$

6. $S=E I$

$$
=(71.6)(4)
$$

$S=286.4$ VA 


\section{Power in Parallel R-C-L Circuits}

Example: An $800 \Omega$ resistance, $100 \Omega \mathrm{X}_{\mathrm{L}}$, and an $80 \Omega \mathrm{X}_{\mathrm{C}}$ are in parallel with a $120 \mathrm{~V}, 60 \mathrm{~Hz}$ source, as shown in Figure 9.

Find: $1 . \mathbf{I}_{\mathrm{T}}$

2. pf

3. $\mathrm{P}$

4. $Q$

5. S

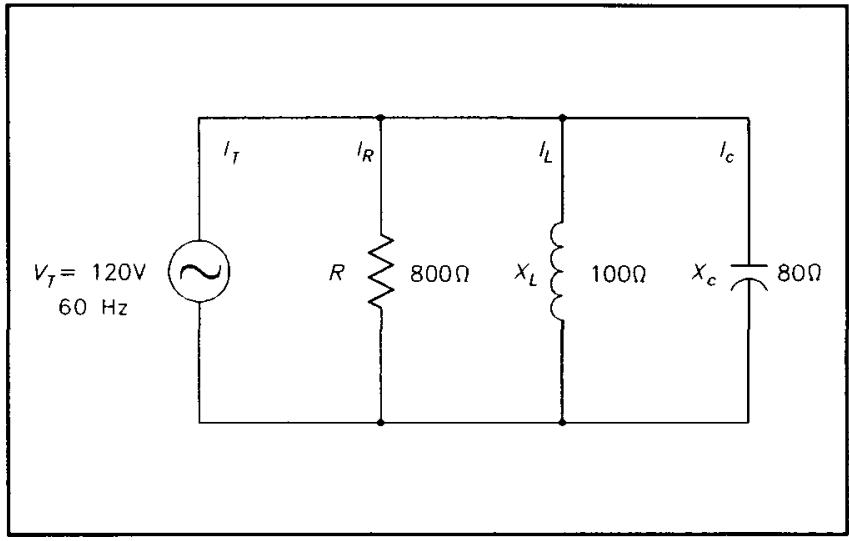

Figure 9 Parallel R-C-L Circuit

Solution:

$$
\text { 1. } \begin{aligned}
I_{T} & =\sqrt{I_{R}^{2}+\left(I_{C}-I_{L}\right)^{2}} \quad I_{R}=\frac{V_{T}}{R} \quad I_{L}=\frac{V_{T}}{X_{L}} \quad I_{C}=\frac{V_{T}}{X_{C}} \\
& =\sqrt{\left(\frac{V_{T}}{R}\right)^{2}+\left(\frac{V_{T}}{X_{L}}-\frac{V_{T}}{X_{C}}\right)^{2}} \\
& =\sqrt{\left(\frac{120}{800}\right)^{2}+\left(\frac{120}{100}-\frac{120}{80}\right)^{2}} \\
& =\sqrt{0.15^{2}+(1.2-1.5)^{2}} \\
& =\sqrt{0.15^{2}+(-0.3)^{2}} \\
I_{T} & =0.34 \text { amps }
\end{aligned}
$$


2. $\mathrm{pf}=\cos \theta \quad \theta=\arctan \left(\frac{\mathrm{I}_{\mathrm{C}}-\mathrm{I}_{\mathrm{L}}}{\mathrm{I}_{\mathrm{R}}}\right)$

$$
\begin{aligned}
& =\cos \left(\arctan \left(\frac{I_{C}-I_{L}}{I_{R}}\right)\right] \\
& =\cos \left(\arctan \left(\frac{1.5-1.2}{0.15}\right)\right) \\
& =\cos (\arctan (2)) \\
& =\cos \left(63.4^{\circ}\right) \\
\text { pf } & =0.45
\end{aligned}
$$

3. $\mathrm{P}=\mathrm{EI} \cos \theta$

$$
=(120)(0.34)(0.45)
$$

$\mathrm{P}=18.36$ watts

4. $\mathrm{Q}=\mathrm{EI} \sin \theta$

$$
=(120)(0.34)(0.89)
$$

$$
\mathrm{Q}=36.4 \mathrm{VAR}
$$

5. $\mathrm{S}=\mathrm{EI}$

$$
=(120)(0.34)
$$

$\mathrm{S}=40.8 \mathrm{VA}$ 


\section{Summary}

$\mathrm{AC}$ power relationships are summarized below.

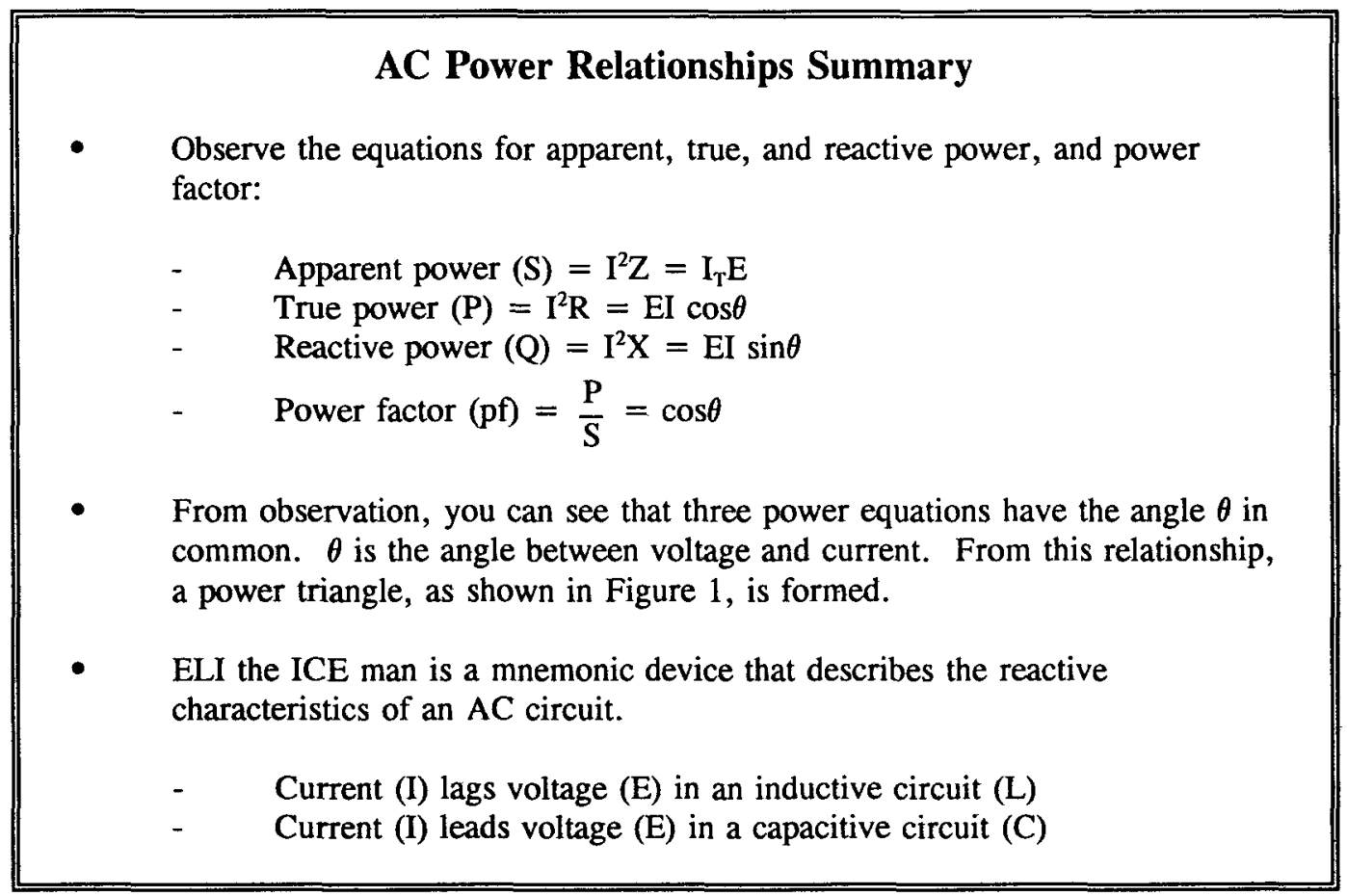




\section{THREE-PHASE CIRCUITS}

The design of three-phase $A C$ circuits lends itself to a more efficient method of producing and utilizing an $A C$ voltage.

EO 1.5 STATE the reasons that three-phase power systems are used in the industry.

EO 1.6 Given values for current, voltage, and power factor in a three-phase system, CALCULATE the following:

a. Real power

b. Reactive power

c. Apparent power

EO 1.7 Given a diagram of a wye- or delta-connected threephase system, DESCRIBE the voltage/current relationships of the circuit.

EO 1.8 STATE the indications of an unbalanced load in a threephase power system.

\section{Three-Phase Systems}

A three-phase $(3 \phi)$ system is a combination of three single-phase systems. In a $3 \phi$ balanced system, power comes from a $3 \phi \mathrm{AC}$ generator that produces three separate and equal voltages, each of which is $120^{\circ}$ out of phase with the other voltages (Figure 10). 

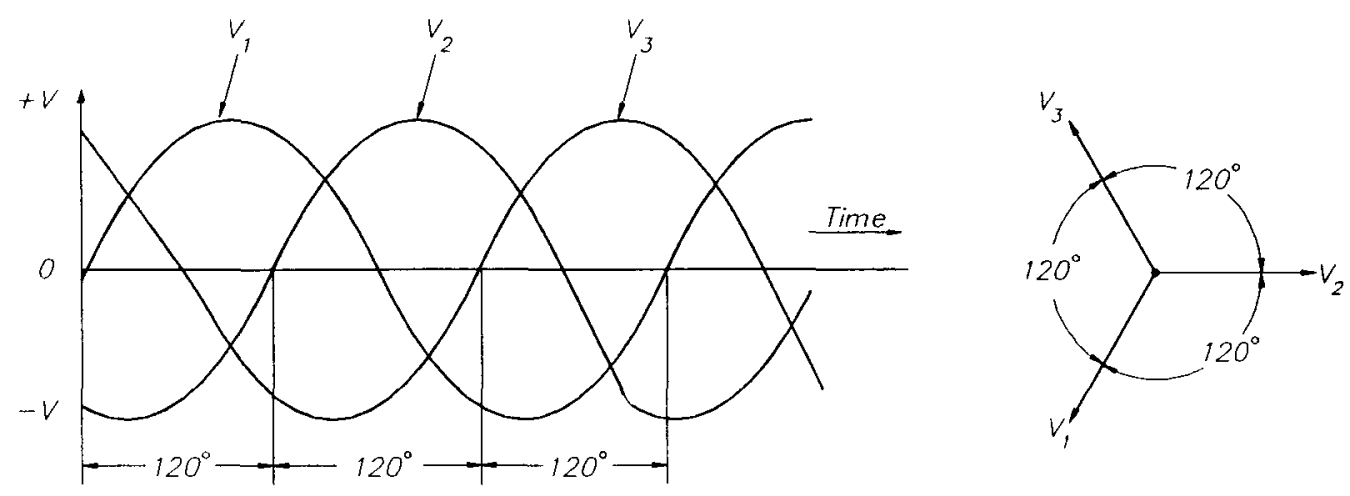

Figure 10 Three-Phase AC

Three-phase equipment (motors, transformers, etc.) weighs less than single-phase equipment of the same power rating. They have a wide range of voltages and can be used for single-phase loads. Three-phase equipment is smaller in size, weighs less, and is more efficient than single-phase equipment.

Three-phase systems can be connected in two different ways. If the three common ends of each phase are connected at a common point and the other three ends are connected to a $3 \phi$ line, it is called a wye, or $Y_{-}$, connection (Figure 11). If the three phases are connected in series to form a closed loop, it is called a delta, or $\Delta$-, connection. 


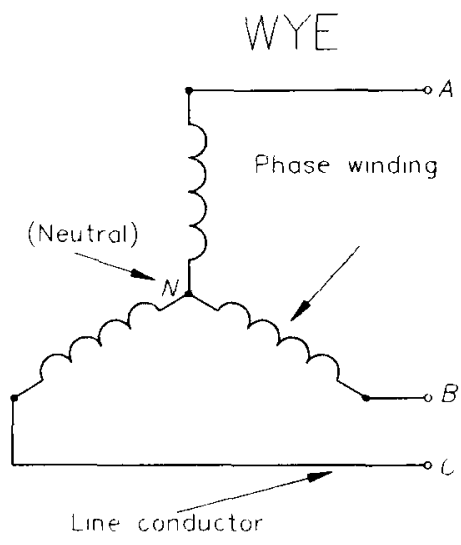

[)ELTA

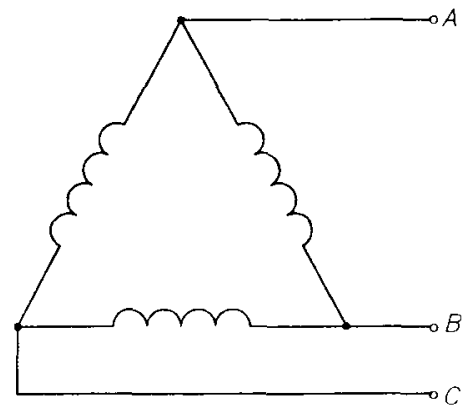

Figure $113 \phi$ AC Power Connections

\section{Power in Balanced $3 \phi$ Loads}

Balanced loads, in a $3 \phi$ system, have identical impedance in each secondary winding (Figure 12). The impedance of each winding in a delta load is shown as $Z_{\Delta}$ (Figure 12a), and the impedence in a wye load is shown as $Z_{y}$ (Figure 12b). For either the delta or wye connection, the lines $\mathrm{A}, \mathrm{B}$, and $\mathrm{C}$ supply a $3 \phi$ system of voltages.
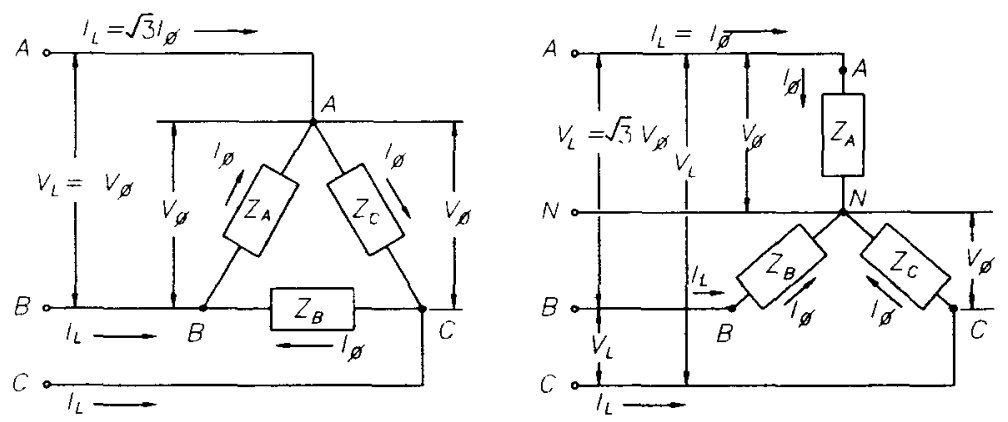

(a) Balanced $\Delta$ load, $Z_{A}=Z_{B}=Z_{C}=Z_{\Delta}$

(b) Balanced $Y$ load, $Z_{A}=Z_{B}=Z_{C}=Z_{Y}$

Figure $123 \phi$ Balanced Loads 
In a balanced delta load, the line voltage $\left(V_{L}\right)$ is equal to the phase voltage $\left(V_{\phi}\right)$, and the line current $\left(I_{L}\right)$ is equal to the square root of three times the phase current $\left(\sqrt{3} I_{\phi}\right)$. Equation (9-5) is a mathematical representation of $V_{L}$ in a balanced delta load. Equation (9-6) is a mathematical representation of $I_{L}$ in a balanced delta load.

$$
\begin{aligned}
& V_{L}=V_{\phi} \\
& I_{L}=\sqrt{3} I_{\phi}
\end{aligned}
$$

In a balanced wye load, the line voltage $\left(V_{L}\right)$ is equal to the square root of three times phase voltage $\left(\sqrt{3} V_{\phi}\right)$, and line current $\left(I_{L}\right)$ is equal to the phase current $\left(I_{\phi}\right)$. Equation $(9-7)$ is a mathematical representation of $V_{L}$ in a balanced wye load. Equation (9-8) is a mathematical representation of $I_{L}$ in a balanced wye load.

$$
\begin{aligned}
& \mathrm{V}_{\mathrm{L}}=\sqrt{3} \mathrm{~V}_{\phi} \\
& \mathrm{I}_{\mathrm{L}} \doteq \mathrm{I}_{\phi}
\end{aligned}
$$

Because the impedance of each phase of a balanced delta or wye load has equal current, phase power is one third of the total power. Equation (9-10) is the mathematical representation for phase power $\left(\mathbf{P}_{\phi}\right)$ in a balanced delta or wye load.

$$
P_{\phi}=V_{\phi} I_{\phi} \cos \theta
$$

Total power $\left(\mathrm{P}_{\mathrm{T}}\right)$ is equal to three times the single-phase power. Equation (9-11) is the mathematical representation for total power in a balanced delta or wye load.

$$
\mathrm{P}_{\mathrm{T}}=3 \mathrm{~V}_{\phi} \mathrm{I}_{\phi} \cos \theta
$$

In a delta-connected load, $V_{L}=V_{\phi}$ and $I_{\phi}=\frac{\sqrt{3} I_{L}}{3}$ so:

$$
P_{T}=\sqrt{3} V_{L} I_{L} \cos \theta
$$

In a wye-connected load, $I_{L}=I_{\phi}$ and $V_{\phi}=\frac{\sqrt{3} V_{L}}{3}$ so:

$$
P_{T}=\sqrt{3} V_{L} I_{L} \cos \theta
$$


As you can see, the total power formulas for delta- and wye-connected loads are identical.

Total apparent power $\left(S_{\mathrm{T}}\right)$ in volt-amperes and total reactive power $\left(Q_{\mathrm{T}}\right)$ in volt-amperes-reactive are related to total real power $\left(\mathrm{P}_{\mathrm{T}}\right)$ in watts (Figure 13).

A balanced three-phase load has the real, apparent, and reactive powers given by:

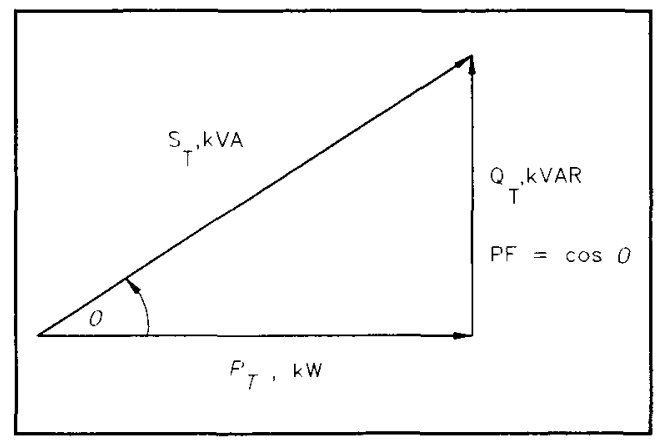

$$
\begin{aligned}
& \mathrm{P}_{\mathrm{T}}=\sqrt{3} \mathrm{~V}_{\mathrm{T}} \mathrm{I}_{\mathrm{L}} \cos \theta \\
& \mathrm{S}_{\mathrm{T}}=\sqrt{3} \mathrm{~V}_{\mathrm{T}} \mathrm{I}_{\mathrm{L}} \\
& \mathrm{Q}_{\mathrm{T}}=\sqrt{3} \mathrm{~V}_{\mathrm{T}} \mathrm{I}_{\mathrm{L}} \sin \theta
\end{aligned}
$$

Figure $133 \phi$ Power Triangle

Example 1: Each phase of a delta-connected $3 \phi \mathrm{AC}$ generator supplies a full load current of 200 A at 440 volts with a 0.6 lagging power factor, as shown in Figure 14.

Find: $1 . \mathrm{V}_{\mathrm{L}}$

2. $\mathrm{I}_{\mathrm{L}}$

3. $\mathrm{P}_{\mathrm{T}}$

4. $\mathrm{Q}_{\mathrm{T}}$

5. $\mathrm{S}_{\mathrm{T}}$

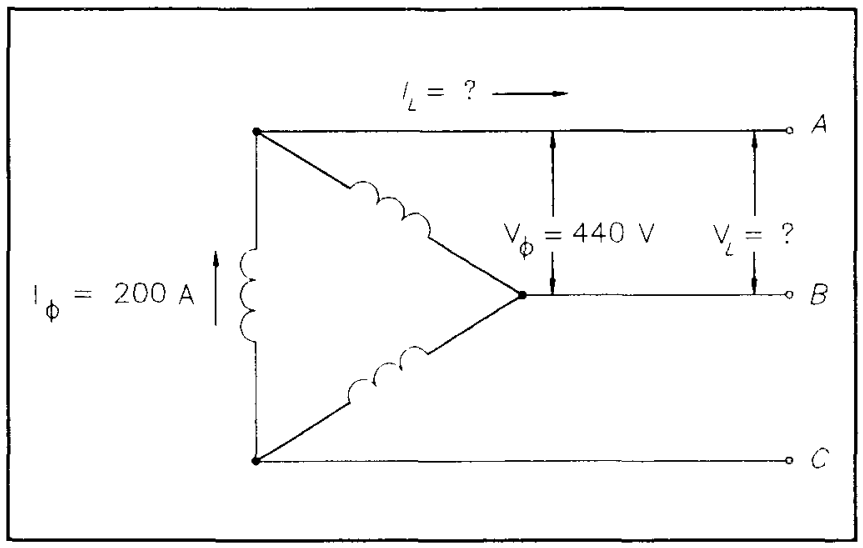

Figure 14 Three-Phase Delta Generator

Solution:

1. $\begin{aligned} \mathrm{V}_{\mathrm{L}} & =\mathrm{V}_{\phi} \\ \mathrm{V}_{\mathrm{L}} & =440 \text { volts }\end{aligned}$ 
2. $\mathrm{I}_{\mathrm{L}}=\sqrt{3} \mathrm{I}_{\phi}$

$$
=(1.73)(200)
$$

$I_{L}=346$ amps

3. $\mathrm{P}_{\mathrm{T}}=\sqrt{3} \mathrm{~V}_{\mathrm{L}} \mathrm{I}_{\mathrm{L}} \cos \theta$

$=(1.73)(440)(346)(0.6)$

$\mathrm{P}_{\mathrm{T}}=158.2 \mathrm{~kW}$

4. $\mathrm{Q}_{\mathrm{T}}=\sqrt{3} \mathrm{~V}_{\mathrm{L}} \mathrm{I}_{\mathrm{L}} \sin \theta$

$=(1.73)(440)(346)(0.8)$

$\mathrm{Q}_{\mathrm{T}}=210.7 \mathrm{kVAR}$

5. $\mathrm{S}_{\mathrm{T}}=\sqrt{3} \mathrm{~V}_{\mathrm{L}} \mathrm{I}_{\mathrm{L}}$

$=(1.73)(440)(346)$

$\mathrm{S}_{\mathrm{T}}=263.4 \mathrm{kVA}$

Example 2: Each phase of a wyeconnected $3 \phi$ AC generator supplies a $100 \mathrm{~A}$ current at a phase voltage of $240 \mathrm{~V}$ and a power factor of 0.9 lagging, as shown in Figure 15.

Find: $1 . \mathrm{V}_{\mathrm{L}}$

2. $P_{\mathrm{T}}$

3. $\mathrm{Q}_{\mathrm{T}}$

4. $\mathrm{S}_{\mathrm{T}}$

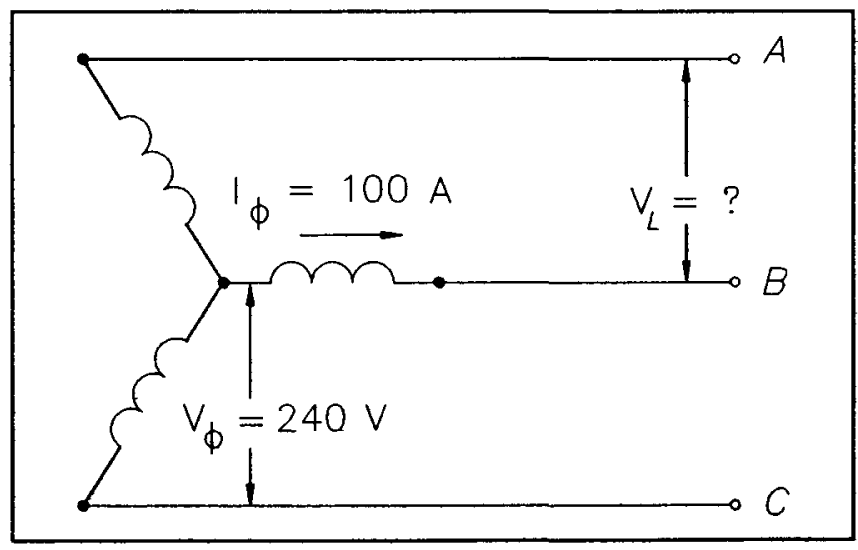

Figure 15 Three-Phase Wye Generator 
Solution:

1. $\mathrm{V}_{\mathrm{L}}=\sqrt{3} \mathrm{~V}_{\phi}$

$$
=(1.73)(240)
$$

$V_{L}=415.2$ volts

2. $\mathrm{P}_{\mathrm{T}}=\sqrt{3} \mathrm{~V}_{\mathrm{L}} \mathrm{I}_{\mathrm{L}} \cos \theta$

$=(1.73)(415.2)(100)(0.9)$

$\mathrm{P}_{\mathrm{T}}=64.6 \mathrm{~kW}$

3. $\mathrm{Q}_{\mathrm{T}}=\sqrt{3} \mathrm{~V}_{L} \mathrm{I}_{\mathrm{L}} \sin \theta$

$=(1.73)(415.2)(100)(0.436)$

$\mathrm{Q}_{\mathrm{T}}=31.3 \mathrm{kVAR}$

4. $\mathrm{S}_{\mathrm{T}}=\sqrt{3} \mathrm{~V}_{\mathrm{L}} \mathrm{I}_{\mathrm{L}}$

$=(1.73)(415.2)(100)$

$\mathrm{S}_{\mathrm{T}}=71.8 \mathrm{kVA}$

\section{Unbalanced $3 \phi$ Loads}

An important property of a three-phase balanced system is that the phasor sum of the three line or phase voltages is zero, and the phasor sum of the three line or phase currents is zero. When the three load impedances are not equal to one another, the phasor sums and the neutral current $\left(I_{n}\right)$ are not zero, and the load is, therefore, unbalanced. The imbalance occurs when an open or short circuit appears at the load.

If a three-phase system has an unbalanced load and an unbalanced power source, the methods of fixing the system are complex. Therefore, we will only consider an unbalanced load with a balanced power source.

Example: A $3 \phi$ balanced system, as shown in Figure 16a, contains a wye load. The line-toline voltage is $240 \mathrm{~V}$, and the resistance is $40 \Omega$ in each branch. 

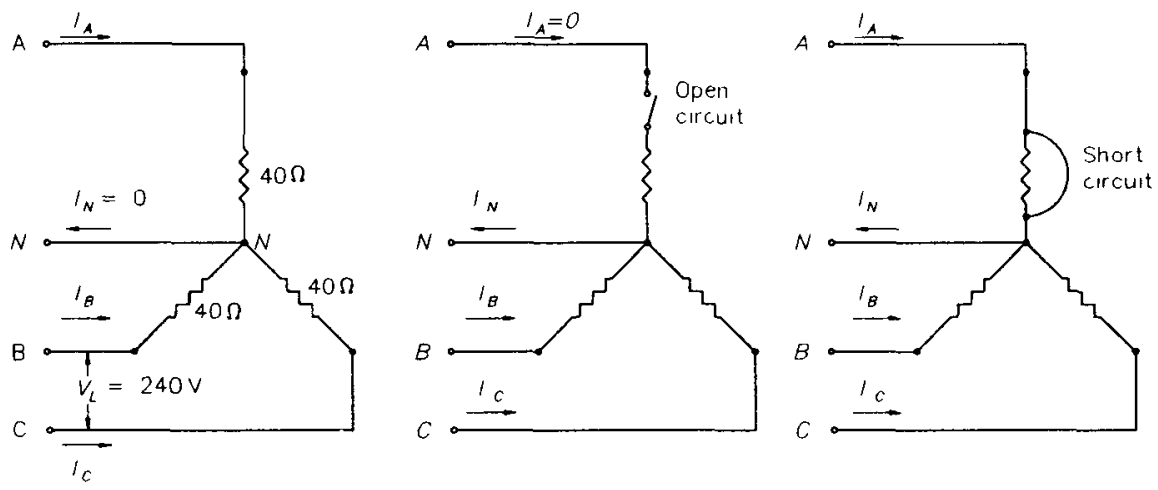

(a) Balanced 3申 lood, $I_{N}=0$

(b) Unbolanced $3-\phi 1000$
open circuit $I_{N}=I_{B}+I_{C}$

(i) Unbalunced 3-申 lood, shot curcuit, $I_{N}=I_{A}$

Figure $163 \phi$ Unbalanced Load

Find line current and neutral current for the following load conditions.

1. balanced load

2. open circuit phase A (Figure 16b)

3. short circuit in phase A (Figure 16c)

1. $I_{L}=I_{\phi} \quad I_{\phi}=\frac{V_{\phi}}{R_{\phi}} \quad V_{\phi}=\frac{V_{L}}{\sqrt{3}}$

$$
\begin{aligned}
I_{L} & =\frac{\left(\frac{V_{L}}{\sqrt{3}}\right)}{R_{\phi}} \\
& =\frac{\left(\frac{240}{1.73}\right)}{40} \\
& =\frac{138.7}{40} \\
I_{L} & =3.5 \text { amps } \quad I_{N}=0
\end{aligned}
$$


2. Current flow in lines $\mathrm{B}$ and $\mathrm{C}$ becomes the resultant of the loads in $\mathrm{B}$ and $\mathrm{C}$ connected in series.

$$
\begin{aligned}
I_{B} & =\frac{V_{L}}{R_{B}+R_{C}} \quad I_{C}=I_{B} \\
& =\frac{240}{40+40} \\
I_{B} & =3 \mathrm{amps} \quad I_{C}=3 \mathrm{amps} \\
I_{N} & =I_{B}+I_{C} \\
& =3+3 \\
I_{N} & =6 \text { amps } \\
\text { 3. } \quad I_{B} & =\frac{V_{L}}{R_{B}} \quad I_{C}=I_{B} \\
& =\frac{240}{40} \quad I_{C}=6 \mathrm{amps}
\end{aligned}
$$

The current in Phase A is equal to the neutral line current, $I_{A}=I_{N}$. Therefore, $I_{N}$ is the phasor sum of $I_{B}$ and $I_{C}$.

$$
\begin{aligned}
I_{N} & =\sqrt{3} I_{B} \\
& =(1.73)(6) \\
I_{N} & =10.4 \mathrm{amps}
\end{aligned}
$$

In a fault condition, the neutral connection in a wye-connected load will carry more current than the phase under a balanced load. Unbalanced three-phase circuits are indicated by abnormally high currents in one or more of the phases. This may cause damage to equipment if the imbalance is allowed to continue. 


\section{Summary}

Three-phase circuits are summarized below.

\section{Three-Phase Circuits Summary}

- Three-phase power systems are used in the industry because:

- $\quad$ Three-phase circuits weigh less than single-phase circuits of the same power rating.

- $\quad$ They have a wide range of voltages and can be used for single-phase loads.

- Three-phase equipment is smaller in size, weighs less, and is more efficient than single-phase equipment.

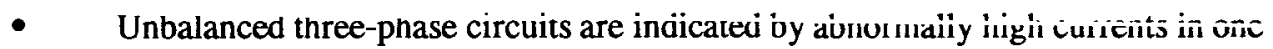
or more of the phases. 
Department of Energy

Fundamentals Handbook

ELECTRICAL SCIENCE

Module 10

AC Generators 
LIST OF FIGURES $\ldots \ldots \ldots \ldots \ldots \ldots \ldots \ldots \ldots \ldots \ldots \ldots$

LIST OF TABLES $\ldots \ldots \ldots \ldots \ldots \ldots \ldots \ldots \ldots \ldots \ldots$

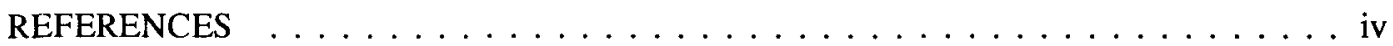

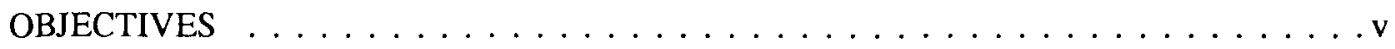

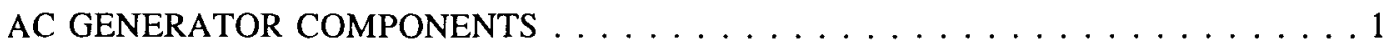

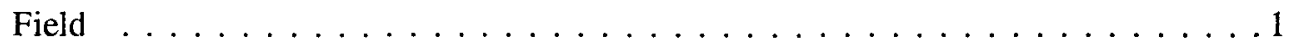

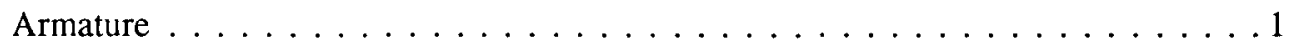

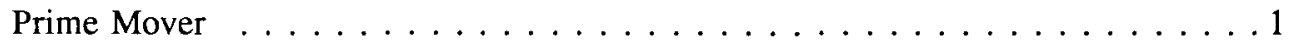

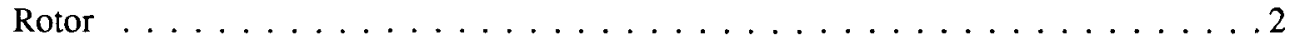

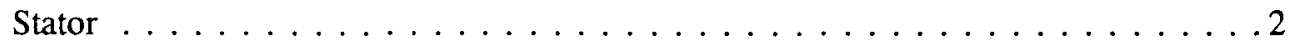

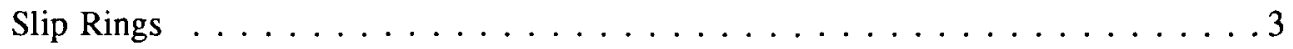

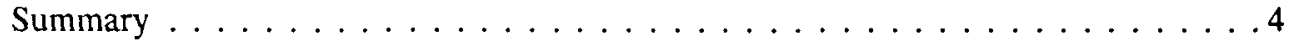

AC GENERATOR THEORY $\ldots \ldots \ldots \ldots \ldots \ldots \ldots \ldots \ldots \ldots \ldots \ldots \ldots \ldots \ldots$

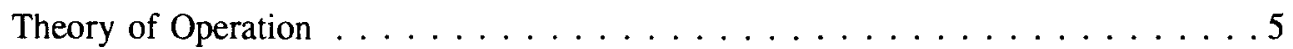

Losses in an $\mathrm{AC}$ Generator . . . . . . . . . . . . . . . . . 6

Hysteresis Losses . . . . . . . . . . . . . . . . . . . . . 7

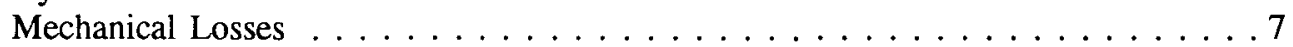

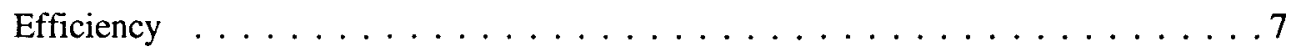

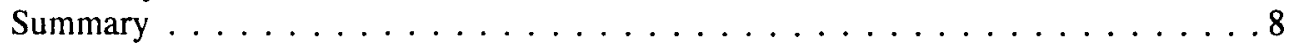

AC GENERATOR OPERATION $\ldots \ldots \ldots \ldots \ldots \ldots \ldots$

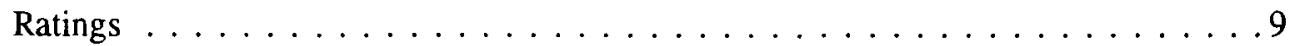

Paralleling AC Generators . . . . . . . . . . . . . . . 10

Types of AC Generators . . . . . . . . . . . . . . . . . . 10

Three-Phase AC Generators . . . . . . . . . . . . . . . . 11

AC Generator Connections . . . . . . . . . . . . . . . . . . 12

Summary . . . . . . . . . . . . . . . . . . . . . 14 


\section{LIST OF FIGURES}

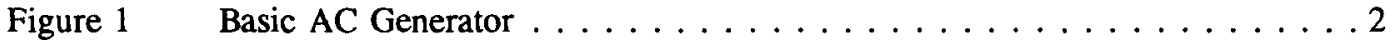

Figure $2 \quad$ Comparison of $\mathrm{DC}$ and $\mathrm{AC}$ Generator Outputs $\ldots \ldots \ldots$

Figure $3 \quad$ Simple AC Generator $\ldots \ldots \ldots \ldots \ldots \ldots \ldots \ldots \ldots \ldots \ldots \ldots \ldots \ldots \ldots$

Figure $4 \quad$ AC Generator Nameplate Ratings $\ldots \ldots \ldots \ldots$

Figure $5 \quad$ Stationary Field, Rotating Armature AC Generator . . . . . . . . . . 10

Figure 6 Simple AC Generator - Rotating Field,

Stationary Armature . . . . . . . . . . . . . . . . . 11

Figuie $7 \quad$ Stationäy Armature $3 \phi$ Generator $\ldots \ldots \ldots 11$

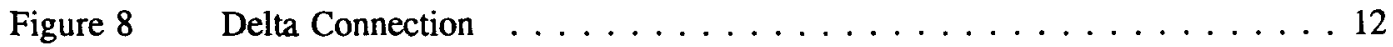

Figure 9 Characteristics of a Delta-Connected Generator . . . . . . . . . 12

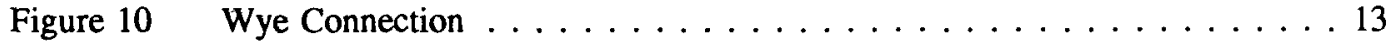

Figure 11 Characteristics of a Wye-Connected AC Generator . . . . . . . . . . 13 


\section{LIST OF TABLES}

NONE 


\section{REFERENCES}

- Gussow, Milton, Schaum's Outline Series, Basic Electricity, McGraw-Hill.

- $\quad$ Academic Program for Nuclear Power Plant Personnel, Volume IV, Columbia, MD:

General Physics Corporation, Library of Congress Card \#A 326517, 1982.

- $\quad$ Academic Program for Nuclear Power Plant Personnel, Volume II, Columbia, MD:

General Physics Corporation, Library of Congress Card \#A 326517, 1982.

- Nasar and Unnewehr, Electromechanics and Electric Machines, John Wiley and Sons.

- Van Valkenburgh, Nooger, and Neville, Basic Electricity, Vol. 5, Hayden Book Company.

- $\quad$ Lister, Eugene C., Electric Circuits and Machines, $5^{\text {th }}$ Edition, McGraw-Hill.

- Croft, Carr, Watt, and Summers, American Electricians Handbook, $10^{\text {th }}$ Edition, McGraw-Hill.

- Mason, C. Russel, The Art and Science of Protective Relaying, John Wiley and Sons.

- Mileaf, Harry, Electricity One - Seven, Revised $2^{\text {nd }}$ Edition, Hayden Book Company.

- Buban and Schmitt, Understanding Electricity and Electronics, $3^{\text {rd }}$ Edition, McGraw-Hill.

- Kidwell, Walter, Electrical Instruments and Measurements, McGraw-Hill. 


\section{TERMINAL OBJECTIVE}

1.0 Given the type and application of an AC generator, DESCRIBE the operating characteristics of that generator including methods of voltage production, advantages of each type, and methods for paralleling.

\section{ENABLING OBJECTIVES}

1.1 STATE the purpose of the following components of an AC generator:
a. Field
b. Armature
c. Prime mover
d. Rotor
e. Stator
f. Slip rings

1.2 Given the speed of rotation and number of poles, CALCULATE the frequency output of an $\mathrm{AC}$ generator.

1.3 LIST the three losses found in an AC generator.

1.4 Given the prime mover input and generator output, DETERMINE the efficiency of an $\mathrm{AC}$ generator.

1.5 DESCRIBE the bases behind the $\mathrm{kW}$ and current ratings of an $\mathrm{AC}$ generator.

1.6 DESCRIBE the conditions that must be met prior to paralleling two AC generators including consequences of not meeting these conditions.

1.7 DESCRIBE the difference between a stationary field, rotating armature AC generator and a rotating field, stationary armature $\mathrm{AC}$ generator.

1.8 EXPLAIN the differences between a wye-connected and delta-connected AC generator including advantages and disadvantages of each type. 
Intentionally Left Blank 


\section{AC GENERATOR COMPONENTS}

$A C$ generators are widely used to produce $A C$ voltage. To understand how these generators operate, the function of each component of the generator must first be understood.

EO 1.1 STATE the purpose of the following components of an AC generator:

a. Field

b. Armature

c. Prime mover

d. Rotor

e. Stator

f. Slip rings

\section{Field}

The field in an AC generator consists of coils of conductors within the generator that receive a voltage from a source (called excitation) and produce a magnetic flux. The magnetic flux in the field cuts the armature to produce a voltage. This voltage is ultimately the output voltage of the AC generator.

\section{$\underline{\text { Armature }}$}

The armature is the part of an AC generator in which voltage is produced. This component consists of many coils of wire that are large enough to carry the full-load current of the generator.

\section{Prime Mover}

The prime mover is the component that is used to drive the $\mathrm{AC}$ generator. The prime mover may be any type of rotating machine, such as a diesel engine, a steam turbine, or a motor. 


\section{Rotor}

The rotor of an $\mathrm{AC}$ generator is the rotating component of the generator, as shown in Figure 1. The rotor is driven by the generator's prime mover, which may be a steam turbine, gas turbine, or diesel engine. Depending on the type of generator, this component may be the armature or the field. The rotor will be the armature if the voltage output is generated there; the rotor will be the field if the field excitation is applied there.

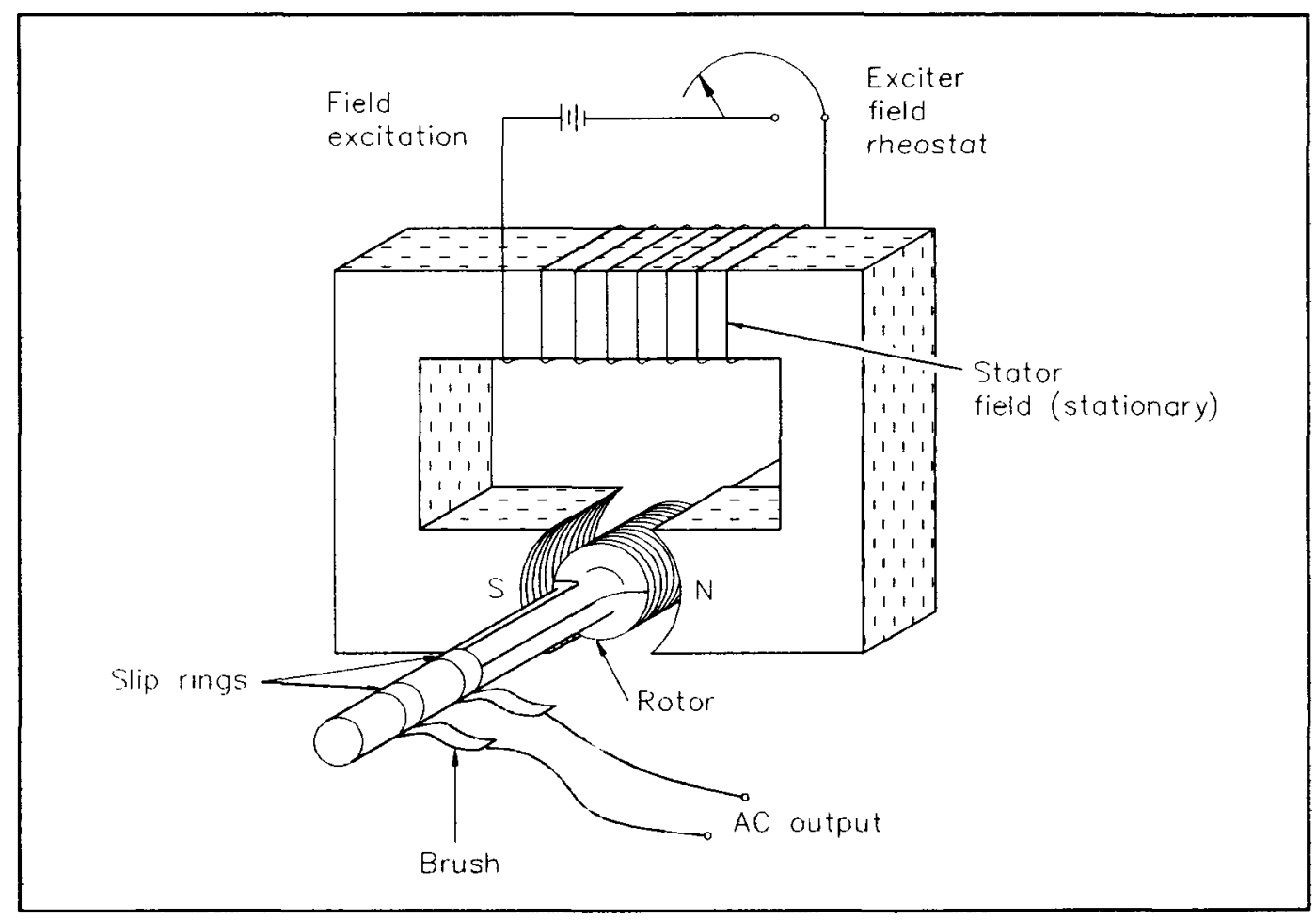

Figure 1 Basic AC Generator

\section{Stator}

The stator of an AC generator is the part that is stationary (refer to Figure 1). Like the rotor, this component may be the armature or the field, depending on the type of generator. The stator will be the armature if the voltage output is generated there; the stator will be the field if the field excitation is applied there. 


\section{Slip Rings}

Slip rings are electrical connections that are used to transfer power to and from the rotor of an AC generator (refer to Figure 1). The slip ring consists of a circular conducting material that is connected to the rotor windings and insulated from the shaft. Brushes ride on the slip ring as the rotor rotates. The electrical connection to the rotor is made by connections to the brushes.

Slip rings are used in AC generators because the desired output of the generator is a sine wave. In a DC generator, a commutator was used to provide an output whose current always flowed in the positive direction, as shown in Figure 2. This is not necessary for an AC generator. Therefore, an $\mathrm{AC}$ generator may use slip rings, which will allow the output current and voltage to oscillate through positive and negative values. This oscillation of voltage and current takes the shape of a sine wave.
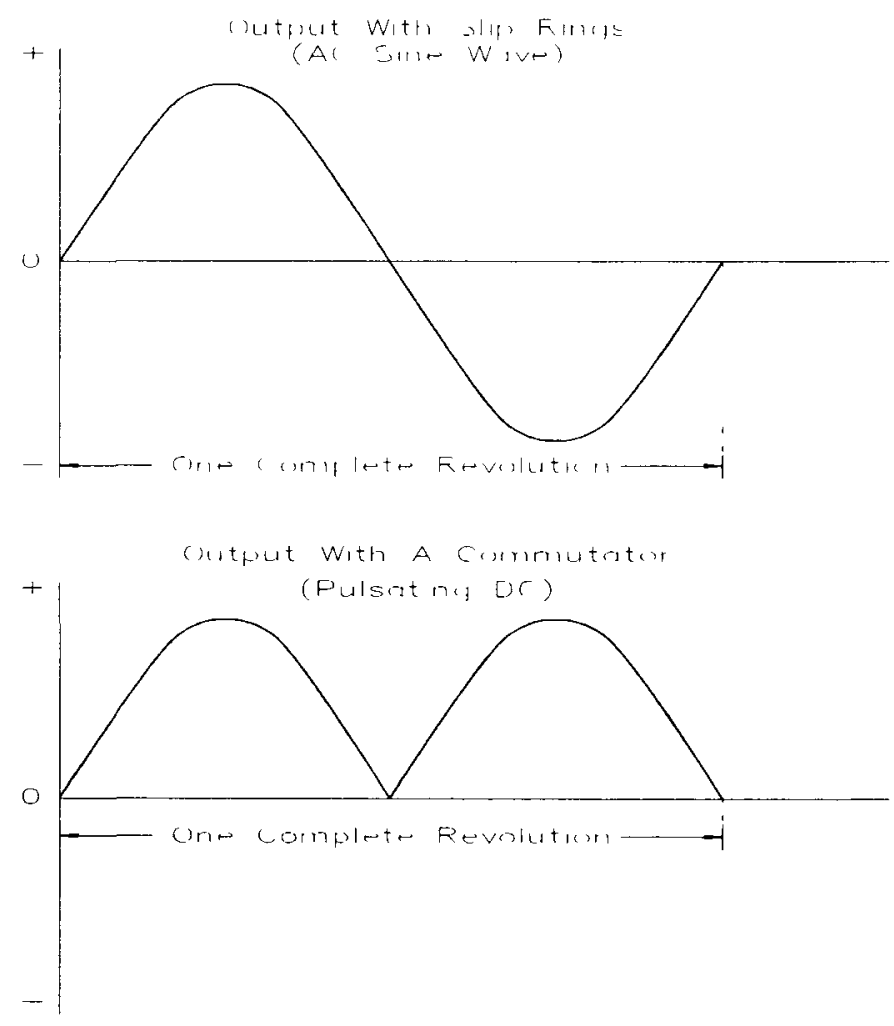

Figure 2 - Comparison of DC and AC Generator Outputs 


\section{Summary}

The important information in this chapter is summarized below.

\section{AC Generator Components Summary}

- The field in an AC generator consists of coils of conductors within the generator that receive a voltage from a source (called excitation) and produce a magnetic flux.

- The armature is the part of an AC generator in which output voltage is produced.

- The prime mover is the component that is used to drive the $\mathrm{AC}$ generator.

- The rotor of an AC generator is the part that is driven by the prime mover and that rotates.

- The stator of an AC generator is the part that is stationary.

- Slip rings are electrical connections that are used to transfer power to and from the rotor of an $\mathrm{AC}$ generator. 


\section{AC GENERATOR THEORY}

$A C$ generators are widely used to produce $A C$ voltage. To understand how these generators operate, the basic theory of operation must first be understood.

EO 1.2 Given the speed of rotation and number of poles, CALCULATE the frequency output of an AC generator.

EO 1.3 LIST the three losses found in an AC generator.

EO 1.4 Given the prime mover input and generator output, DETERMINE the efficiency of an AC generator.

\section{Theory of Operation}

A simple AC generator consists of: (a) a strong magnetic field, (b) conductors that rotate through that magnetic field, and (c) a means by which a continuous connection is provided to the conductors as they are rotating (Figure 3). The strong magnetic field is produced by a current flow through the field coil of the rotor. The field coil in the rotor receives excitation through the use of slip rings and brushes. Two brushes are spring-held in contact with the slip rings to provide the

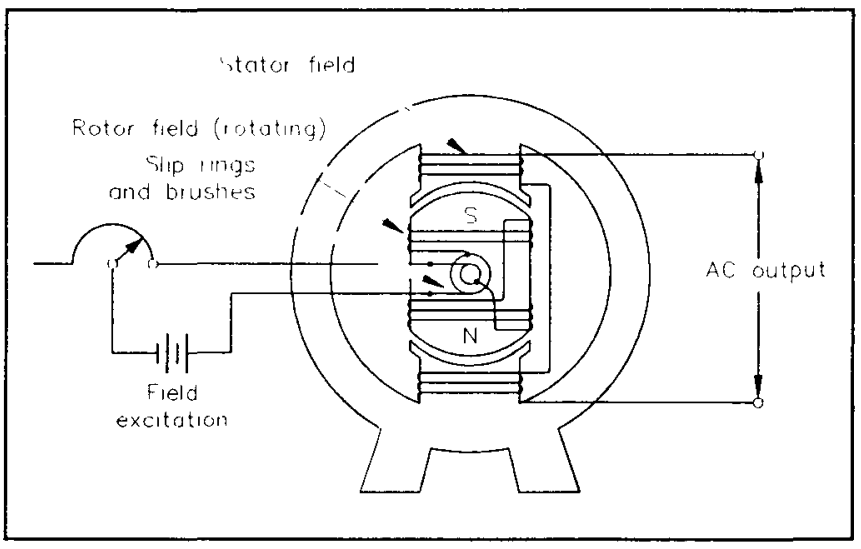

Figure 3 Simple AC Generator continuous connection between the field coil and the external excitation circuit. The armature is contained within the windings of the stator and is connected to the output. Each time the rotor makes one complete revolution, one complete cycle of $\mathrm{AC}$ is developed. A generator has many turns of wire wound into the slots of the rotor.

The magnitude of AC voltage generated by an AC generator is dependent on the field strength and speed of the rotor. Most generators are operated at a constant speed; therefore, the generated voltage depends on field excitation, or strength. 
The frequency of the generated voltage is dependent on the number of field poles and the speed at which the generator is operated, as indicated in Equation (10-1).

$$
f=\frac{N P}{120}
$$

where

$$
\begin{array}{rll}
\mathbf{f} & = & \text { frequency }(\mathrm{Hz}) \\
\mathbf{P} & = & \text { total number of poles } \\
\mathbf{N} & = & \text { rotor speed }(\mathrm{rpm}) \\
120 & = & \text { conversion from minutes to seconds and from poles to pole pairs }
\end{array}
$$

The 120 in Equation (10-1) is derived by multiplying the following conversion factors.

$$
\frac{60 \text { seconds }}{1 \text { minute }} \times \frac{2 \text { poles }}{\text { pole pair }}
$$

In this manner, the units of frequency (hertz or cycles/sec.) are derived.

\section{Losses in an AC Generator}

The load current flows through the armature in all AC generators. Like any coil, the armature has some amount of resistance and inductive reactance. The combination of these make up what is known as the internal resistance, which causes a loss in an AC generator. When the load current flows, a voltage drop is developed across the internal resistance. This voltage drop subtracts from the output voltage and, therefore, represents generated voltage and power that is lost and not available to the load. The voltage drop in an $\mathrm{AC}$ generator can be found using Equation (10-2).

$$
\text { Voltage drop }=I_{2} R_{a}+I_{a} X_{L a}
$$

where

$$
\begin{aligned}
& \mathbf{I}_{\mathbf{a}}=\text { armature current } \\
& \mathbf{R}_{\mathbf{a}}=\text { armature resistance } \\
& \mathbf{X}_{\mathbf{L}}=\text { armature inductive reactance }
\end{aligned}
$$




\section{Hysteresis Losses}

Hysteresis losses occur when iron cores in an $\mathrm{AC}$ generator are subject to effects from a magnetic field. The magnetic domains of the cores are held in alignment with the field in varying numbers, dependent upon field strength. The magnetic domains rotate, with respect to the domains not held in alignment, one complete turn during each rotation of the rotor. This rotation of magnetic domains in the iron causes friction and heat. The heat produced by this friction is called magnetic hysteresis loss.

To reduce hysteresis losses, most AC armatures are constructed of heat-treated silicon steel, which has an inherently low hysteresis loss. After the heat-treated silicon steel is formed to the desired shape, the laminations are heated to a dull red and then allowed to cool. This process, known as annealing, reduces hysteresis losses to a very low value.

\section{Mechanical Losses}

Rotational or mechanical losses can be caused by bearing friction, brush friction on the commutator, and air friction (called windage), which is caused by the air turbulence due to armature rotation. Careful maintenance can be instrumental in keeping bearing friction to a minimum. Clean bearings and proper lubrication are essential to the reduction of bearing friction. Brush friction is reduced by ensuring: proper brush seating, proper brush use, and maintenance of proper brush tension. A smooth and clean commutator also aids in the reduction of brush friction. In very large generators, hydrogen is used within the generator for cooling; hydrogen, being less dense than air, causes less windage losses than air.

\section{Efficiency}

Efficiency of an AC generator is the ratio of the useful power output to the total power input. Because any mechanical process experiences some losses, no AC generators can be 100 percent efficient. Efficiency of an AC generator can be calculated using Equation (10-3).

$$
\text { Efficiency }=\frac{\text { Output }}{\text { Input }} \times 100
$$

Example: Given a $5 \mathrm{hp}$ motor acting as the prime mover of a generator that has a load demand of $2 \mathrm{~kW}$, what is the efficiency of the generator?

Solution:

In order to calculate efficiency, the input and output power must be in the same units. As described in Thermodynamics, the horsepower and the watt are equivalent units of power. 
Therefore, the equivalence of these units is expressed with a conversion factor as follows.

$$
\left(\frac{550 \frac{\mathrm{ft}-\mathrm{lbf}}{\mathrm{sec}}}{1 \mathrm{hp}}\right)\left(\frac{1 \mathrm{~kW}}{737.6 \frac{\mathrm{ft}-\mathrm{lbf}}{\mathrm{sec}}}\right)\left(\frac{1000 \mathrm{w}}{1 \mathrm{~kW}}\right)=746 \frac{\mathrm{W}}{\mathrm{hp}}
$$

$$
\begin{aligned}
& \text { Input Power }=5 \mathrm{hp} \times 746 \frac{\mathrm{W}}{\mathrm{hp}}=3730 \mathrm{~W} \\
& \text { Output Power }=2 \mathrm{~kW}=2000 \mathrm{~W} \\
& \text { Efficiency }=\frac{\text { Output }}{\text { Input }}=\frac{2000 \mathrm{~W}}{3730 \mathrm{~W}}=0.54 \times 100=54 \%
\end{aligned}
$$

\section{Summary}

The important information covered in this chapter is summarized below.

\section{AC Generator Theory Summary}

- The frequency of the generated voltage in an AC generator can be calculated by multiplying the number of poles by the speed of the generator and dividing by a factor of 120 .

- The three losses found in an AC generator are:

- Internal voltage drops due to the internal resistance and impedance of the generator

- Hysteresis losses

- Mechanical losses

- Efficiency of an AC generator can be calculated by dividing the output by the input and multiplying by 100 . 


\section{AC GENERATOR OPERATION}

Because of the nature of $A C$ voltage and current, the operation of an $A C$ generator requires that rules and procedures be followed. In addition, there are various types of $A C$ generators available, each type having advantages and disadvantages.

EO 1.5 DESCRIBE the bases behind the $k W$ and current ratings of an $\mathrm{AC}$ generator.

EO 1.6 DESCRIBE the conditions that must be met prior to paralleling two $\mathrm{AC}$ generators including consequences of not meeting these conditions.

EO 1.7 DESCRIBE the difference between a stationary field, rotating armature $\mathrm{AC}$ generator and a rotating field, stationary armature $\mathrm{AC}$ generator.

EO 1.8 EXPLAIN the differences between a wye-connected and delta-connected $\mathrm{AC}$ generator including advantages and disadvantages of each type.

\section{$\underline{\text { Ratings }}$}

Typical name plate data for an AC generator (Figure 4) includes: (1) manufacturer; (2) serial number and type number; (3) speed (rpm), number of poles, frequency of output, number of phases, and maximum supply voltage; (4) capacity rating in KVA and $\mathrm{kW}$ at a specified power factor and maximum output voltage; (5) armature and field current per phase; and (6) maximum temperature rise.

Power $(\mathrm{kW})$ ratings of an $\mathrm{AC}$ generator are based on the ability of the prime mover to overcome generator losses and the ability of the machine to dissipate the internally generated heat. The current rating of an AC generator is based on the insulation rating of

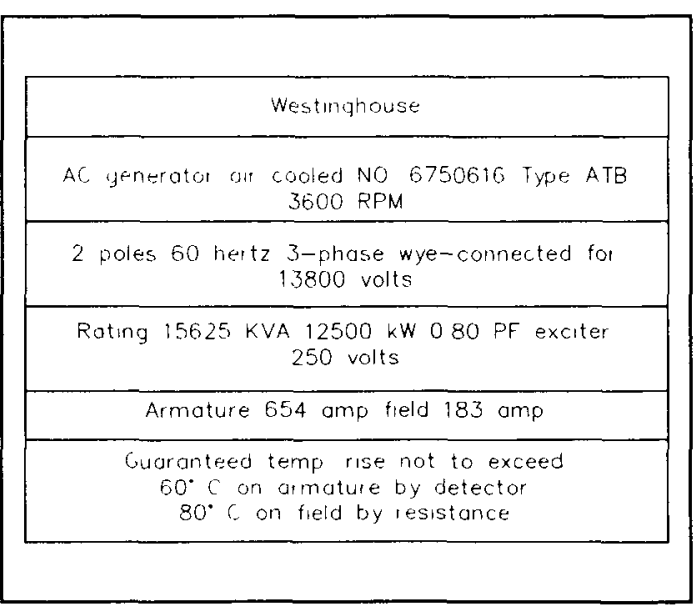

Figure 4 AC Generator Nameplate Ratings the machine. 


\section{Paralleling AC Generators}

Most electrical power grids and distribution systems have more than one AC generator operating at one time. Normally, two or more generators are operated in parallel in order to increase the available power. Three conditions must be met prior to paralleling (or synchronizing) AC generators.

- Their terminal voltages must be equal. If the voltages of the two AC generators are not equal, one of the $\mathrm{AC}$ generators could be picked up as a reactive load to the other $\mathrm{AC}$ generator. This causes high currents to be exchanged between the two machines, possibly causing generator or distribution system damage.

- Their frequencies must be equal. A mismatch in frequencies of the two AC generators will cause the generator with the lower frequency to be picked up as a load on the other generator (a condition referred to as "motoring"). This can cause an overload in the generators and the distribution system.

- Their output voltages must be in phase. A mismatch in the phases will cause large opposing voltages to be developed. The worst case mismatch would be $180^{\circ}$ out of phase, resulting in an opposing voltage between the two generators of twice the output voltage. This high voltage can cause damage to the generators and distribution system due to high currents.

During paralleling operations, voltages of the two generators that are to be paralleled are indicated through the use of voltmeters. Frequency matching is accomplished through the use of output frequency meters. Phase matching is accomplished through the use of a synchroscope, a device that senses the two frequencies and gives an indication of phase differences and a relative comparison of frequency differences.

\section{Types of AC Generators}

As previously discussed, there are two types of AC generators: the stationary field, rotating armature; and the rotating field, stationary armature.

Small AC generators usually have a stationary field and a rotating armature (Figure 5). One important disadvantage to this arrangement is that the slip-ring and brush assembly is in series with the load circuits and, because of worn or dirty components, may interrupt the flow of current.

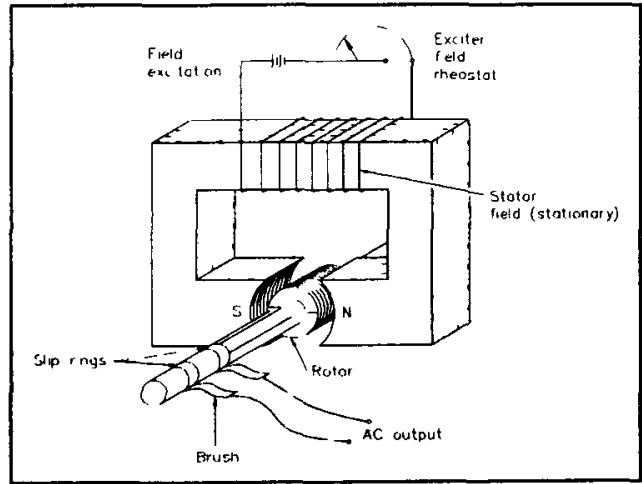

Figure 5 Stationary Field, Rotating Armature AC Generator 
If DC field excitation is connected to the rotor, the stationary coils will have $\mathrm{AC}$ induced into them (Figure 6). This arrangement is called a rotating field, stationary armature $\mathrm{AC}$ generator.

The rotating field, stationary armature type $\mathrm{AC}$ generator is used when large power generation is involved. In this type of generator, a DC source is supplied to the rotating field coils, which produces a magnetic field around the rotating element. As the rotor is turned by the prime mover, the field will cut the conductors of the

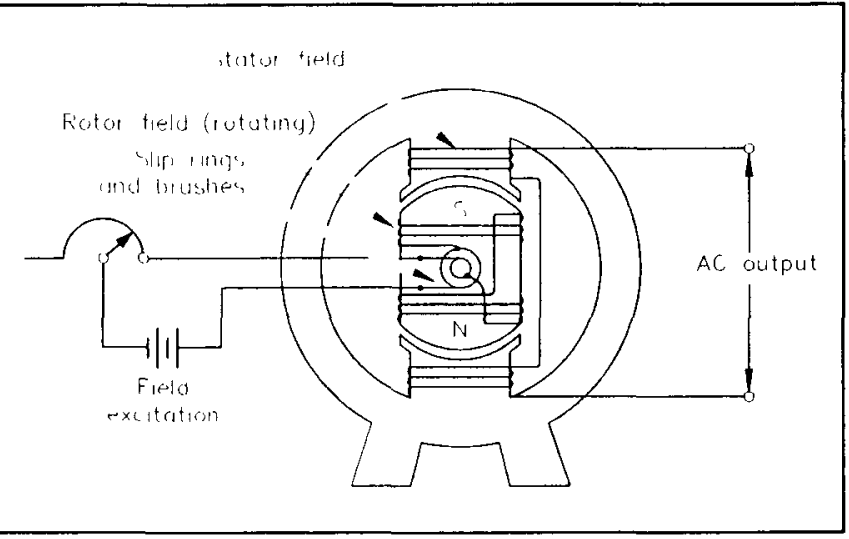

Figure 6 Simple AC Generator - Rotating Field, Stationary Armature stationary armature, and an EMF will be induced into the armature windings.

This type of AC generator has several advantages over the stationary field, rotating armature AC generator: (1) a load can be connected to the armature without moving contacts in the circuit; (2) it is much easier to insulate stator fields than rotating fields; and (3) much higher voltages and currents can be generated.

\section{Three-Phase AC Generators}

The principles of a three-phase generator are basically the same as that of a single-phase generator, except that there are three equally-spaced windings and three output voltages that are all $120^{\circ}$ out of phase with one another. Physically adjacent loops (Figure 7 ) are separated by $60^{\circ}$ of rotation; however, the loops are connected to the slip rings in such a manner that there are 120 electrical degrees between phases.

The individual coils of each winding are combined and represented as a single coil. The significance of Figure 7 is that it shows that the three-phase generator has three separate armature windings that are 120 electrical degrees out of phase.

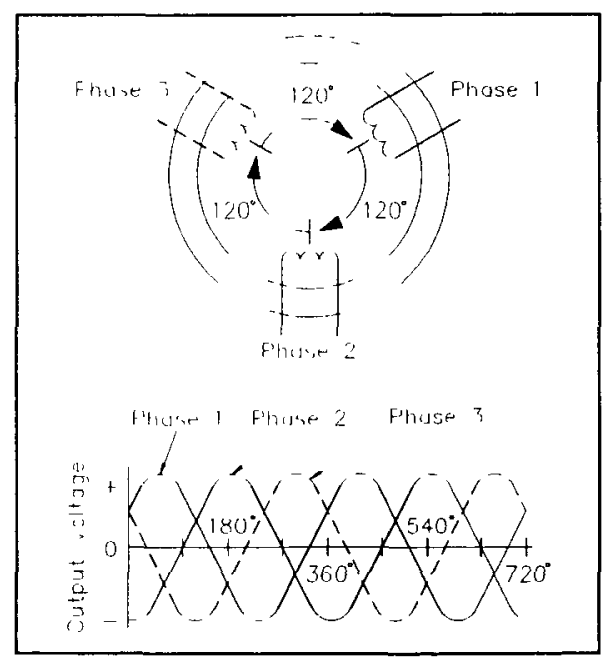

Figure 7 Stationary Armature $3 \phi$ Generator 


\section{$\underline{\text { AC Generator Connections }}$}

As shown in Figure 7, there are six leads from the armature of a three-phase generator, and the output is connected to an external load. In actual practice, the windings are connected together, and only three leads are brought out and connected to the external load.

Two means are available to connect the three armature windings. In one type of connection, the windings are connected in series, or delta-connected ( $\Delta$ ) (Figure 8).

In a delta-connected generator, the voltage between any two of the phases, called line voltage, is the same as the

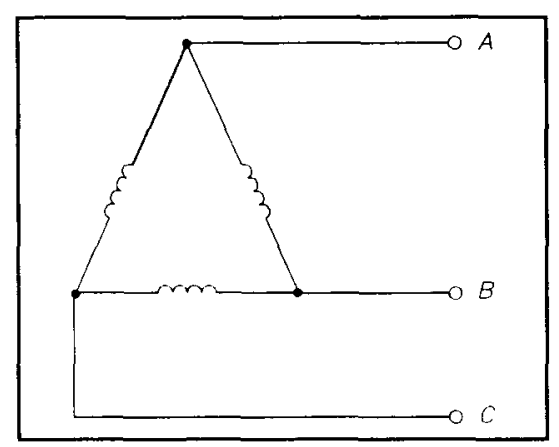

Figure 8 Delta Connection voltage generated in any one phase. As shown in Figure 9, the three phase voltages are equal, as are the three line voltages. The current in any line is $\sqrt{3}$ times the phase current. You can see that a delta-connected generator provides an increase in current, but no increase in voltage.

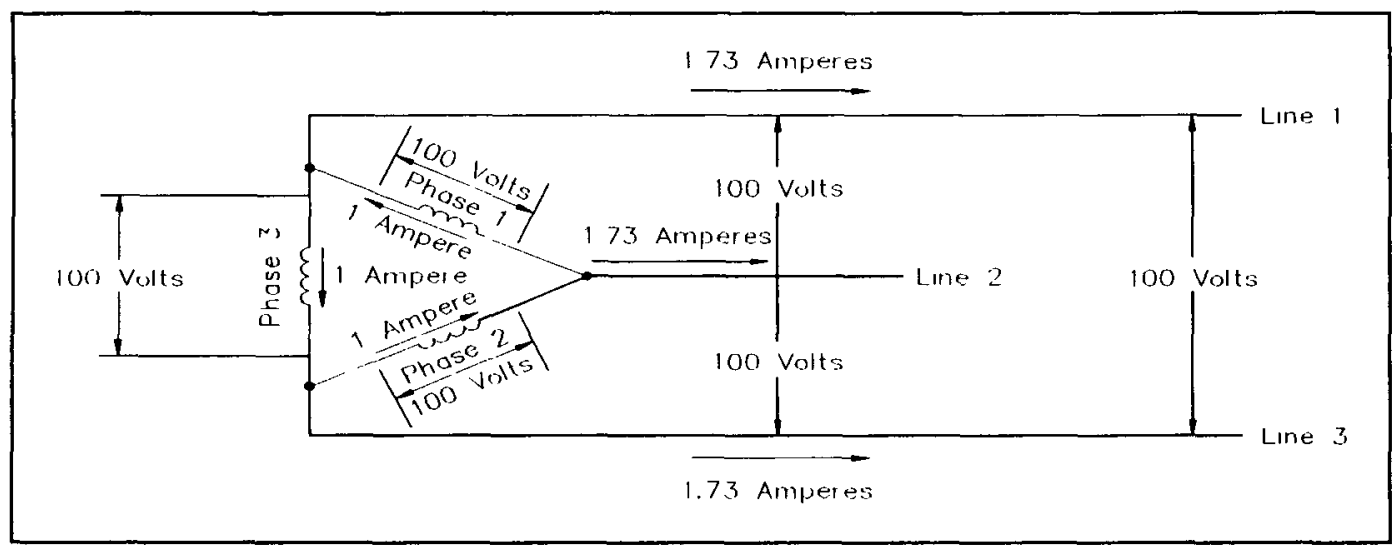

Figure 9 Characteristics of a Delta-Connected Generator

An advantage of the delta-connected $\mathrm{AC}$ generator is that if one phase becomes damaged or open, the remaining two phases can still deliver three-phase power. The capacity of the generator is reduced to $57.7 \%$ of what it was with all three phases in operation. 
In the other type of connection, one of the leads of each winding is connected, and the remaining three leads are connected to an external load. This is called a wye connection (Y) (Figure 10).

The voltage and current characteristics of the wye-connected $\mathrm{AC}$ generator are opposite to that of the delta connection. Voltage between any two lines in a wyeconnected AC generator is 1.73 (or $\sqrt{3}$ ) times any one phase voltage, while line

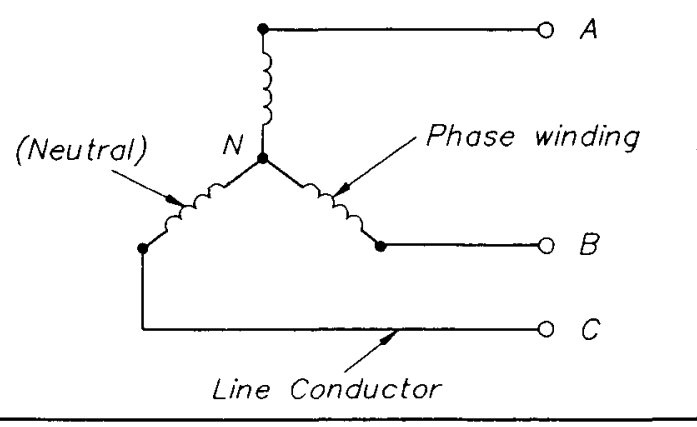

Figure 10 Wye Connection currents are equal to phase currents. The wye-connected AC generator provides an increase in voltage, but no increase in current (Figure 11).

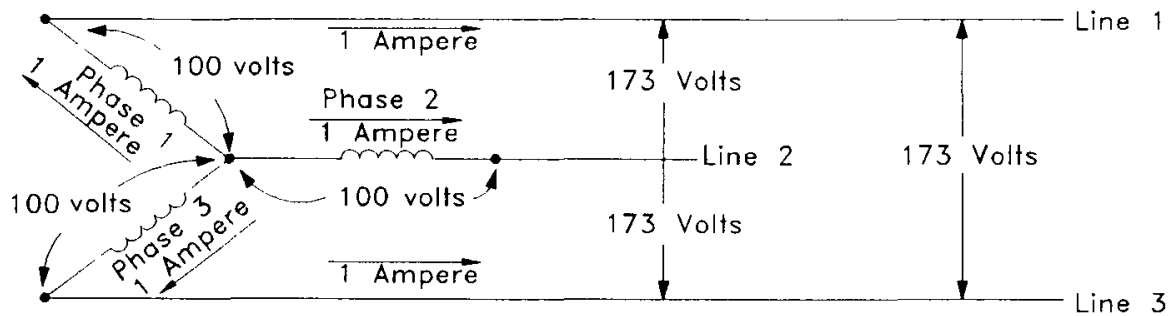

Figure 11 Characteristics of a Wye-Connected AC Generator

An advantage of a wye-connected $\mathrm{AC}$ generator is that each phase only has to carry $57.7 \%$ of line voltage and, therefore, can be used for high voltage generation. 


\section{Summary}

The important information covered in this chapter is summarized below.

\section{AC Generator Operation Summary}

- $\quad$ Power (kW) ratings of an $\mathrm{AC}$ generator are based on the ability of the prime mover to overcome generation losses and the ability of the machine to dissipate the heat generated internally. The current rating of an $\mathrm{AC}$ generator is based on the insulation rating of the machine.

- There are three requirements that must be met to parallel $\mathrm{AC}$ generators:

1) Their terminal voltages must be equal. A mismatch may cause high currents and generator or distribution system damage.

2) Their frequencies must be equal. A mismatch in frequencies can cause one generator to "motor," causing an overload in the generators and the distribution system.

3) Their output voltages must be in phase. A mismatch in the phases will cause large opposing voltages to be developed, resulting in damage to the generators and distribution system due to high currents.

- The disadvantage of a stationary field, rotating armature is that the slip-ring and brush assembly is in series with the load circuits and, because of worn or dirty components, may interrupt the flow of current.

- A stationary armature, rotating field generator has several advantages: (1) a load can be connected to the armature without moving contacts in the circuit; (2) it is much easier to insulate stator fields than rotating fields; and (3) much higher voltages and currents can be generated.

- The advantage of the delta-connected AC generator is that if one phase becomes damaged or open, the remaining two phases can still deliver three-phase power at a reduced capacity of $57.7 \%$.

- The advantage of a wye-connected AC generator is that each phase only has to carry $57.7 \%$ of line voltage and, therefore, can be used for high voltage generation. 
Department of Energy

Fundamentals Handbook

\section{ELECTRICAL SCIENCE \\ Module 11 \\ Voltage Regulators}




\section{TABLE OF CONTENTS}

LIST OF FIGURES $\ldots \ldots \ldots \ldots \ldots \ldots \ldots \ldots \ldots \ldots \ldots \ldots \ldots$

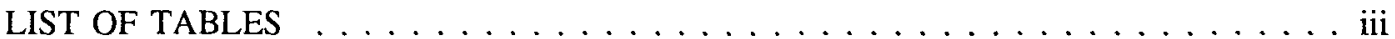

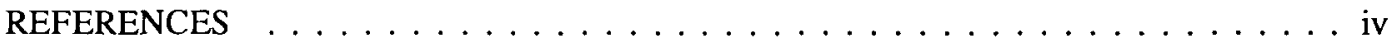

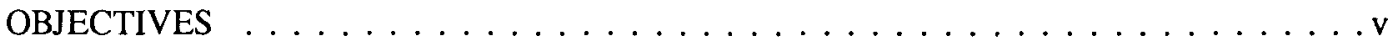

VOLTAGE REGULATORS ........................

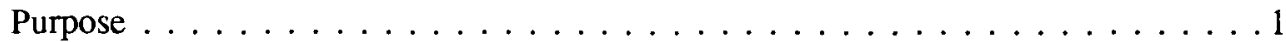

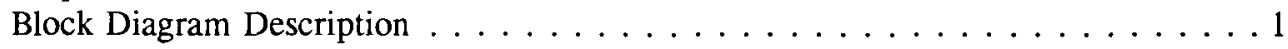

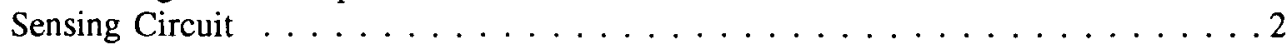

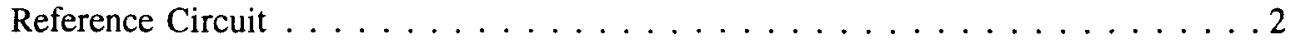

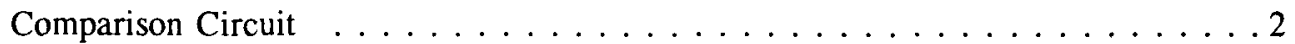

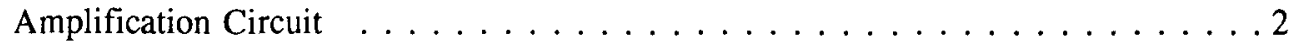

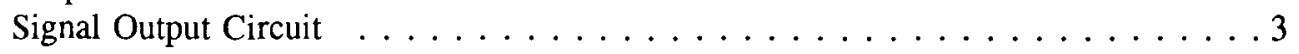

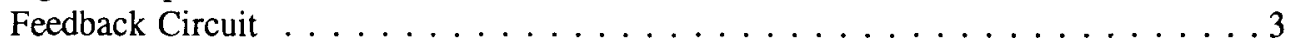

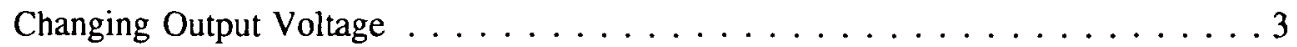

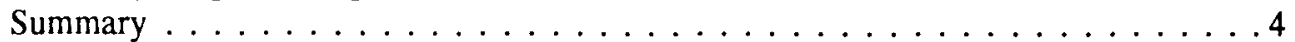




\section{LIST OF FIGURES}

Figure $1 \quad$ Voltage Regulator Block Diagram $\ldots \ldots \ldots \ldots \ldots$ 


\section{LIST OF TABLES}

NONE 


\section{REFERENCES}

- Gussow, Milton, Schaum's Outline Series, Basic Electricity, McGraw-Hill.

- $\quad$ Academic Program for Nuclear Power Plant Personnel, Volume IV, Columbia, MD: General Physics Corporation, Library of Congress Card \#A 326517, 1982.

- $\quad$ Academic Program for Nuclear Power Plant Personnel, Volume II, Columbia, MD: General Physics Corporation, Library of Congress Card \#A 326517, 1982.

- Nasar and Unnewehr, Electromechanics and Electric Machines, John Wiley and Sons.

- Van Valkenburgh, Nooger, and Neville, Basic Electricity, Vol. 5, Hayden Book Company.

- $\quad$ Lister, Eugene C., Electric Circuits and Machines, $5^{\text {th }}$ Edition, McGraw-Hill.

- Croft, Carr, Watt, and Summers, American Electricians Handbook, $10^{\text {th }}$ Edition, McGraw-Hill.

- Mileaf, Harry, Electricity One - Seven, Revised $2^{\text {nd }}$ Edition, Hayden Book Company.

- Buban and Schmitt, Understanding Electricity and Electronics, $3^{\text {rd }}$ Edition, McGraw-Hill.

- Kidwell, Walter, Electrical Instruments and Measurements, McGraw-Hill. 


\section{TERMINAL OBJECTIVE}

1.0 Given a block diagram, DESCRIBE the operation of a typical voltage regulator.

\section{ENABLING OBJECTIVES}

1.1 STATE the purpose for voltage regulation equipment.

1.2 Given a block diagram of a typical voltage regulator, DESCRIBE the function of each of the following components:
a. Sensing circuit
b. Reference circuit
c. Comparison circuit
d. Amplification circuit(s)
e. Signal output circuit
f. Feedback circuit 
Intentionally Left Blank 
Because the voltage from an $A C$ generator varies as the output load and power factor change, a voltage regulator circuit is necessary to permit continuity of the desired output voltage.

EO 1.1 STATE the purpose for voltage regulation equipment.

EO 1.2 Given a block diagram of a typical voltage regulator, DESCRIBE the function of each of the following components:
a. Sensing circuit
b. Reference circuit
c. Comparison circuit
d. Amplification circuit(s)
e. Signal output circuit
f. Feedback circuit

\section{Purpose}

The purpose of a voltage regulator is to maintain the output voltage of a generator at a desired value. As load on an $\mathrm{AC}$ generator changes, the voltage will also tend to change. The main reason for this change in voltage is the change in the voltage drop across the armature winding caused by a change in load current. In an AC generator, there is an IR drop and an IX $\mathrm{L}_{\mathrm{L}}$ drop caused by the $\mathrm{AC}$ current flowing through the resistance and inductance of the windings. The IR drop is dependent on the amount of the load change only. The $\mathrm{IX}_{\mathrm{L}}$ drop is dependent on not only the load change, but also the power factor of the circuit. Therefore, the output voltage of an $\mathrm{AC}$ generator varies with both changes in load (i.e., current) and changes in power factor. Because of changes in voltage, due to changes in load and changes in power factor, AC generators require some auxiliary means of regulating output voltage.

\section{Block Diagram Description}

Figure 1 shows a typical block diagram of an $\mathrm{AC}$ generator voltage regulator. This regulator consists of six basic circuits that together regulate the output voltage of an $\mathrm{AC}$ generator from no-load to full-load. 


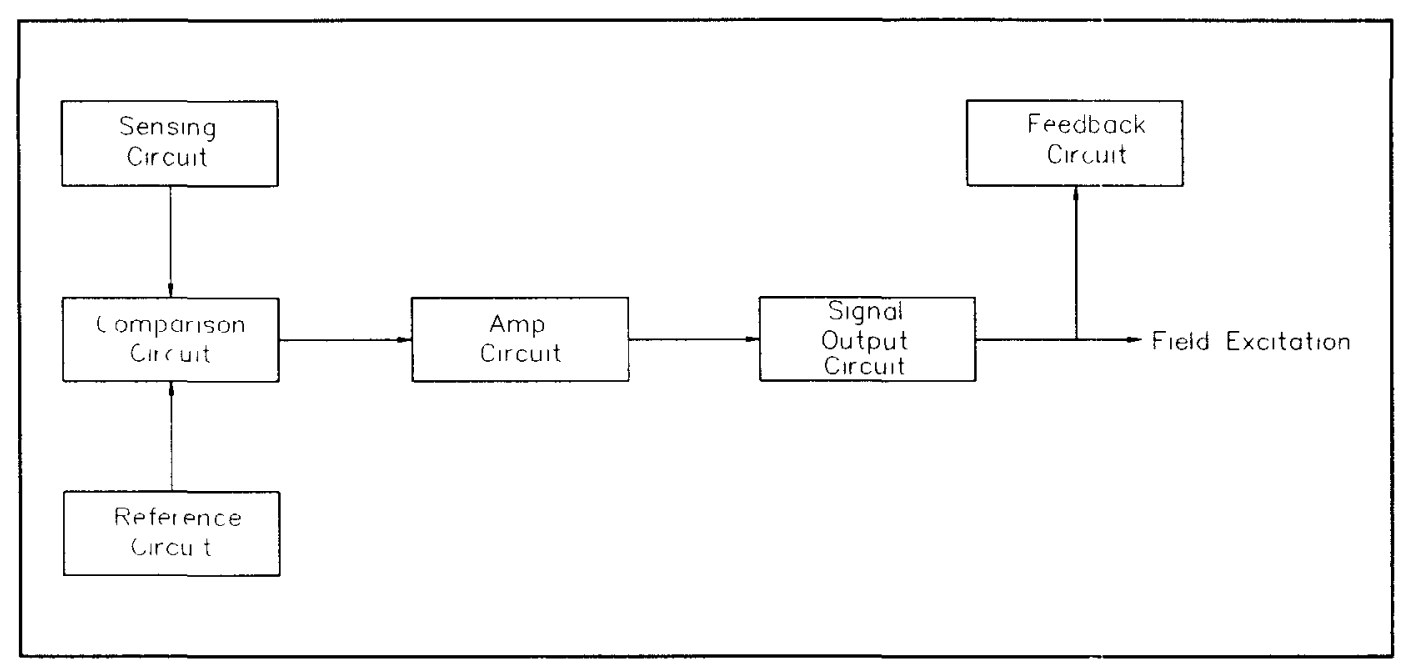

Figure 1 Voltage Regulator Block Diagram

\section{Sensing Circuit}

The sensing circuit senses output voltage of the AC generator. As the generator is loaded or unloaded, the output voltage changes, and the sensing circuit provides a signal of these voltage changes. This signal is proportional to output voltage and is sent to the comparison circuit.

\section{Reference Circuit}

The reference circuit maintains a constant output for reference. This reference is the desired voltage output of the $\mathrm{AC}$ generator.

\section{Comparison Circuit}

The comparison circuit electrically compares the reference voltage to the sensed voltage and provides an error signal. This error signal represents an increase or decrease in output voltage. The signal is sent to the amplification circuit.

\section{Amplification Circuit}

The amplification circuit, which can be a magnetic amplifier or transistor amplifier, takes the signal from the comparison circuit and amplifies the milliamp input to an amp output, which is then sent to the signal output, or field, circuit. 


\section{Signal Output Circuit}

The signal output circuit, which controls field excitation of the AC generator, increases or decreases field excitation to either raise or lower the AC output voltage.

\section{Feedback Circuit}

The feedback circuit takes some of the output of the signal output circuit and feeds it back to the amplification circuit. It does this to prevent overshooting or undershooting of the desired voltage by slowing down the circuit response.

\section{Changing Output Voltage}

Let us consider an increase in generator load and, thereby, a drop in output voltage. First, the sensing circuit senses the decrease in output voltage as compared to the reference and lowers its input to the comparison circuit. Since the reference circuit is always a constant, the comparison circuit will develop an error signal due to the difference between the sensed voltage and the reference voltage. The error signal developed will be of a positive value with the magnitude of the signal dependent on the difference between the sensed voltage and the reference voltage. This output from the comparison circuit will then be amplified by the amplifier circuit and sent to the signal output circuit. The signal output circuit then increases field excitation to the AC generator. This increase in field excitation causes generated voltage to increase to the desired output.

If the load on the generator were decreased, the voltage output of the machine would rise. The actions of the voltage regulator would then be the opposite of that for a lowering output voltage. In this case, the comparison circuit will develop a negative error signal whose magnitude is again dependent on the difference between the sensed voltage and the reference voltage. As a result, the signal output circuit will decrease field excitation to the AC generator, causing the generated voltage to decrease to the desired output. 


\section{Summary}

Voltage regulators are summarized below.

Voltage Regulators Summary
- $\quad$ Purpose - to maintain the output voltage of a generator at a desired value
- $\quad$ Sensing circuit - senses output voltage of the AC generator
Reference circuit - maintains a constant output for reference, or desired, voltage
output of the AC generator
- Comparison circuit - compares reference voltage to output voltage and provides
an error signal to the amplification circuit
Amplification circuit(s) - takes the signal from the comparison circuit and
amplifies the milliamp input to an amp output
- Signal output circuit - controls field excitation of the AC generator
Feedback circuit - prevents overshooting or undershooting of the desired voltage
by slowing down the circuit response

